\title{
NOVEL CONCEPTS FOR THE COMPRESSION OF LARGE VOLUMES OF CARBON DIOXIDE
}

\author{
Final Report \\ Reporting Period Start Date: 10/01/05 \\ Reporting Period End Date: 09/30/07
}

Prepared by

J. Jeffrey Moore, Ph.D.

Marybeth G. Nored

Ryan S. Gernentz

Klaus Brun, Ph.D.

DOE Award No. DE-FC26-05NT42650

SwRI ${ }^{\circledR}$ Project No. 18.11919

Prepared for

U.S. Department of Energy

National Energy Technology Laboratory

626 Cochrans Mills Road

P.O. Box 10940

Pittsburgh, PA 15236-0940

September 28, 2007 


\title{
NOVEL CONCEPTS FOR THE COMPRESSION OF LARGE VOLUMES OF CARBON DIOXIDE
}

\author{
Final Report \\ Reporting Period Start Date: 10/01/05 \\ Reporting Period End Date: 09/30/07 \\ Prepared by \\ J. Jeffrey Moore, Ph.D. \\ Marybeth G. Nored \\ Ryan S. Gernentz \\ Klaus Brun, Ph.D. \\ DOE Award No. DE-FC26-05NT42650 \\ SwRI ${ }^{\circledR}$ Project No. 18.11919 \\ Prepared for \\ U.S. Department of Energy \\ National Energy Technology Laboratory \\ 626 Cochrans Mill Road \\ P.O. Box 10940 \\ Pittsburgh, PA 15236-0940
}

September 28, 2007

Approved:

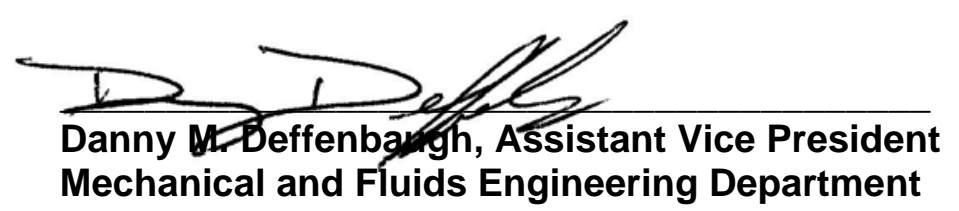




\section{DISCLAIMER}

This report was prepared as an account of work sponsored by an agency of the United States Government. Neither the United States nor any agency thereof, nor any of their employees, makes any warranty, express or implied, or assumes any legal liability or responsibility for the accuracy, completeness, or usefulness of any information, apparatus, product, or process disclosed, or represents that its use would not infringe privately owned rights. Reference herein to any specific commercial product, process, or service by trade name, trademark, manufacturer, or otherwise does not necessarily constitute or imply its endorsement, recommendation, or favoring by the United States Government or any agency thereof. The views and opinions of authors expressed herein do not necessarily state or reflect those of the United States Government or any agency thereof. 


\begin{abstract}
In the effort to reduce the release of $\mathrm{CO}_{2}$ greenhouse gases to the atmosphere, sequestration of $\mathrm{CO}_{2}$ from Integrated Gasification Combined Cycle (IGCC) and Oxy-Fuel power plants is being pursued. This approach, however, requires significant compression power to boost the pressure to typical pipeline levels. The penalty can be as high as $8 \%$ to $12 \%$ on a typical IGCC plant. The goal of this research is to reduce this penalty through novel compression concepts and integration with existing IGCC processes. The primary objective of the study of novel $\mathrm{CO}_{2}$ compression concepts is to boost the pressure of $\mathrm{CO}_{2}$ to pipeline pressures with the minimal amount of energy required. Fundamental thermodynamics were studied to explore pressure rise in both liquid and gaseous states. For gaseous compression, the project investigated novel methods to compress $\mathrm{CO}_{2}$ while removing the heat of compression internal to the compressor. The high-pressure ratio due to the delivery pressure of the $\mathrm{CO}_{2}$ for enhanced oil recovery results in significant heat of compression. Since less energy is required to boost the pressure of a cooler gas stream, both upstream and interstage cooling is desirable. While isothermal compression has been utilized in some services, it has not been optimized for the IGCC environment. This project determined the optimum compressor configuration and developed technology concepts for internal heat removal. Other compression options using liquefied $\mathrm{CO}_{2}$ and cryogenic pumping were explored as well. Preliminary analysis indicates up to a $35 \%$ reduction in power is possible with the new concepts being considered.
\end{abstract}




\section{TABLE OF CONTENTS}

Section

Page

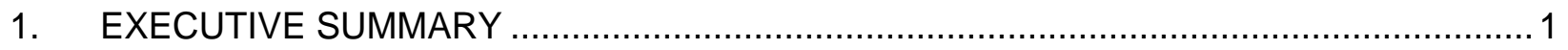

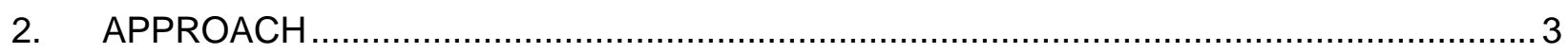

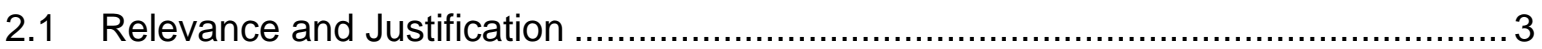

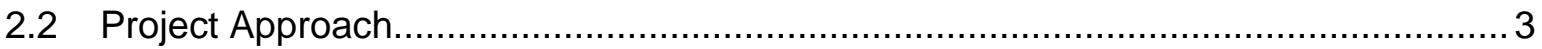

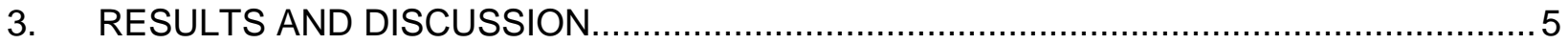

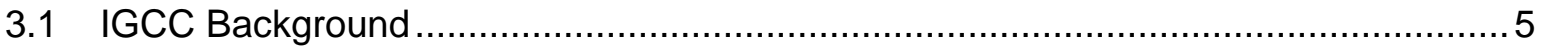

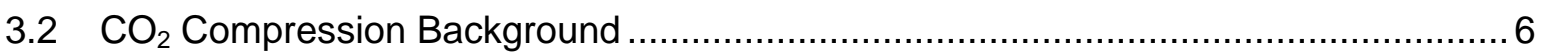

3.2.1 Task 1.1 - Summary of Literature Review ............................................. 7

3.2.2 Description of IGCC Application ........................................................ 7

3.2.3 Current Need for $\mathrm{CO}_{2}$ Technology Improvements in IGCC Plants ............... 11

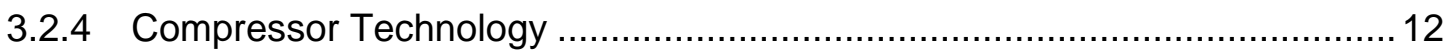

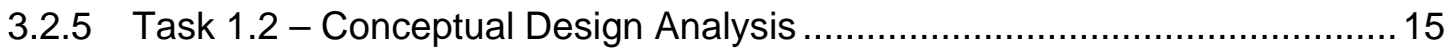

3.2.6 Available Commercial Product Description ............................................... 19

3.2.7 Task 1.4 - Evaluate Intercooling Concepts ........................................... 20

3.2.8 Task 2.1 - Develop Interstage Cooling Concepts ...................................... 21

3.2.9 Task 2.2 - Geometry Generation ......................................................... 31

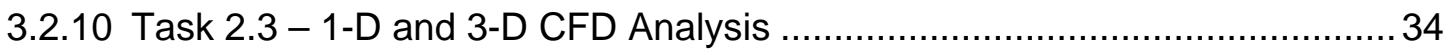

3.2.11 Task 2.5 - Experimental Measurement of Gas Mixing Streams ................... 43

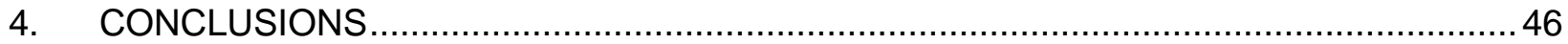

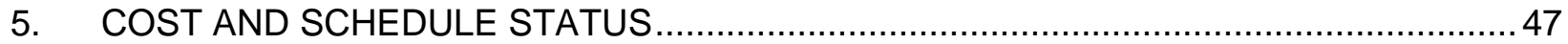

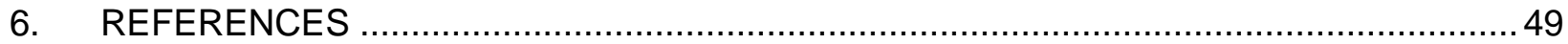

7. LIST OF ACRONYMS AND ABBREVIATIONS ................................................... 51

APPENDIX A: Dresser-Rand Selection of Conventional Centrifugal Compression

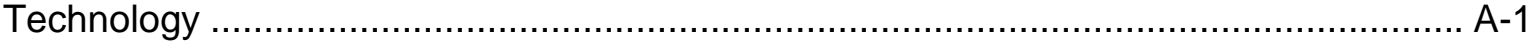

APPENDIX B: Option A - Conventional Centrifugal Compression ..................................... B-1 


\section{LIST OF FIGURES}

Figure

Page

Figure 3-1 Schematic of IGCC Process with $\mathrm{CO}_{2}$ Sequestration (Modified from [1]) ............ 5

Figure 3-2 Pressure-Enthalpy Diagram for Carbon Dioxide [5] .................................. 8

Figure 3-3 Basic Capture Systems for Carbon Dioxide Used in Power Plant

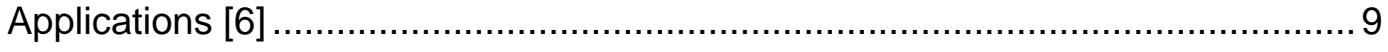

Figure 3-4 Illustration of Pre-Combustion Capture Technology Premise [6]..................... 10

Figure 3-5 Economically Recoverable Oil versus Technology Risk, Cost of Carbon Dioxide and Oil Price [14] ............................................................. 11

Figure 3-6 Five Step Compression Process for Carbon Dioxide with Intercooling .............. 13

Figure 3-7 Hybrid Compression System with Vapor Compression and Cryogenic

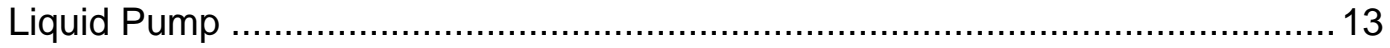

Figure 3-8 Existing Carbon Dioxide Pipeline Infrastructure [13] ................................. 14

Figure 3-9 Inlet Volumetric Flow Rate at Various Pressures ........................................ 15

Figure 3-10 Axial Compressor Application Map (Courtesy of Dresser-Rand) ...................... 16

Figure 3-11 Centrifugal Compressor Application Map (Courtesy of Dresser-Rand)..............17

Figure 3-12 Dresser-Rand Multi-Stage Centrifugal Compressor (Courtesy of Dresser-

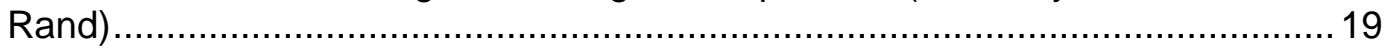

Figure 3-13 Dresser-Rand ISOPAC Compressor (Courtesy of Dresser-Rand)....................20

Figure 3-14 Rocket Engine Turbopump (Courtesy of Barber Nichols) ...............................20

Figure 3-15 Compression Technology Options - on Pressure vs. Enthalpy Diagram for

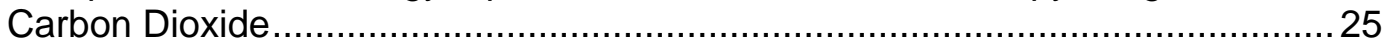

Figure 3-16 Comparison of Thermodynamic Paths for Options A and B..........................25

Figure 3-17 Comparison of Isothermal and Semi-Isothermal Compression Paths............... 27

Figure 3-18 Comparison of Isothermal and Semi-Isothermal Total Horsepower vs. Number of Compression Steps ....................................................... 28

Figure 3-19 Thermodynamic Paths for Option A compared to High Ratio Compression

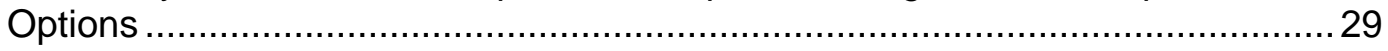

Figure 3-20 Pressure - Enthalpy (P-h) Diagram for Carbon Dioxide [17].........................29

Figure 3-21 Comparison of Option E for Liquid Cryo-Pump to Option A ..............................30

Figure 3-22 Photograph of SwRI Test Rig Compressor Used to Generate CFD Solid

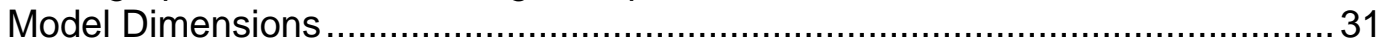

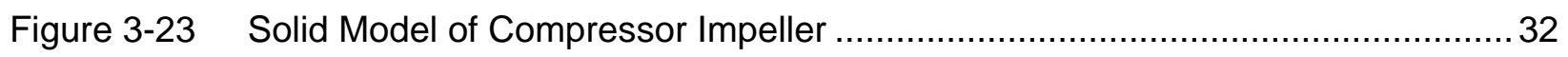

Figure 3-24 Solid Model Assembly of Compressor Stage ........................................... 33

Figure 3-25 "Pie" Model for Use with CFD Analysis .............................................. 33

Figure 3-26 Return Channel Vanes for Use with CFD Analysis .................................. 34

SwRI Project 18.11919; DOE Award No. DE-FC26-05NT42650

Final Technical Progress Report

Reporting Period 10/01/05 - 09/28/07 


\section{LIST OF FIGURES (Cont'd)}

Figure

Page

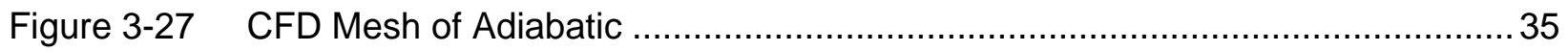

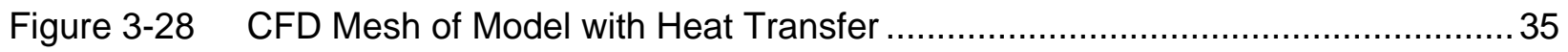

Figure 3-29 Predicted Streamlines in the Entire Stage ............................................ 37

Figure 3-30 Predicted Pressure Contours in Adiabatic Model ....................................... 37

Figure 3-31 Predicted Mach Number Contours in Adiabatic Model................................... 38

Figure 3-32 Predicted Temperature Contours in Adiabatic Model...................................... 38

Figure 3-33 Predicted Total Temperature Contours with Heat Transfer in Diffuser................ 39

Figure 3-34 Predicted Temperature Contours Adiabatic ............................................. 40

Figure 3-35 Predicted Temperature Contours with Heat Transfer in Diffuser (Aluminum

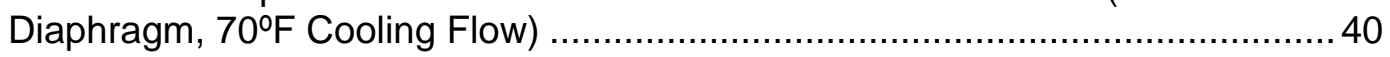

Figure 3-36 Predicted Total Temperature Contours in Return Channel Adiabatic ................ 41

Figure 3-37 Predicted Total Temperature Contours with Heat Transfer in Return Channel (Aluminum Diaphragm, $70^{\circ} \mathrm{F}$ Cooling Flow) .................................... 41

Figure 3-38 Comparison of Static Temperature Rise Across the Stage .............................42

Figure 3-39 Illustration of Heat Transfer Coefficients in Cooling Process for $\mathrm{CO}_{2}$ in

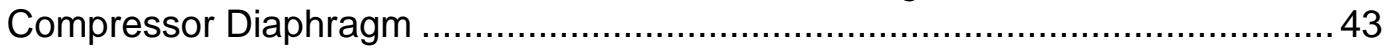

Figure 3-40 Gas Mixing Streams Setup............................................................. 44

Figure 3-41 Gas Stream Temperature of Mixture ................................................. 44

Figure 3-42 Precipitation of $\mathrm{H}_{2} \mathrm{O}$ on Aluminum Plate.............................................. 45

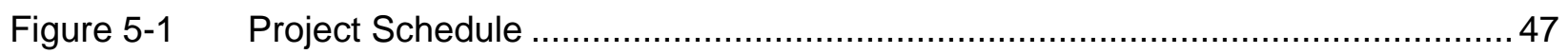




\section{LIST OF TABLES}

$\underline{\text { Table }}$

Page

Table 3-1 Sample Centrifugal Compressor Selection: 300 to 1,500 PSI.......................17

Table 3-2 Sample Centrifugal Compressor Selection: 15 to 300 PSI............................ 18

Table 3-3 Summary of Power Required for the Boosting Pressure from 15 to 1,500

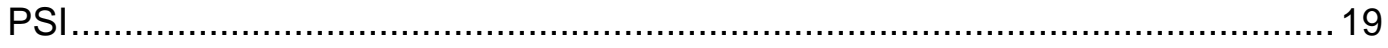

Table 3-4 Typical Waste IGCC Carbon Dioxide Streams ........................................... 21

Table 3-5 SwRI and Dresser-Rand Analysis of Conventional Centrifugal.........................22

Table 3-6 Summary of Compression Technology Options - Power and Cooling

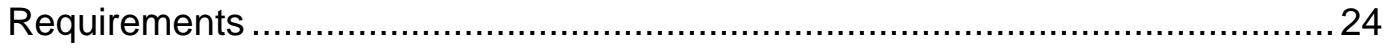

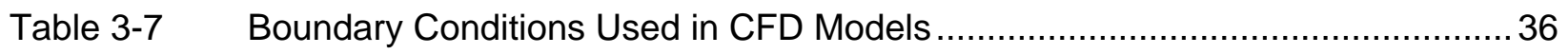

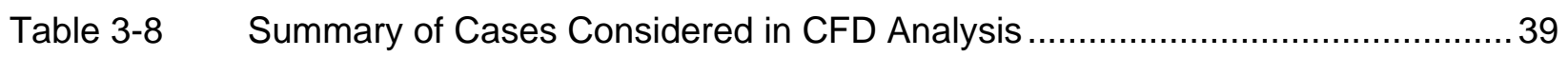

Table 5-1 Project Cost Status............................................................................. 48 


\section{EXECUTIVE SUMMARY}

In the effort to reduce the release of $\mathrm{CO}_{2}$ greenhouse gases to the atmosphere, sequestration of $\mathrm{CO}_{2}$ from Integrated Gasification Combined Cycle (IGCC) and Oxy-Fuel power plants was investigated. Capture and sequestration of $\mathrm{CO}_{2}$, however, requires significant compression power to boost the pressure to typical pipeline levels. The penalty can be as high as $8-12 \%$ on a typical IGCC plant. The goal of the current research was to reduce this penalty through novel compression concepts and integration with existing IGCC processes.

The primary objective was to examine methods of boosting the pressure of $\mathrm{CO}_{2}$ to pipeline pressures with the minimal amount of energy required. First, fundamental thermodynamics were studied to explore if pressure rise in liquid or gaseous states is preferred. Since the first phase of the project involved conceptual brainstorming, flexibility was built into the project to permit investigation of several concepts. Southwest Research Institute ${ }^{\circledR}\left(\mathrm{SwRI}^{\circledR}\right)$ and Dresser-Rand Company partnered in this project to advance the state-of-the-art in pressurization of $\mathrm{CO}_{2}$.

For gaseous compression, the project investigated novel methods to compress $\mathrm{CO}_{2}$ while removing the heat of compression internal to the compressor. The high-pressure ratio compression of $\mathrm{CO}_{2}$ results in significant heat of compression. Since less energy is required to boost the pressure of a cool gas, both upstream and interstage cooling is desirable. While isothermal compression has been utilized in some services, it has not been optimized for the IGCC environment. Furthermore, external intercooling results in higher losses and more complicated piping systems. This project determined the optimum compressor configuration and developed technology for internal heat removal. Other process streams within the IGCC environment, such as $\mathrm{N}_{2}$, steam, and syngas, were considered to provide a total system solution by fully integrating with the air separation units, combined cycle, and the gas cleanup system. Other concepts that liquefy the $\mathrm{CO}_{2}$ and boost pressure through cryogenic pumping were explored in the research as well.

This report describes the activities of Phase I, which resulted in conceptual design options. A thorough literature review was completed to study IGCC, separation methods, compression technologies, and thermodynamic processes. Kick-off meetings were held with both the co-sponsor (Dresser-Rand) and DOE NETL personnel. Initial brainstorming of various compression concepts helped to identify several promising new concepts. These concepts included the integration of $\mathrm{CO}_{2}$ compression with excess nitrogen off the air separation unit (ASU), evaluating different intercooling concepts, and identifying preferred liquid $\mathrm{CO}_{2}$ pumping configurations. The power savings of each of these concepts has been quantified and compared in an evaluation matrix to identify the most promising technology options.

Two of the concepts have the potential of reducing the required compression power by $35 \%$ compared to a conventional compressor selection. A semi-isothermal compression process has been studied as an alternative to the standard method where the gas is continually cooled in the path through the compressor (after each stage). A simple cooling jacket insert used in the diaphragm of each stage could provide this type of continuous cooling. The savings in horsepower in the semi-isothermal process are significant (at least a 30\% reduction in total power). In addition, another concept offering similar savings in required horsepower over a standard compression process is the concept of pumping liquefied $\mathrm{CO}_{2}$. In this concept, the 
primary power requirements are the initial compression required to boost the $\mathrm{CO}_{2}$ to approximately 250 PSIA and the refrigeration power required to liquefy the gas. Once the $\mathrm{CO}_{2}$ is liquefied, the pumping power to boost the pressure to pipeline supply pressure is minimal.

A detailed Computational Fluid Dynamics (CFD) model was developed to investigate the intercooling concepts. The results showed promising performance for the internally cooled diaphragm concept. The R\&D implementation plan for Phases II and III has been completed. Phase II will include a detailed design and prototype test of these two new compression concepts. 


\section{APPROACH}

\subsection{Relevance And Justification}

Stricter environmental performance regulations and high natural gas prices-combined with new technology developments-have made Integrated Gasification Combined Cycle (IGCC) a viable and cost-effective alternative to steam turbine boiler cycles and natural gas combined cycle plants for new electric power generation plants. Coal IGCC offers proven and superior environmental performance when compared to conventional coal boiler-steam turbine power plants. IGCC plants can reach efficiencies approximately $7-10 \%$ higher than those of conventional coal power plants. However, environmental concerns and possible regulation on atmospheric $\mathrm{CO}_{2}$ have severely slowed the movement toward IGCC as the $\mathrm{CO}_{2}$ emissions from a coal IGCC are about four times higher than those for a natural gas combined cycle power plant.

IGCC plants do have the potential to operate completely free of $\mathrm{CO}_{2}$ emissions if the $\mathrm{CO}$ in the synthesis fuel gas stream is shifted to $\mathrm{CO}_{2}$ and the $\mathrm{CO}_{2}$ is separated and sequestered. Pure hydrogen is then used as the combined cycle plant's gas turbine fuel. The resultant separated $\mathrm{CO}_{2}$ stream must be compressed, pipeline transported, and injected into geological underground formations, such as underground salt domes, aquifers, or oil depleted reservoirs. This compression process can consume a significant amount of energy depending on the type of IGCC process, the $\mathrm{CO}_{2}$ take-off point, the distance between power plant and injection point, the formation's internal pressure and depth, and the compression technology chosen. Clearly, to maintain hydrogen IGCC (a competitive power plant alternative), it is critical to minimize the energy consumption required for the $\mathrm{CO}_{2}$ compression process.

Sequestering the $\mathrm{CO}_{2}$, however, requires significant compression power to boost the pressure to typical pipeline levels. This penalty can be as high as $8-12 \%$ on a typical IGCC plant. The goal of this research was to reduce this penalty through novel compression concepts and integration with other IGCC processes.

\subsection{Project ApProach}

The conceptual design and R\&D implementation plan for Phase I of the project consisted of the following milestones:

a Perform thermodynamic and economic analysis to determine the preferred $\mathrm{CO}_{2}$ state (liquid or gas) for pressure boosting.

- Integrate $\mathrm{CO}_{2}$ compression with air separation plant streams.

口 Develop prototype compression (or pumping) concepts.

a Perform advanced analytical analysis of proposed concepts.

口 Identify the best compression concept.

a Develop R\&D implementation plans for Phases II and III. 
The deliverables of this phase will provide the best concept that meets the efficiency goals and integrates into the IGCC environment. Phase II will detail design the optimum solution and perform prototype development testing. Phase III will provide a full-scale compression solution to an existing IGCC plant. This project was co-funded by Dresser-Rand Company. 


\section{RESULTS AND DISCUSSION}

\subsection{IGCC BACKGROUND}

Integrated Gasification Combined Cycle (IGCC) is a process that converts low value fuels, such as coal, petroleum coke, orimulsion, biomass, and municipal wastes into a low heating value/high hydrogen gas. Figure 3-1 shows a typical IGCC process [1]. This gas is then employed as a primary fuel for a gas turbine. Another view of IGCC is to consider it a two-stage combustion of an opportunity feedstock; the feedstock is first partially combusted in a reactor or gasifier, and then the combustion is completed in the gas turbine. In simple terms, the IGCC gasification process "cleans" heavy and/or solid fuels and converts them into a high value fuel (syngas) for gas turbines.

There are several unique techniques to gasify a feedstock, but the most common involves a reactor in which the feedstock undergoes partial oxidation with pure oxygen (i.e., the carbon and hydrogen from the feedstock is released primarily as a mixture of hydrogen and carbon monoxide). This gas is commonly called synthesis gas or syngas. Syngas has a heating value of $100-400 \mathrm{Btu} / \mathrm{scf}$, which is about $10-33 \%$ that of natural gas or oil distillates.

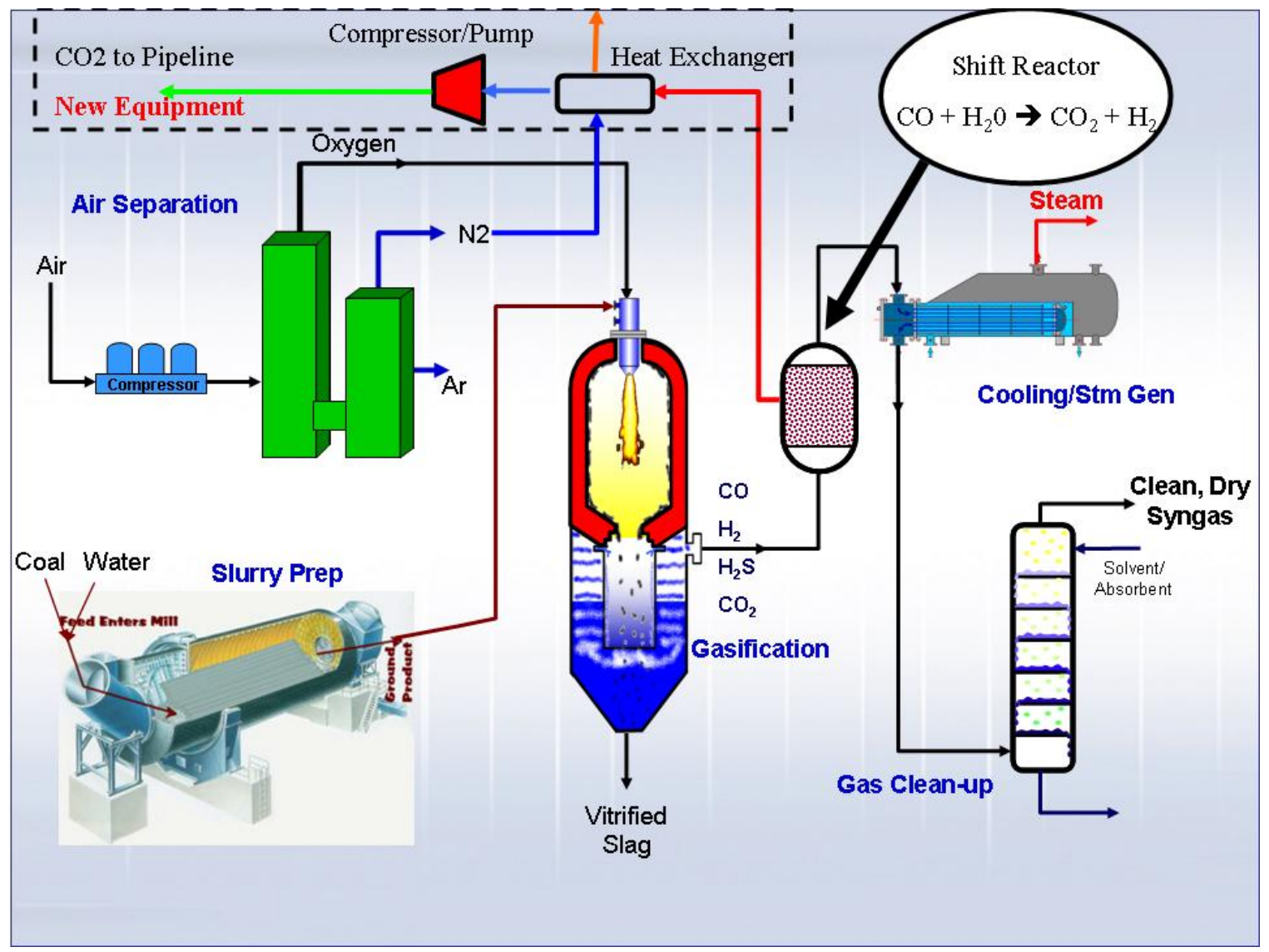

Figure 3-1. Schematic of IGCC Process with $\mathrm{CO}_{2}$ Sequestration (Modified from [1]) 
IGCC generally consists of four separate processes:

\author{
- Gasification \\ ๑ Cryogenic Air Separation \\ - Gas Cleanup \\ a Gas Turbine Combined Cycle
}

For the standard oxygen-blown gasification process, oxygen must be supplied to the reactor; a cryogenic air separation unit (ASU) is employed for this purpose. Post-compression air bleed from the gas turbine can provide/supplement the required air for the cryogenic ASU.

The syngas from the reactor must be cleaned before it can be employed as a gas turbine fuel. This cleanup process typically involves the efficient removal of residual fly ash, sulfur compounds, ammonia, mercury, other metals, alkalytes, and any particulate matter to reduce air pollution and to meet the gas turbine fuel gas specifications. Consequently, in the IGCC process, harmful pollutants are removed from the syngas stream (pre-combustion) rather than from the flue gas (post-combustion). Since these pollutants are much more concentrated in the pressurized syngas stream than in the exhaust flue gas, the IGCC cleanup process is more efficient and has a lower cost than the post-combustion cleanup as employed in any steam-boiler plants. Within this cleanup process, it is also feasible to convert the $\mathrm{CO}$ to $\mathrm{CO}_{2}$ in an exothermic shift reactor and separate the $\mathrm{CO}_{2}$ from the synthesis gas stream using membrane filters. The pure hydrogen is used as the fuel stream for the gas turbine combined cycle within the IGCC, and the separated $\mathrm{CO}_{2}$ stream is sequestered and stored in a geological underground formation or other storage concept. Thus, IGCC provides the potential for a zero $\mathrm{CO}_{2}$ emission coal power plant [2].

\title{
3.2 $\mathrm{CO}_{2}$ COMPRESSION BACKGROUND
}

The compression of $\mathrm{CO}_{2}$ is currently required in a variety of processes, including natural gas processing, fertilizer plants, and liquefaction facilities. $\mathrm{CO}_{2}$ is used in a variety of products and processes, including fire extinguishers, carbonation of soft drinks, enhanced oil recovery, and the production of various chemicals. When combined with water in air, it forms carbonic acid. $\mathrm{CO}_{2}$ is also well known to be a greenhouse gas that contributes to global warming. Increasing the concentration of $\mathrm{CO}_{2}$ in greenhouses to $1,000 \mathrm{ppm}$ (from standard atmosphere of $360 \mathrm{ppm}$ ) can increase crop yield by $20 \%$.

Sequestering $\mathrm{CO}_{2}$ from the combustion of fossil fuels like natural gas and coal prevents the $\mathrm{CO}_{2}$ from reaching the atmosphere and has received much attention in recent years. Once sequestered, $\mathrm{CO}_{2}$ may be moved via transmission pipelines and stored in depleted oil and gas fields, deep salt reservoirs, unminable coal seams, or by dispersion in ocean environments [3]. $\mathrm{CO}_{2}$ may also be used for enhanced oil recovery (EOR) and even enhanced natural gas recovery, though gas recovery has not been proven viable yet. Studies are underway on pilot fields to determine if $\mathrm{CO}_{2}$ injection for EOR is a permanent form of gas storage [4].

In IGCC plants, sequestration can occur with the fuel gas stream utilizing a water gas shift reaction process as described above. This separation process occurs at typical pressures ranging from 300-1,200 PSIG (for pressurized gasifiers). The $\mathrm{CO}_{2}$ may then be compressed and transported via pipelines at typical pressures around 1,500 PSIG. The pressure ratio in this

SwRI Project 18.11919; DOE Award No. DE-FC26-05NT42650

Final Technical Progress Report 
application is relatively low, and the volume flow through the compressor is relatively small resulting in a smaller compressor frame size requirement. In applications where atmospheric gasification is used, such as biomass gasification, the initial $\mathrm{CO}_{2}$ pressure would be substantially lower.

For an oxy-fuel process, oxygen from an air separation unit (ASU) combusts with pulverized coal or oil in specially designed boilers. The $\mathrm{CO}_{2}$ rich flue gas stream permits economic separation and compression of $\mathrm{CO}_{2}$. However, compression to typical pipeline pressures requires large pressure ratios (100:1) and high volume flow requirements. These gas conditions increase the compression power required. $\mathrm{CO}_{2}$ scrubbing of conventional pulverized coal (PC) flue gas has the additional complication of lower $\mathrm{CO}_{2}$ concentrations.

\subsubsection{Task 1.1 - Summary of Literature Review}

Integrated Gasification Combined Cycle (IGCC) plants use available coal or other fuel stock to produce synthetic gas streams. One of the waste products of the present day IGCC plant is carbon dioxide, produced in the creation of the synthetic gas stream. Emissions of carbon dioxide from an IGCC plant may be reduced if the carbon dioxide stream can be efficiently captured from the process gas and compressed for transport and delivery. At present, the cost of separating and compressing the $\mathrm{CO}_{2}$ for delivery at sequestration sites accounts for an efficiency penalty of $8-15 \%$ in the overall IGCC plant efficiency. More efficient separation and compression methods would reduce the cost of compression and the efficiency penalty associated with sequestering the waste $\mathrm{CO}_{2}$.

A literature review was conducted to better understand the physical processes involved in extracting and compressing carbon dioxide. The selection and design of the most efficient compression technology is dependent upon the separation method used. The separation technology determines the thermodynamic state of the carbon dioxide entering the process. Various separation technologies are available, which deliver carbon dioxide at different pressures and in different streams. The literature review summarized below will be used to study the options available for compression technologies.

\subsubsection{Description of IGCC Application}

The IGCC plant delivers the waste $\mathrm{CO}_{2}$ stream at varied pressures, depending on where the $\mathrm{CO}_{2}$ is separated from the fuel gas stream. In a pre-combustion process using physical adsorption with Selexol, the separation pressure varies from 1 bar (1 atm) to as high as 20 bar. The higher-pressure separation methods inherently reduce the volume of carbon dioxide that must be separated. The gas must be compressed to a pressure between 1,500 and 2,200 PSI in order to be transported and delivered for use in enhanced oil recovery applications. The capacity required through the compressor is significant. The mass flow rate of $\mathrm{CO}_{2}$ from a typical $400 \mathrm{MW}$ IGCC plant is 600,000 to $700,000 \mathrm{lb} / \mathrm{hr}$. At atmospheric pressure, the equivalent volumetric flow rate is 85,500-100,000 ACFM (123-144 MMSCFD).

At its initial suction condition (15 to $120 \mathrm{PSI}, 70^{\circ} \mathrm{F}$ to $90^{\circ} \mathrm{F}$ ), the carbon dioxide is in vapor form. At the final delivery point conditions (2,200 PSI, $70^{\circ} \mathrm{F}$ to $90^{\circ} \mathrm{F}$ ), the carbon dioxide is a supercritical fluid. Depending upon the compression process, the carbon dioxide may remain in vapor form until it reaches the supercritical state or the carbon dioxide may be converted to liquid at cryogenic conditions until it reaches the final state as a supercritical fluid.

SwRI Project 18.11919; DOE Award No. DE-FC26-05NT42650

Final Technical Progress Report

September 28, 2007

Reporting Period 10/01/05 - 09/28/07 
Figure 3-2 shows the pressure-enthalpy diagram for carbon dioxide with the indicated final suction and discharge points. In reality, the compression cycle must take place on either the vapor side (right side of Figure 3-2) or liquid side (left side of Figure 3-2) of the dome. Various compression options are available with differing levels of efficiency, depending upon the number of thermodynamic points, cooling steps and pumping/compression losses.

The separation process in an IGCC plant dictates the delivery suction pressure and the number of streams of $\mathrm{CO}_{2}$ produced for compression. Carbon dioxide is typically separated from the process stream using either pre-combustion, post-combustion, or oxy-fuel combustion systems. Post-combustion systems separate the $\mathrm{CO}_{2}$ from the flue gas produced in a combustion process using primary fuel. Pre-combustion systems process a primary fuel source prior to combustion and typically produce two separate streams of carbon dioxide and hydrogen, which is used as the primary fuel source. Oxy-fuel combustion systems use oxygen instead of air for combustion and produce a waste gas stream composed of $\mathrm{H}_{2} \mathrm{O}$ and carbon dioxide. The carbon dioxide is then readily captured from the water vapor stream. The three methods of $\mathrm{CO}_{2}$ capture are compared to a traditional industrial separation process for $\mathrm{CO}_{2}$ in Figure 3-3. In an IGCC plant, the preferred method is pre-combustion separation.

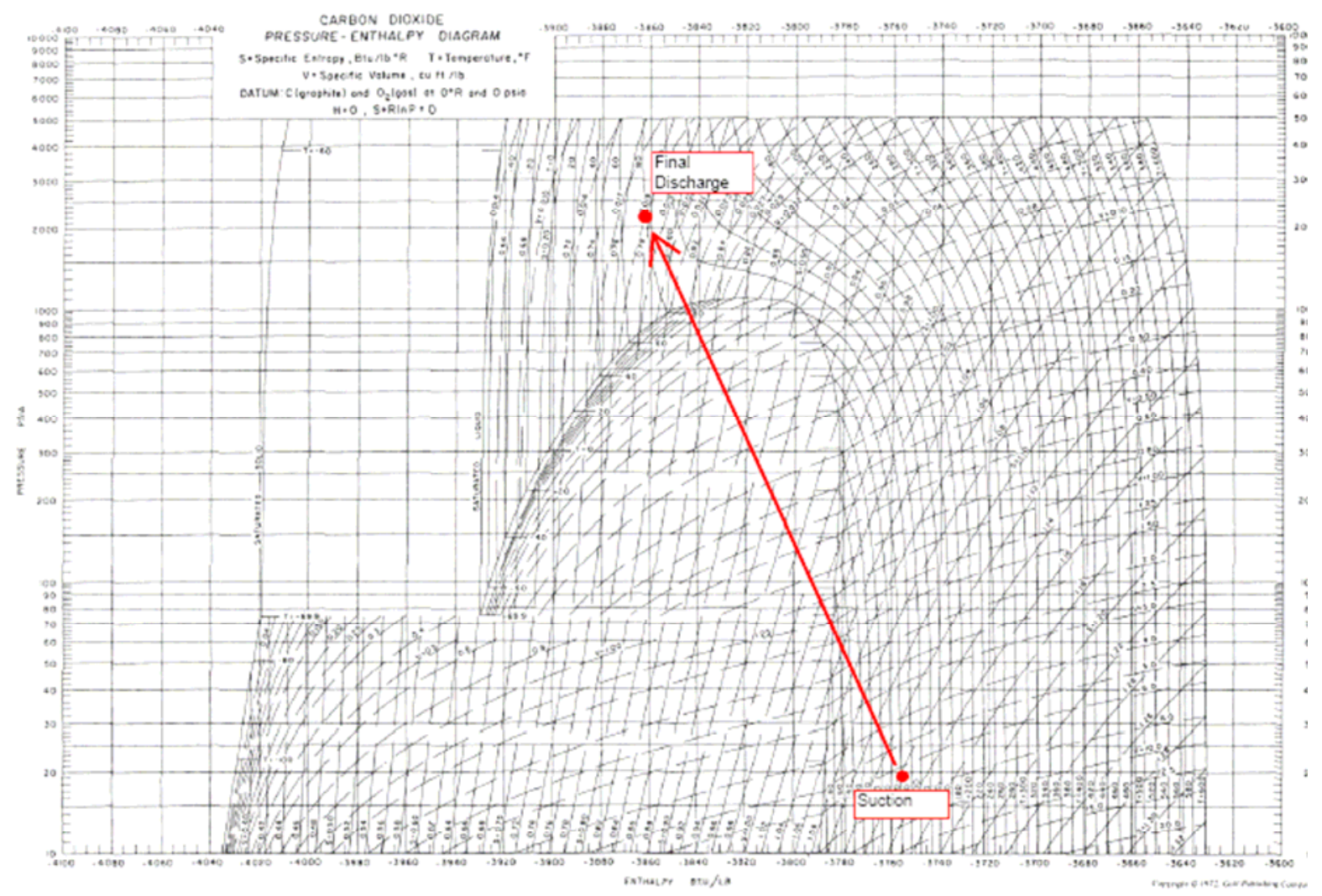

Figure 3-2. Pressure-Enthalpy Diagram for Carbon Dioxide [5] 


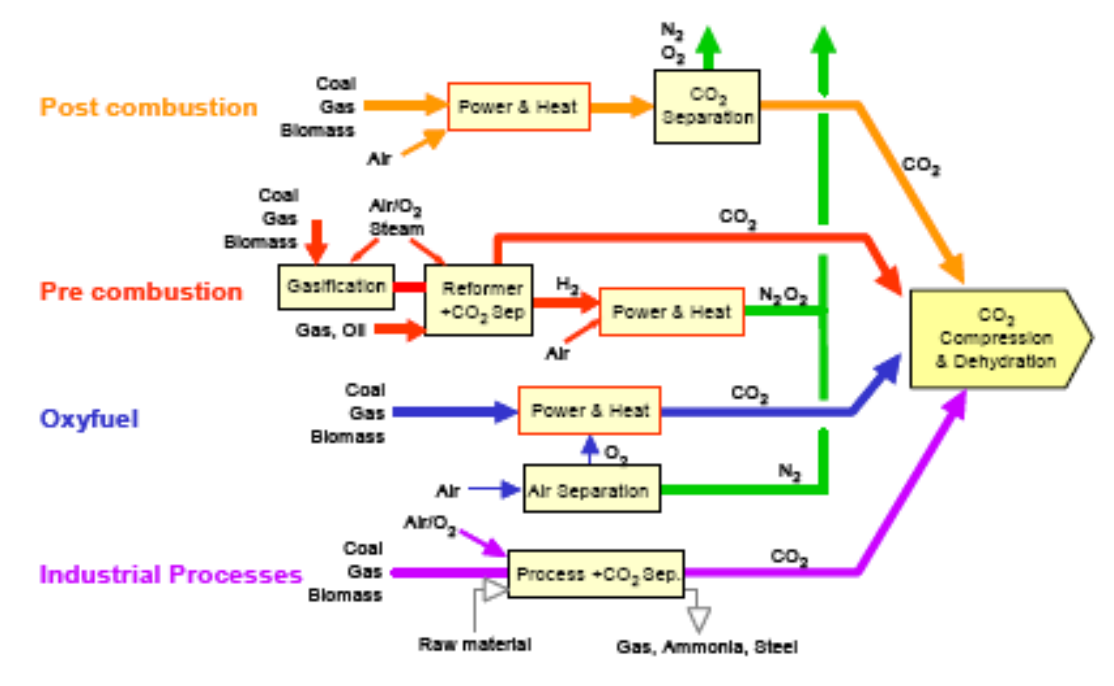

Figure 3-3. Basic Capture Systems for Carbon Dioxide Used in Power Plant Applications [6]

Currently, large-scale power plants producing more than 100 megawatts of electricity do not employ $\mathrm{CO}_{2}$ capture systems, although these larger plants are the major producers of $\mathrm{CO}_{2}$ emissions and will be in the future. Pre-combustion technologies for separation of $\mathrm{CO}_{2}$ in an IGCC plant are commercially ready (Intergovernmental Panel on Climate Control (IPCC) 2005 Report on Carbon Dioxide Capture and Storage). Pre-combustion technologies are preferred (over post-combustion systems) in an IGCC plant because the available extraction pressure is higher, reducing the required volume of $\mathrm{CO}_{2}$ to be separated. In a pre-combustion separation process, the fuel source (a hydrocarbon mixture) reacts with either steam or oxygen to produce carbon monoxide and hydrogen. Then, a shift reaction occurs to produce carbon dioxide and hydrogen by adding steam to carbon monoxide gas. Carbon dioxide is finally separated from the hydrogen fuel in the final stage.

Various carbon dioxide separation methods exist, namely chemical absorption, physical adsorption or absorption, liquid distillation, or membrane technology. The methods are illustrated in Figure 3-4. In separation technology using sorbents, the process gas is put in intimate contact with liquid or solid sorbent to absorb or adsorb onto the carrier sorbent. A pressure or temperature changes occurs to cause the sorbent to release the $\mathrm{CO}_{2}$. Examples of sorbents are monoethanolamine (MEA), hot potassium carbonate $\left(\mathrm{K}_{2} \mathrm{CO}_{3}\right)$, and commercially produced mixtures such as Selexol. Selexol is currently used to separate $\mathrm{CO}_{2}$ in many industrial applications. The use of chemical absorption or physical adsorption/absorption appears to be the most promising existing technology for $\mathrm{CO}_{2}$ separation.

Improvements to sorbtion technologies will reduce the energy penalty associated with capturing carbon dioxide in the future. The cost of $\mathrm{CO}_{2}$ recovery using MEA and $\mathrm{K}_{2} \mathrm{CO}_{3}$ absorption in an IGCC system was recently improved by energy integration schemes in a 2004 study [7]. Adsorption technology using molecular sieves, activated carbon and natural zeolite were also shown to capture high amounts of $\mathrm{CO}_{2}[8]$. 


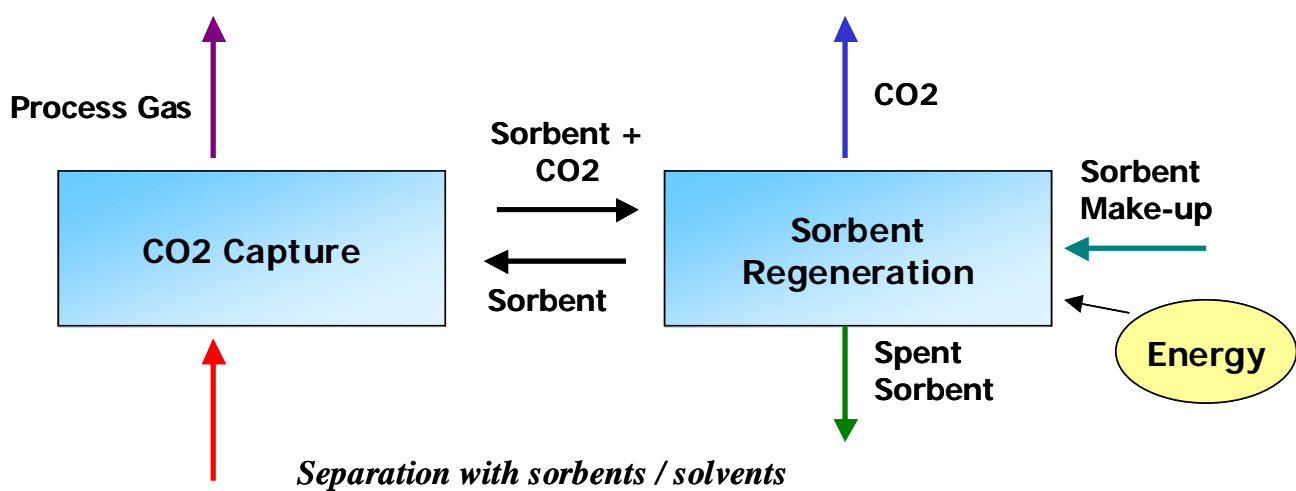

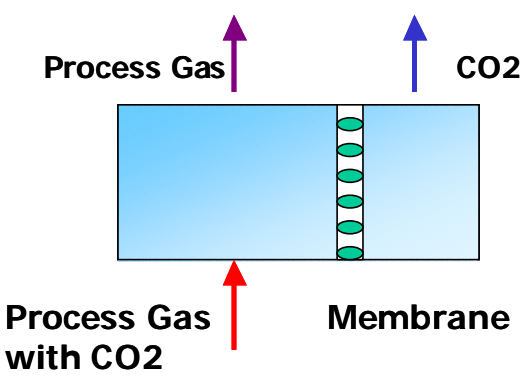

Separation with a membrane

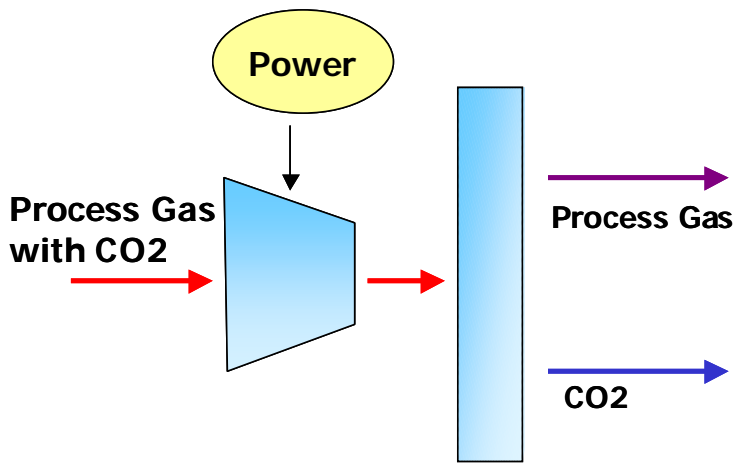

Separation with cryogenic distillation

Figure 3-4. Illustration of Pre-Combustion Capture Technology Premise [6]

Membranes allow the $\mathrm{CO}_{2}$ to selectively permeate through the membrane. High-pressure gas works best in membrane applications because the flow is often pressure driven. Membrane technologies have not been applied to the $\mathrm{CO}_{2}$ capture conditions required in an IGCC plant. The technology may need improvements in the area of reliability and size in order to meet the current application.

The gas stream may also be liquefied and distilled to separate the heavier $\mathrm{CO}_{2}$ gas from the lighter process mixture. This process of cryogenic distillation is a less available technology, which may need further development. The technology has not been employed in industrial $\mathrm{CO}_{2}$ separation systems to date.

An example of a new capture technology is the SIMTECHE process which uses hydrate formation to separate $\mathrm{CO}_{2}$ from syngas at relatively high pressures. The benefits of separating carbon dioxide at higher pressures are considerable because the cost of compression (and cooling) the $\mathrm{CO}_{2}$ stream is reduced. In the SIMTECHE, the process forms gas hydrates, which are rich in carbon dioxide using a proprietary technology (neither adsorption or absorption) [9]. The SIMTECHE process can capture 70-90\% of the carbon dioxide in the gas stream, depending upon the use of organic promoters. An obvious advantage of this new technology is the ability to deliver captured $\mathrm{CO}_{2}$ at a suction pressure of 5 to 10 times the pressure of current separation technology [10]. However, the ability to capture the majority of the $\mathrm{CO}_{2}$ stream is critical to reduce the costs and emissions of an IGCC plant. 


\subsubsection{Current Need for $\mathrm{CO}_{2}$ Technology Improvements in IGCC Plants}

The process associated with carbon dioxide capture increases the cost of produced electricity by a factor of 1.2 to 2.0 , due to the energy required to remove and compress carbon dioxide with current technology. The increase in cost for an IGCC plant is less than the increase in cost in a natural gas combined cycle (NGCC) plant or a pulverized coal (PC) combustion process using $\mathrm{CO}_{2}$ capture. The cost of electricity production increases by $40-85 \%$ in a PC plant and $35-70 \%$ in a natural gas combined cycle plant, compared to an increase of $20-55 \%$ in an IGCC plant [6].

Other sources actually find the increase in electricity cost gaps to be larger between IGCC plants and NGCC or PC. Pashos found the increased cost of $\mathrm{CO}_{2}$ capture to be $25 \%$ in the case of an IGCC plant compared to $60 \%$ for a NGCC plant or $72 \%$ for a PC plant [11]. Shine made the same calculation using an IGCC plant with a shift reactor and the Selexol absorption technology [12]. He found a 25-35\% increase for the IGCC plant, compared to estimations of $\mathrm{CO}_{2}$ capture at $50-75 \%$ in flue gas applications, such as a gas turbine or coal fired boiler [12, 13]. Regardless, the comparable costs of implementing a $\mathrm{CO}_{2}$ capture system in an IGCC plant will be less than other power plant capture systems. The present study aims to reduce this cost by designing a more efficient compression system for large volumes of $\mathrm{CO}_{2}$.

The combination of high oil prices, low coal prices, and more efficient capture and compression technology will drive the competitiveness of the future zero-emission IGCC plant. Figure 3-5 illustrates the trade-offs between the cost of recovered $\mathrm{CO}_{2}$, the price of oil, and the risk of new separation technology. Improved technology will increase the amount of economically recoverable oil, using $\mathrm{CO}_{2}$ as the injection gas [14].

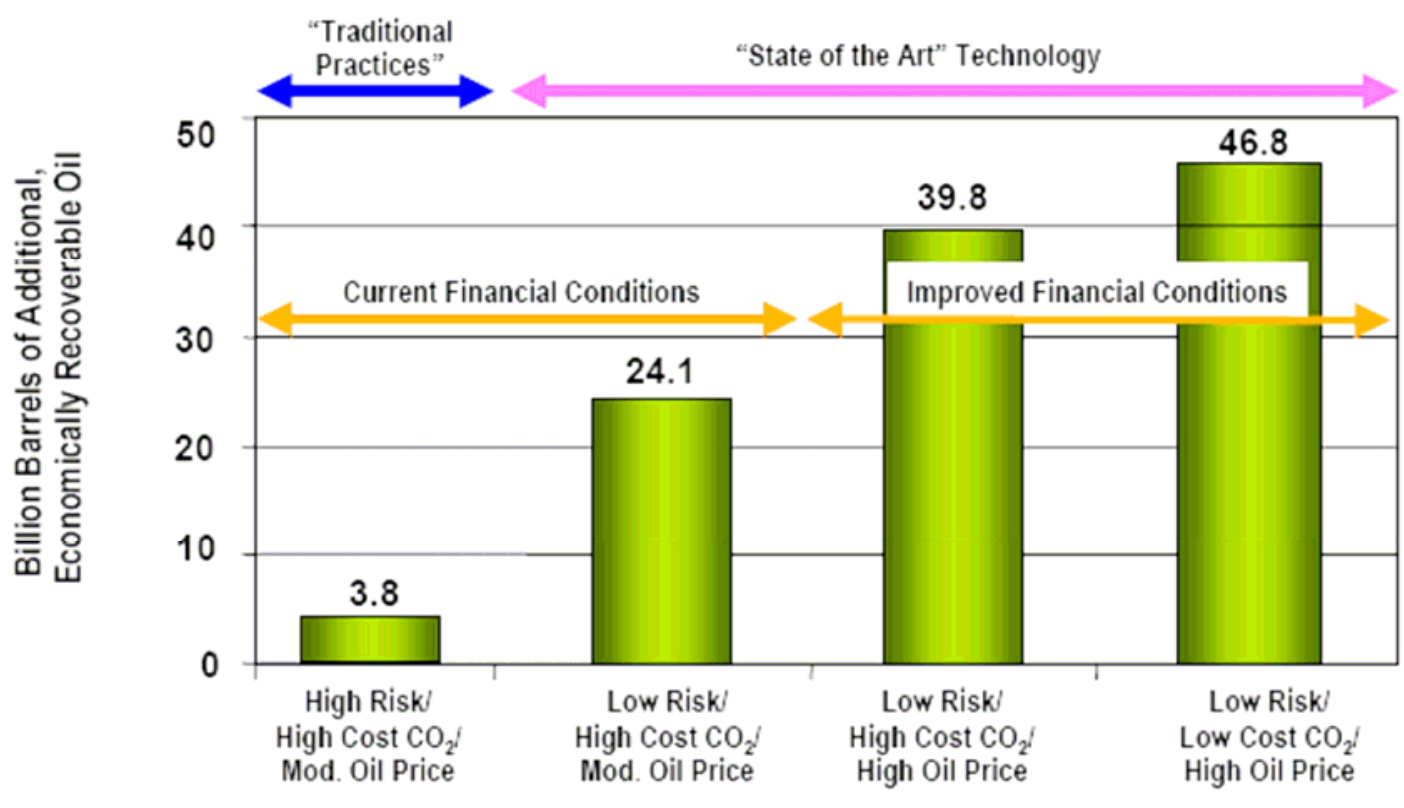

Figure 3-5. Economically Recoverable Oil versus Technology Risk, Cost of Carbon Dioxide and Oil Price [14] 


\subsubsection{Compressor Technology}

To compress carbon dioxide with traditional technology from an initial pressure ranging from 15 to 100 PSI to a final pressure of 2,200 PSI, multiple stages of compression will be required. The optimum ratio for $\mathrm{CO}_{2}$ compression is 3.5 to 4.0, according to compressor manufacturers. Diaphragm or the traditional reciprocating compressors are the traditional technology used to deliver high discharge pressures or for high-pressure ratio applications. Below 40 bar (550 PSI), positive displacement compressors (rotary or screw) may also be used, but more stages may be required because these machines are pressure ratio limited. Centrifugal compressors will also be considered because of their ability to process large volumes of gas at both low and high pressures.

Screw compressors were first used with $\mathrm{CO}_{2}$ in the food industry in 1981. They have since become a standard in the industry. $\mathrm{CO}_{2}$ compression from atmospheric conditions to 300 PSI can be accomplished in two stages. The lubricant separation systems in the modern day screw compressor lower the lubricant levels in the delivered $\mathrm{CO}_{2}$. Dehydration through cooling is required prior to compression to remove contained water in the $\mathrm{CO}_{2}$ stream.

Shock compression is an alternative "new" compression technology. Shock compression is accomplished by dramatically slowing down a high velocity inlet line of process gas by diverting the gas around a fixed body and into a small channel. By forcing the flow into small channels, the process gas stream is slowed from a supersonic speed to subsonic speed, which creates a shockwave and a corresponding rise in pressure. Ramgen Power Systems has developed a shock compressor for the air compressor market. A similar multi-stage compressor for process-gas applications is currently in development. Additional analysis is required to determine if the shock compression process reduces horsepower, once cooling considerations are taken into account [15].

At the initial separation point, the large volume of $\mathrm{CO}_{2}$ produced by a large IGCC plant may require a centrifugal compressor to accommodate the larger volumes. The number of compression stages and intercooling between stages will affect the overall horsepower required for the compression process. Isothermal centrifugal compressors are a consideration for this application because the process gas may be cooled in between each stage of compression, which reduces the total horsepower requirement (Dresser-Rand). In addition, the specific properties of $\mathrm{CO}_{2}$ must be taken into account. As Figure 3-2 shows, the vapor-liquid dome for carbon dioxide is different from a predominant hydrocarbon gas composition. The liquid region for $\mathrm{CO}_{2}$ may be reached by lowering the temperature of $\mathrm{CO}_{2}$ at a pressure of approximately 100 PSI. The cryogenic liquid region offers additional flexibility because cryogenic pumps consume considerably less power than gas compressors. Preliminary analysis of various compression options suggests that cryogenic pumping applications show potential for horsepower savings. Two preliminary analyses are shown in Figure 3-6 and Figure 3-7. Instead of using a path of compression through the vapor region, the liquid region uses less horsepower and requires less cooling. 


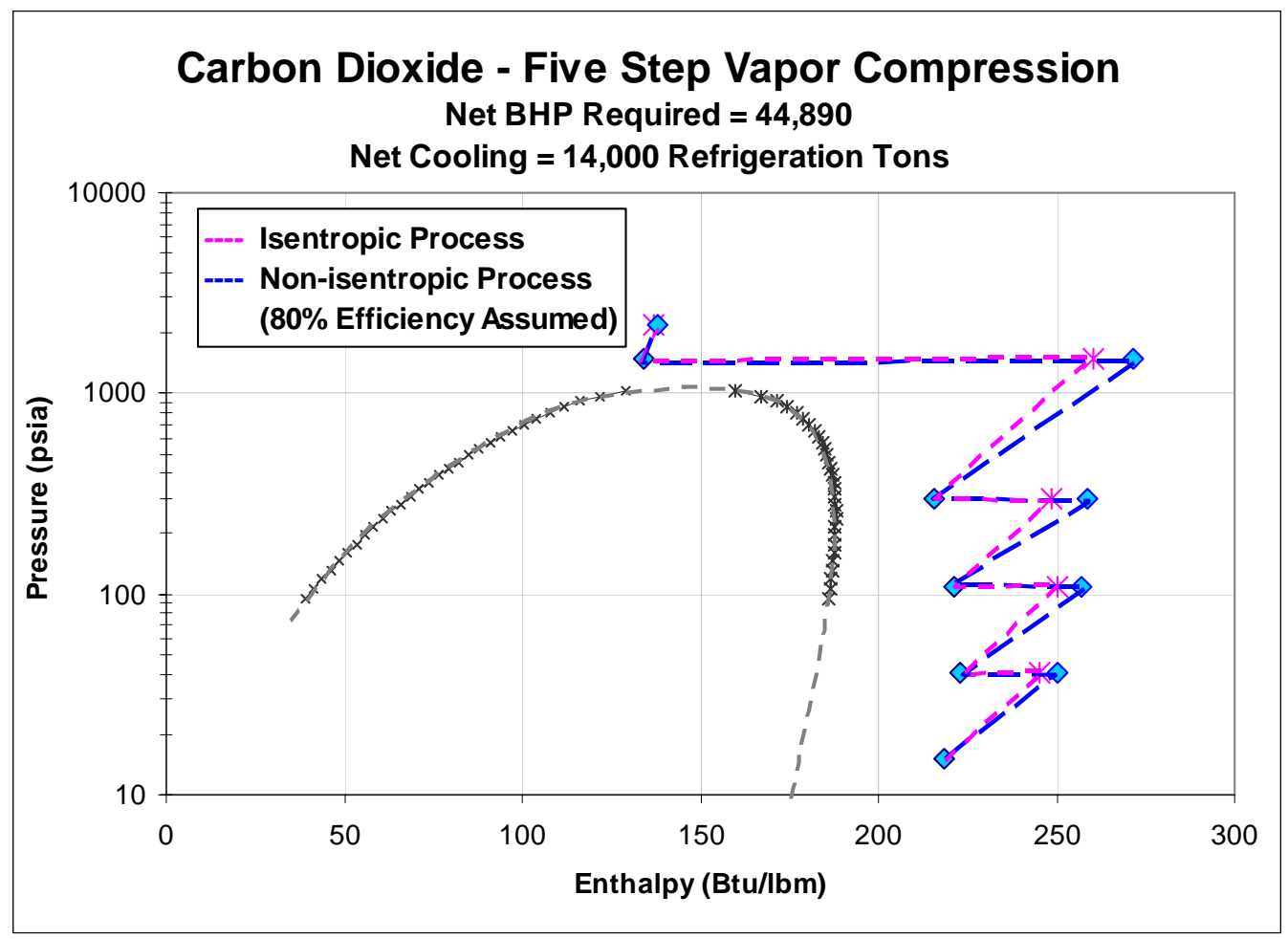

Figure 3-6. Five Step Compression Process for Carbon Dioxide with Intercooling

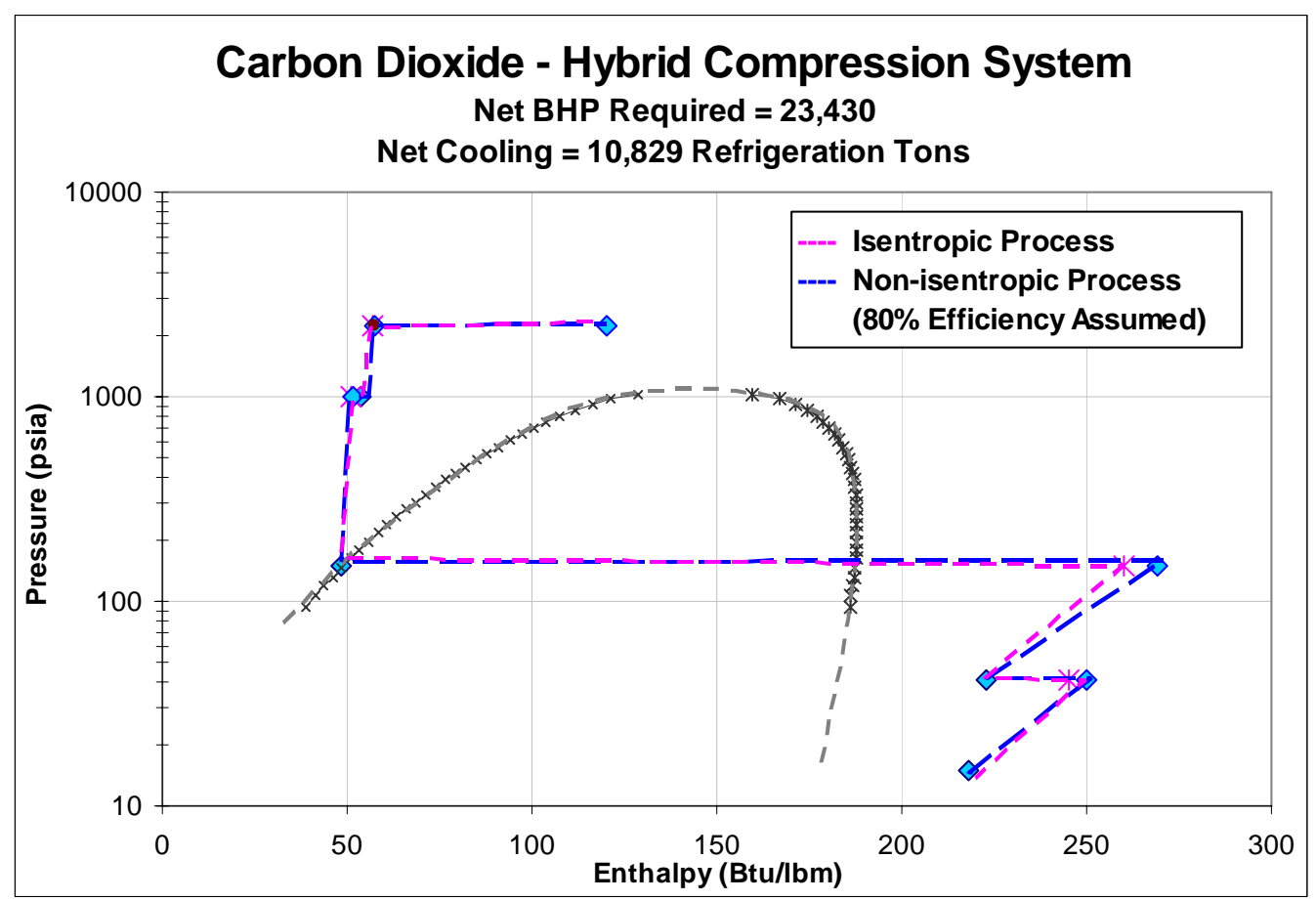

Figure 3-7. Hybrid Compression System with Vapor Compression and Cryogenic Liquid Pump 
However, liquid $\mathrm{CO}_{2}$ transport may not be as effective as gas pipeline transport. The carbon dioxide pipeline infrastructure is already in place in parts of the United States, with future $\mathrm{CO}_{2}$ pipelines already in the preliminary planning stages. Figure 3-8 depicts the country's carbon dioxide pipeline network, as it existed in 2005 [13]. Past studies also suggests that high pressure gaseous $\mathrm{CO}_{2}$ is the most efficient method of $\mathrm{CO}_{2}$ transport. Transportation options for $\mathrm{CO}_{2}$ were examined in constructing the SACROC $\mathrm{CO}_{2}$ pipeline, which was the first $\mathrm{CO}_{2}$ pipeline constructed in the United States to move anthropogenic carbon dioxide from Shell Oil Company gas processing plants to the Texas Val Verde basin for enhanced oil recovery. At the time, the use of trucks or rail options was considerably more costly than high-pressure (at 9.6 MPa) gas pipeline transport. High-pressure transport was analyzed to be $20 \%$ less costly than low-pressure (4.8 MPa) transport due to the large volume of pipeline required for the low-pressure option [6]. Transportation of $\mathrm{CO}_{2}$ by pipeline is still preferred by operating companies for many reasons. Though the initial capital costs for a pipeline are considerably high, the other options (by truck, rail, or cargo) present higher operational costs, increased carbon monoxide emissions in the transportation process, and have a significantly higher risk to public safety.

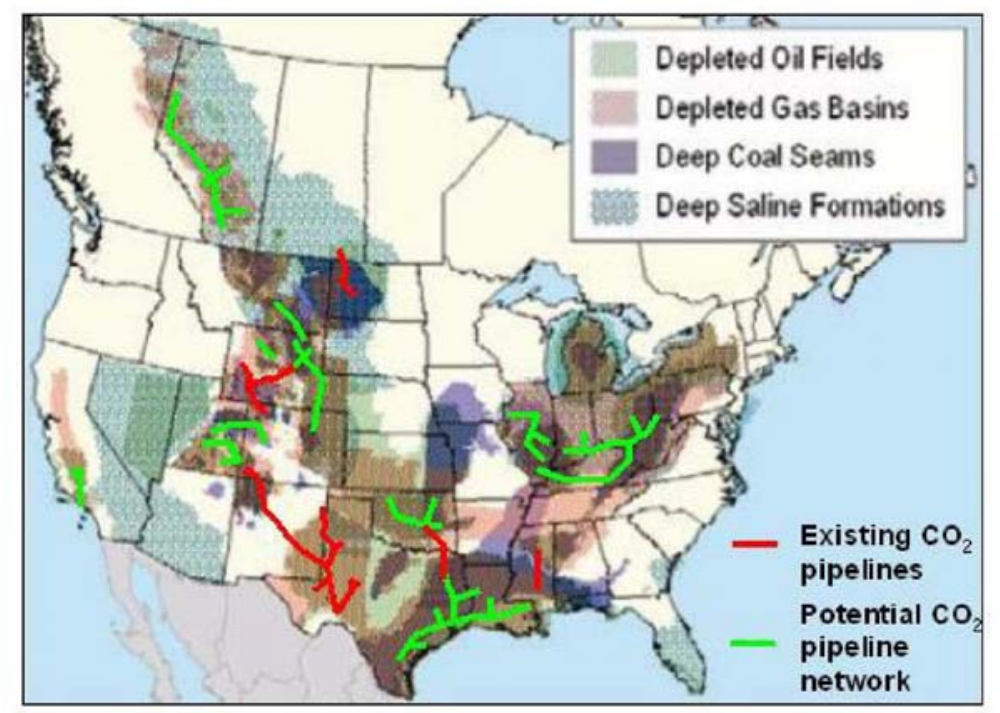

Figure 3-8. Existing Carbon Dioxide Pipeline Infrastructure [13]

Liquid transport may need to be reconsidered with the current technology improvements compared to the analysis previously done in the SACROC pipeline construction. The use of liquefaction technology and experience with LNG transport in the last three to five years may be transferred to liquid carbon dioxide transport applications [6].

Carbon dioxide has a low critical temperature of $31.1^{\circ} \mathrm{C}$ and critical pressure of $73.8 \mathrm{bar}$ (1,070 PSI). At supercritical pressure, heat is rejected during compression. $\mathrm{CO}_{2}$ has seen an increased presence in the refrigerant industry (especially in Europe over the last ten years) because its supercritical properties allow it to be compressed very efficiently. Many times, $\mathrm{CO}_{2}$ liquid compressors operate in a transcritical region. $\mathrm{CO}_{2}$ is useful in compression cycles requiring heating and cooling at the same time. The coefficient of performance may be improved by $15-20 \%$ for a twin screw compressor by designing for a transcritical compression and expansion process in the same unit [16]. 
In transporting $\mathrm{CO}_{2}$, the two-phase region must be considered, which exists below 1,100 PSI. This equates to maintaining a certain minimum temperature in the pipeline as the $\mathrm{CO}_{2}$ is transported and compressed up to 1,100 PSI. Once the pressure is above the supercritical point, the $\mathrm{CO}_{2}$ is in a supercritical state where it acts as neither gas nor liquid. In addition, the corrosion rates of $\mathrm{CO}_{2}$ must be considered. The corrosion rate suggested by field data amounts to 0.00025 to $0.0025 \mathrm{~mm}$ per year, without the presence of water vapor. If the $\mathrm{CO}_{2}$ is not dehydrated, hydrates may increase the corrosion rate considerably due to the formation of carbonic acid.

\subsubsection{Task 1.2 - Conceptual Design Analysis}

For an example 400 MW IGCC plant, a typical $\mathrm{CO}_{2}$ mass flow rate of 600,000 to $700,000 \mathrm{lbm} / \mathrm{hr}$ exists from the shift reactors. Figure 3-9 plots the required inlet volume flow for a given inlet pressure. The plot shows the strong sensitivity to inlet pressure on the inlet volume flow rate. For a 600-PSI $\mathrm{CO}_{2}$ stream pressure, a volume flow of only 2,465 ACFM is required. If, for example, this $\mathrm{CO}_{2}$ stream comes from combustion flue gas at atmospheric pressure, then a volume flow rate of over 100,000 ACFM is required. This is over 40 times the greater flow rate. Since volume flow increases with the square of the scale factor, a compressor over six times larger is required. The requirement of large frame compressors increases both the capital and operating expenses of the plant.

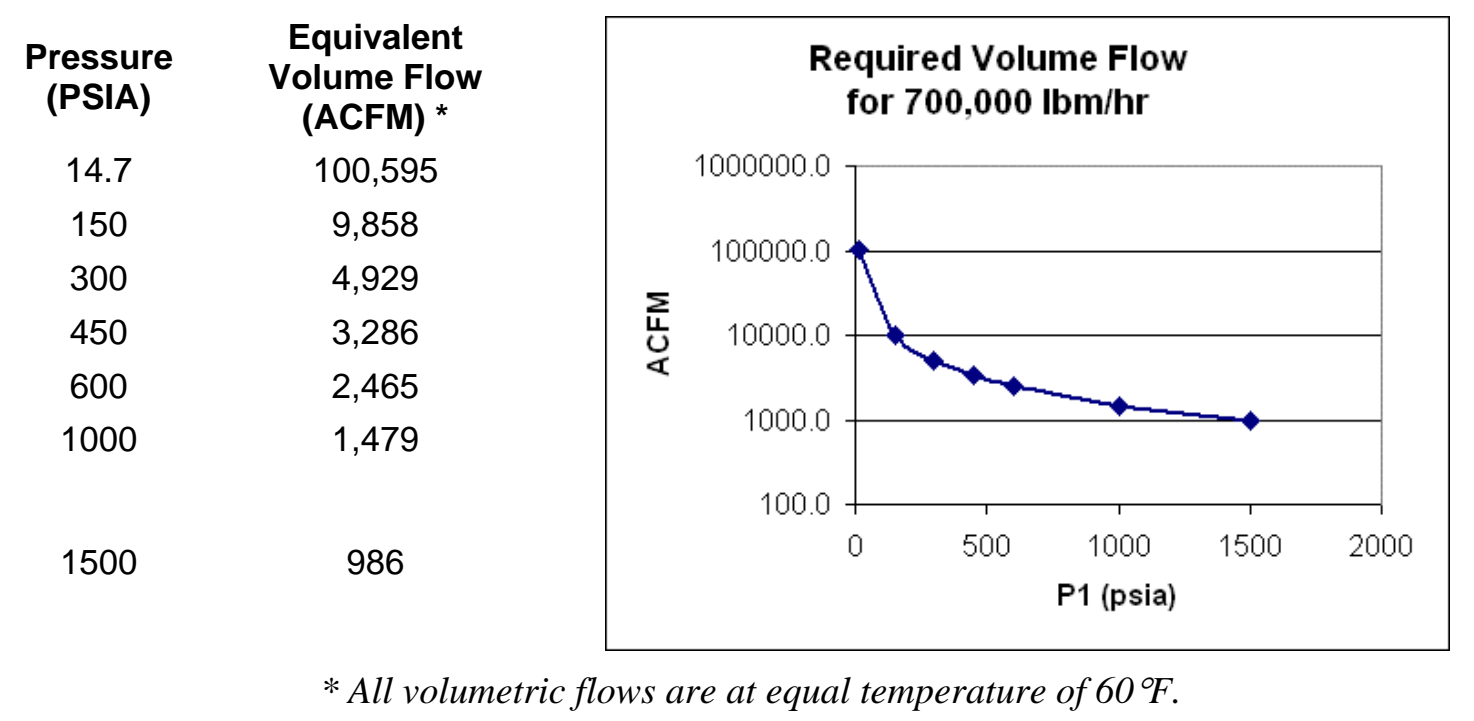

Figure 3-9. Inlet Volumetric Flow Rate at Various Pressures

In order to better understand the compression requirement, preliminary compressor selections were made using the above case study. For high volume applications, axial compressors offer many advantages. Figure 3-10 shows an axial compressor application map for a family of Dresser-Rand axial air compressors. The requirement of 100,000 ACFM for an ambient inlet pressure falls near the middle of the application map. The pressure ratio would be about 1.5 times greater than for air due to the higher molecular weight. This compressor would boost the pressure to just over 100 PSI. Therefore, multiple compressor bodies with intercoolers would be required. 


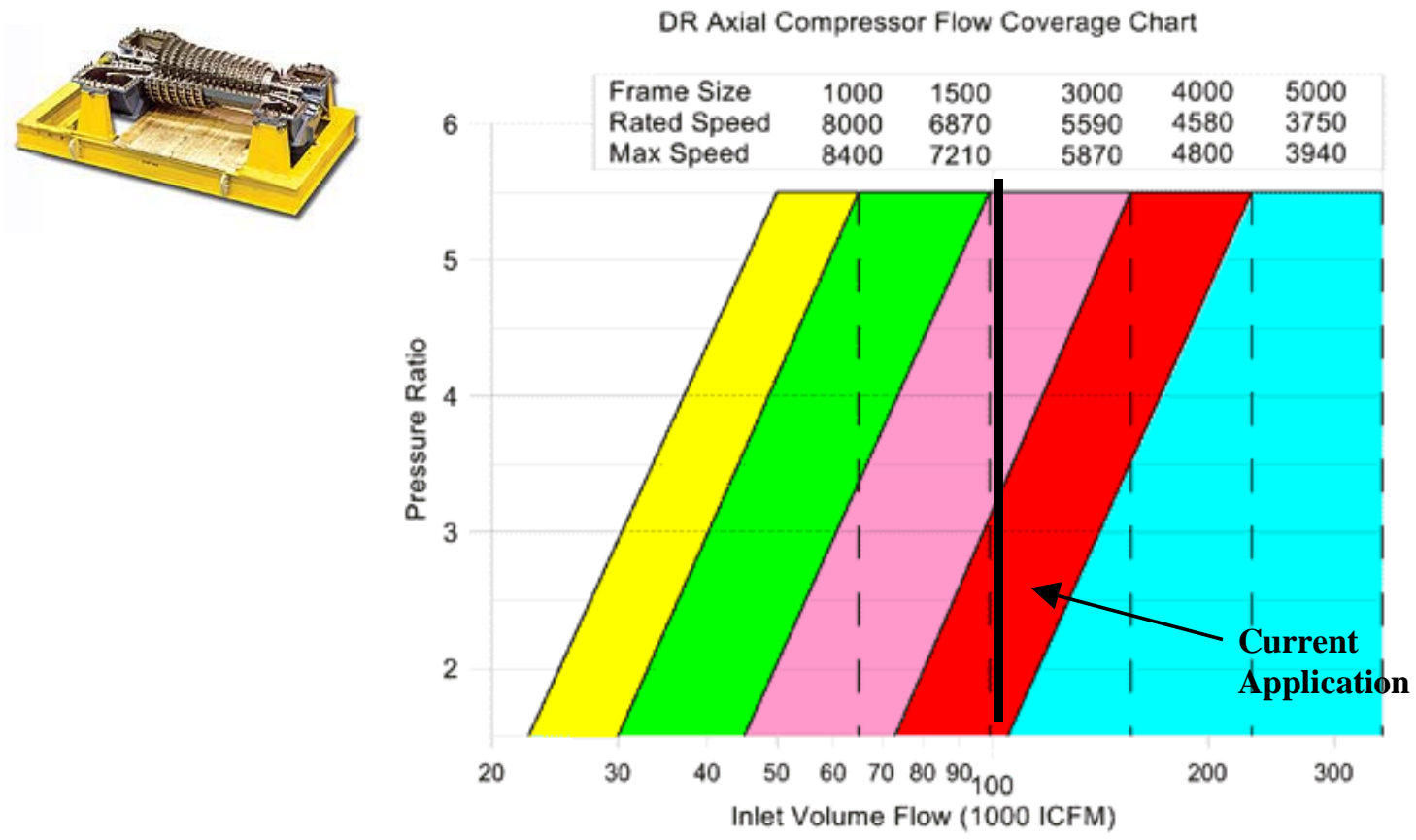

Figure 3-10. Axial Compressor Application Map (Courtesy of Dresser-Rand)

A centrifugal compressor solution is investigated next. Figure 3-11 shows an application map for the range of multi-stage centrifugal compressors, named the DATUM, produced by Dresser-Rand. The frame sizes range from 2 to 28 in steps of two. The volume flow for a 15PSI inlet and a 300-PSI inlet are superimposed on the chart. The higher inlet pressure (300 PSIA) requires a frame 2 or 4 . The low inlet pressure (14.7 PSIA) requires a frame 24 compressor. To give an indication of the size difference, the frame 24 can use as large as a 48inch inlet nozzle flange, while the frame 4 is less than 12 inches.

Table 3-1 shows an actual compressor configuration for the higher inlet pressure using the Dresser-Rand compressor selection tool. As indicated above, a frame 4 was selected requiring only three impellers and consuming 14,500 HP. To demonstrate a point, the same application is used, but assuming perfect isothermal compression where each impeller sees the same $80^{\circ} \mathrm{F}$ inlet temperature. The power required reduces to $10,500 \mathrm{HP}$, which is $37 \%$ less power. Reducing the inlet temperature to the saturation temperature of $0^{\circ} \mathrm{F}$ reduces the power required to 10,830 HP. For comparison, a low-speed reciprocating selection was also made and shows a horsepower requirement of 13,900 HP. While this is less than the standard centrifugal, it is significantly higher than an isothermal offering.

The low inlet pressure selection is shown in Table 3-2. This selection calls for a twocasing solution using a frame 26 compressor with the first containing two stages and the second containing four stages in a back-to-back arrangement, indicating a power requirement of $29,570 \mathrm{HP}$. The power requirement reduces to $24,000 \mathrm{HP}$, if the inlet temperature is reduced to $-100^{\circ} \mathrm{F}$. 


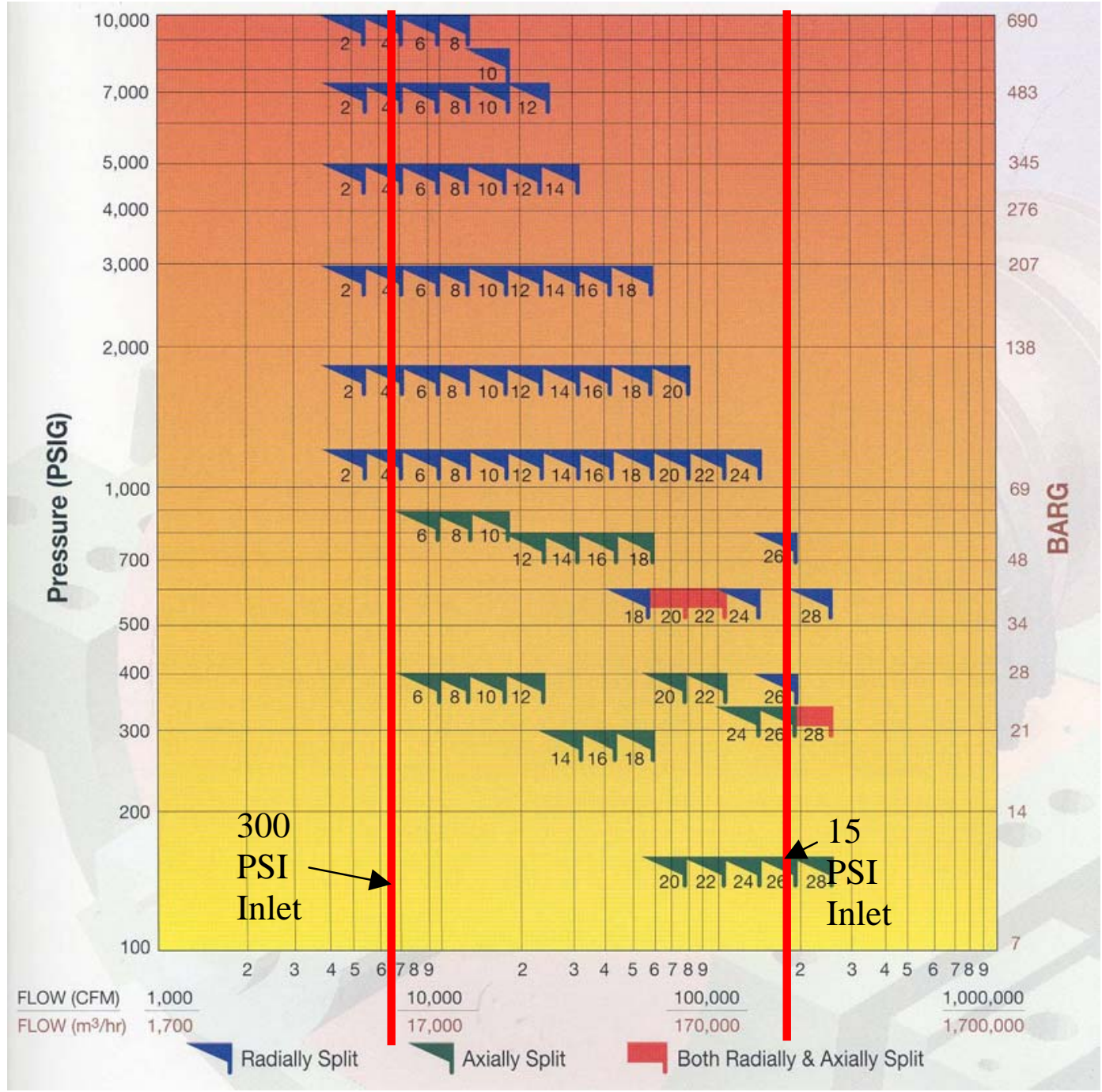

Figure 3-11. Centrifugal Compressor Application Map (Courtesy of Dresser-Rand)

Table 3-1. Sample Centrifugal Compressor Selection: 300 to 1,500 PSI

\begin{tabular}{|l|l|l|}
\hline SECTION INLET P & PSIA & 300 \\
\hline SECTION INLET T & F & 80 \\
\hline SECTION INLET Q & ACFM & 4,564 \\
\hline SECTION DISCHARGE P & PSIA & 1,500 \\
\hline SECTION DISCHARGE T & F & 362 \\
\hline RATIO & & 5.00 \\
\hline HEAD & FT-LB/LB & 33,461 \\
\hline EFFICIENCY & $\%$ & 81 \\
\hline COMP DESIGNATION & & D4R \\
\hline STAGES & & 3.00 \\
\hline SHAFT SPEED & RPM & 17,710 \\
\hline POWER & BHP & 14,510 \\
\hline ISOTHERMAL COMPRESSION POWER & BHP & 10,530 \\
\hline
\end{tabular}


Table 3-2. Sample Centrifugal Compressor Selection: 15 to 300 PSI

\begin{tabular}{|l|l|l|l|l|}
\hline CASING NUMBER & & 1.00 & 2.00 & 3.00 \\
\hline SECTION INLET P & PSIA & 15 & 40 & 109 \\
\hline SECTION INLET T & F & 80 & 105 & 105 \\
\hline SECTION INLET Q & ACFM & 101,717 & 39,333 & 14,188 \\
\hline SECTION DISCHARGE P & PSIA & 41 & 111 & 300 \\
\hline SECTION DISCHARGE T & F & 232 & 277 & 297 \\
\hline RATIO & & 2.71 & 2.74 & 2.74 \\
\hline HEAD & FT-LB/LB & 21,363 & 22,620 & 22,455 \\
\hline EFFICIENCY & $\%$ & 85 & 81 & 73 \\
\hline COMP DESIGNATION & & D26R & D26R & D26R \\
\hline STAGES & & 2.00 & 2.00 & 2.00 \\
\hline SHAFT SPEED & RPM & 3,350 & 3,350 & 3,350 \\
\hline POWER & BHP & 8,820 & 9,910 & 10,840 \\
\hline TOTAL POWER (if train) & BHP & 29,570 & & \\
\hline
\end{tabular}

The total power required in compressing $\mathrm{CO}_{2}$ from 15 to 1,500 PSI is 44,080 HP (33 MW). This represents $8.2 \%$ of the $400 \mathrm{MW}$ plant output. If compression starts from an elevated fuel gas stream (IGCC process), then only 14,500 HP is required, representing about 3\% of the plant output. This power requirement may be reduced by about $37 \%$ using isothermal compression. These values do not account for the power required for gas transmission along required pipelines.

The cryogenic pumping option discussed above would utilize a centrifugal pump to boost the liquid $\mathrm{CO}_{2}$ from 15 to 1,500 PSI, similar to a rocket engine turbopump used for liquid oxygen and hydrogen. The assumed mass flow rate used above $(700,000 \mathrm{lbm} / \mathrm{hr})$ would result in 1,200 gallons per minute flow rate. This flow rate is in the range of rocket engine pumps but is higher than commercially available pumps and would likely require development for this application. Like rocket engine pumps, the low net positive suction head (NPSH) for ambient inlet pressure presents some cavitation issues that must be overcome. For higher inlet pressures (IGCC process), significantly less head is required and no NPSH issues would exist. The calculated power to boost the pressure from 15 to 1,500 PSI in liquid form is only 1,283 HP.

Table 3-3 summarizes the required power for the various options. The reciprocating compressor option does not reduce the power significantly over a conventional centrifugal. Isothermal compression and reduced inlet temperature approaches both significantly reduce the required power of compression. Combining these two approaches would result in further savings. The liquid turbopump option possesses the greatest potential savings, reducing required power by over an order of magnitude. Obviously, the approach is dependent on the ability to liquefy the $\mathrm{CO}_{2}$ without additional horsepower requirements.

The liquid turbopump option possesses significant potential for reducing cost of pressurization, but this concept needs further investigation to prove its viability. Significant improvements can be realized even with gaseous compression as shown above. 
Table 3-3. Summary of Power Required for the Boosting Pressure from 15 to 1,500 PSI

\begin{tabular}{|l|c|}
\hline \multicolumn{1}{|c|}{ Configuration } & Horsepower Required \\
\hline Conventional Centrifugal LP/Recip HP & 43,499 \\
\hline Conventional Centrifugal LP/HP & 44,080 \\
\hline Isothermal Compression - Centrifugal LP/HP & 27,770 \\
\hline Reduced Inlet Temperature - Centrifugal LP/HP & 34,830 \\
\hline Liquid Turbopump Option & $1,283^{*}$ \\
\hline *Does not include the power required to liquefy the $\mathrm{CO}_{2}$ \\
\hline
\end{tabular}

\subsubsection{Available Commercial Product Description}

The following is a brief review of existing compression technology. Figure 3-12 shows a high-pressure (up to 3,800 PSI) centrifugal compressor produced by Dresser-Rand named the DATUM and is used for natural gas re-injection. This demanding service pushes the state-ofthe-art in the amount of pressure ratio in a single casing (over 9:1).

Figure 3-13 shows a Dresser-Rand integrally geared compressor called the ISOPAC. It permits isothermal compression using intercoolers between the stages. The required piping and cooler arrangement can be complex and possess greater losses than a standard multi-stage compressor with internal cooling as is being proposed in this project.

Figure 3-14 shows a picture of a turbopump developed by Barbour Nichols for the Fastrac rocket engine designed, built, and tested by NASA Marshall Space Flight Center [17]. These turbopumps provide pressure boost for kerosene and liquid oxygen that feed the engine producing 60,000 lbs. of thrust. This technology could be applied to the pumping of liquid $\mathrm{CO}_{2}$.

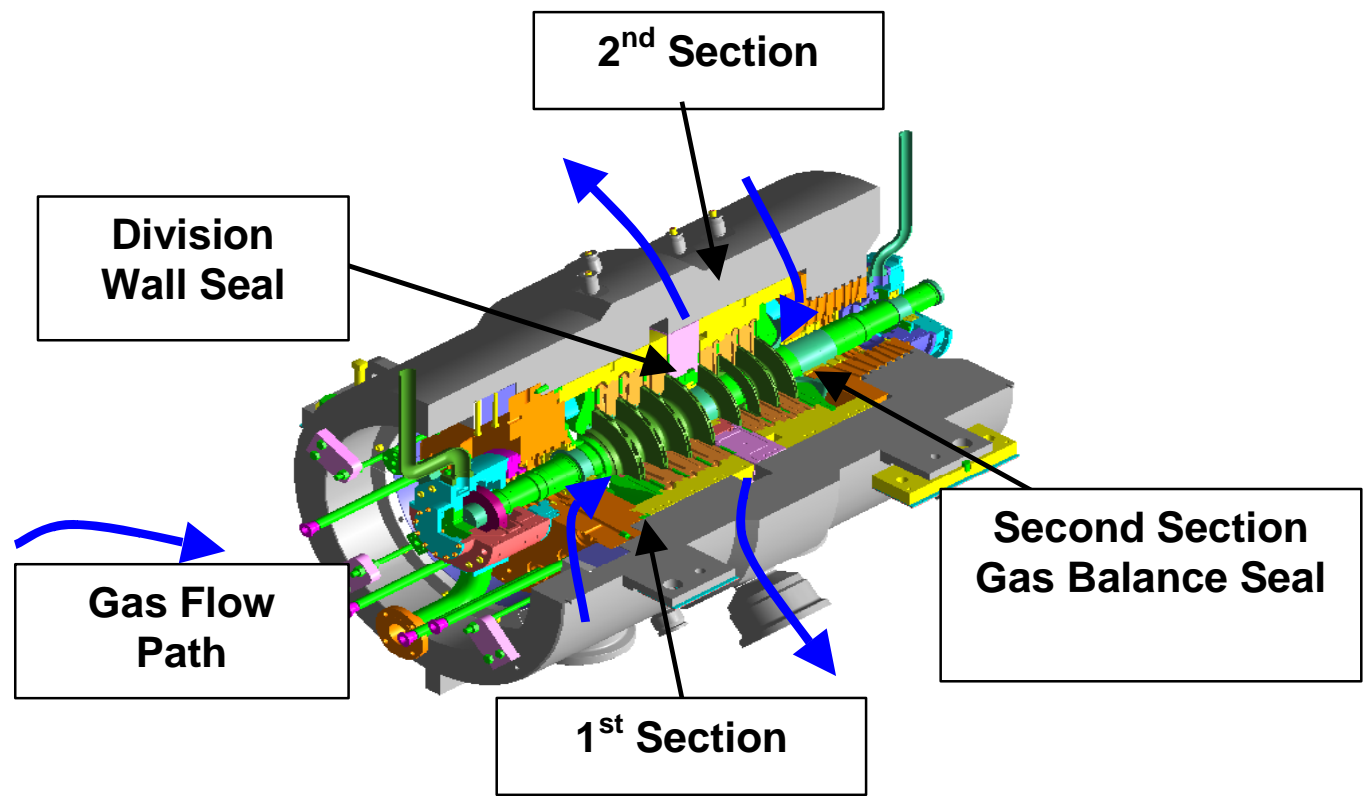

Figure 3-12. Dresser-Rand Multi-Stage Centrifugal Compressor (Courtesy of Dresser-Rand) 


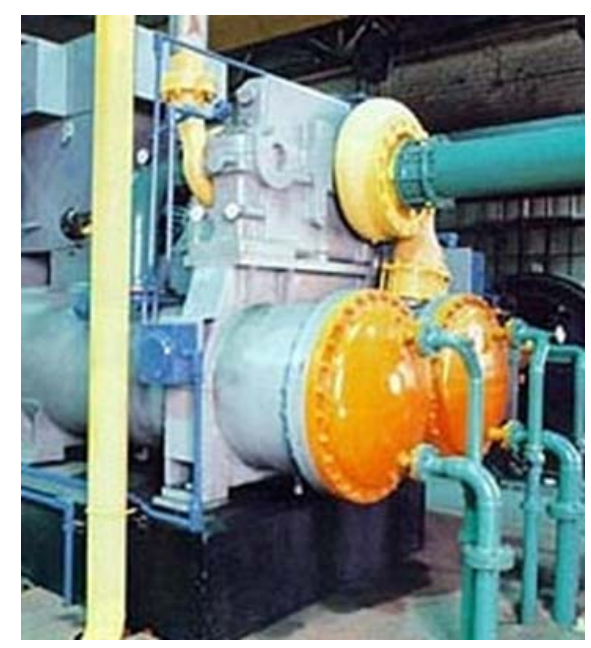

Figure 3-13. Dresser-Rand ISOPAC Compressor (Courtesy of Dresser-Rand)

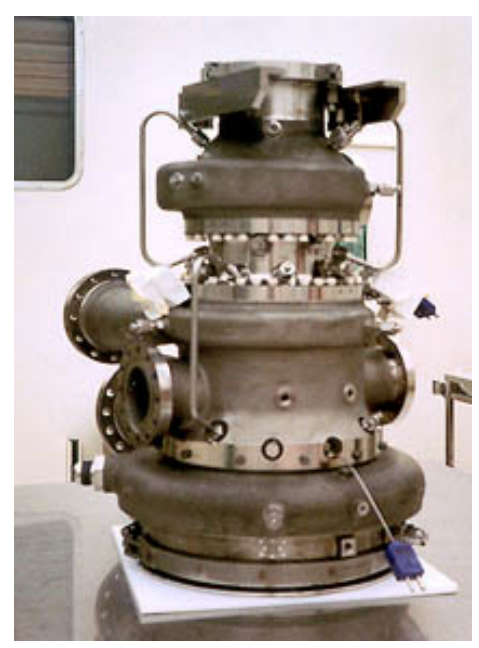

Figure 3-14. Rocket Engine Turbopump (Courtesy of Barber Nichols)

\subsubsection{Task 1.4 - Evaluate Intercooling Concepts}

Several intercooling schemes were considered in the investigation of technology concepts needed to provide intercooling throughout the compression process. Intercooled compressors offer a significant energy savings over traditional compression. A description of the various technology options that were explored is provided below.

- The traditional approach to intercooled compression is to use air-to-gas heat exchangers between compressor sections. This offers a fairly significant drop in required horsepower because the gas temperature is reduced 3-4 times throughout the compression process (from 15 to 2,200 PSI).

a A newer approach to intercooled compression is to use isothermal compression, which requires cooling the gas between each stage of compression. The compressor arrangement for this approach would either be an integrally geared or multi-stage centrifugal compressor with internal cooling. The primary heat exchange mechanism would be ambient air. This process allows for more cooling (and therefore higher efficiency) than the traditional process. The option is still limited by the temperature of the ambient air, thus, use of isothermal compression in climates with cooler ambient temperatures allows for higher efficiency.

- A third option investigated in the project uses a sub-ambient cooling scheme. Subambient cooling is provided by excess nitrogen gas from the air separation unit (ASU). Intercooling to a lower temperature offers more energy savings due to the variation in the enthalpy at higher temperatures and pressures. (Compression at lower temperatures requires less enthalpy departure.) The nitrogen gas may be used as a cooling source upstream of the inlet $\mathrm{CO}_{2}$ gas or in the internal diaphragms at the exit of each compression stage in the multi-stage compression option. Additional transpirational cooling, using liquid or gaseous nitrogen from the ASU, should be considered. Finally, intercooling can also be provided using gas mixing schemes with the sub-ambient temperature nitrogen gas and the $\mathrm{CO}_{2}$ gas. 


\subsubsection{Task 2.1 - Develop Interstage Cooling Concepts}

Various options for the compression of carbon dioxide as a waste stream from an IGCC plant have been examined. The compression technology options have been compared in terms of efficiency and required horsepower in order to determine the least costly compression technology for the IGCC plant application. To further study the advantages of the various technologies, it was assumed that the carbon dioxide was removed through a reformer process in the production of hydrogen rich syngas from natural gas. The waste carbon dioxide at near atmospheric pressure is transferred to a compression unit onsite at the power generation plant.

Based on a typical solvent absorption process for the removal of carbon dioxide, the carbon dioxide waste stream was assumed to be divided into a low pressure ( 22 PSIA), medium pressure ( 170 PSIA), and high pressure ( 250 PSIA) waste stream. The mass flow rates of each stream were typical of a current IGCC plant/ $\mathrm{CO}_{2}$ separation process. The expected delivery pressure for the carbon dioxide was assumed to be 2,215 PSIA at $70^{\circ} \mathrm{F}$. A typical $\mathrm{CO}_{2}$ flow rate of approximately 51 MMSCFD is also assumed. The carbon dioxide at the final delivery pressure is in a supercritical state. Table 3-4 shows the assumed pressures and temperatures for the waste $\mathrm{CO}_{2}$ streams resulting from the separation process.

Table 3-4. Typical Waste IGCC Carbon Dioxide Streams

\begin{tabular}{|c|c|c|c|c|}
\hline & LP CO${ }_{2}$ & $\mathrm{MP} \mathrm{CO} 2$ & $\mathrm{HP} \mathrm{CO}{ }_{2} 1$ & $\mathrm{HP} \mathrm{CO}_{2} 2$ \\
\hline \multicolumn{5}{|l|}{ Mole Fraction } \\
\hline $\mathrm{Ar}$ & 0.0000 & 0.0005 & 0.0008 & 0.0029 \\
\hline $\mathrm{CH}_{4}$ & 0.0004 & 0.0047 & 0.0053 & 0.0174 \\
\hline CO & 0.0000 & 0.0005 & 0.0007 & 0.0025 \\
\hline $\mathrm{CO}_{2}$ & 0.9952 & 0.9763 & 0.8742 & 0.8187 \\
\hline COS & $1.9 \mathrm{ppmv}$ & $0.8 \mathrm{ppmv}$ & $0.6 \mathrm{ppmv}$ & $0.6 \mathrm{ppmv}$ \\
\hline $\mathrm{H}_{2}$ & 0.0005 & 0.0168 & 0.0405 & 0.1573 \\
\hline $\mathrm{H}_{2} \mathrm{O}$ & 0.0039 & 0.0012 & 0.0010 & 0.0009 \\
\hline $\mathrm{H}_{2} \mathrm{~S}$ & $45.5 \mathrm{ppmv}$ & $13.0 \mathrm{ppmv}$ & $7.5 \mathrm{ppmv}$ & $8.7 \mathrm{ppmv}$ \\
\hline $\mathrm{N}_{2}$ & 0.0000 & 0.0000 & 0.0775 & 0.0001 \\
\hline Total & 1.0000 & 1.0000 & 1.0000 & 1.0000 \\
\hline Flowrate $\left(\mathrm{lb} \mathrm{b}_{\mathrm{mol}} / \mathrm{hr}\right)$ & 8,052 & 3,905 & 9,265 & 3,649 \\
\hline Flowrate (Ib/hr) & 353,298 & 168,445 & 378,775 & 134,431 \\
\hline Flowrate (Ib/min) & 5,888 & 2,807 & 6,313 & 2,241 \\
\hline Flowrate (ACFM) & 33,257 & 2,158 & 3,374 & 1,073 \\
\hline Temperature $\left({ }^{\circ} \mathrm{F}\right)$ & 51.0 & 68.0 & 90.0 & 75.0 \\
\hline Pressure (PSIA) & 21.9 & 160.0 & 250.0 & 299.0 \\
\hline Density $\left(\mathrm{lb} / \mathrm{ft}^{3}\right)$ & 0.177 & 1.301 & 1.871 & 2.088 \\
\hline Molecular Weight & 43.878 & 43.131 & 40.882 & 36.836 \\
\hline
\end{tabular}

\subsubsection{Option A - Conventional Approach}

The initial analysis of horsepower was conducted for a conventional approach to compressing the $\mathrm{CO}_{2}$, using multiple stages of centrifugal compression. The conventional technology is presented as Option A. The low-pressure stream is compressed and blended with the medium pressure stream (which enters the compressor as a side stream). The final high- 
pressure stream is blended with the two lower pressure streams to compress the carbon dioxide to its final delivery pressure of 2,215 PSIA. In this conventional approach, the polytropic efficiency is maintained between $80-85 \%$ on average.

Dresser-Rand calculated the horsepower and polytropic efficiency. The resulting machinery selection is shown in Appendix A. The compressor train consists of two parallel trains with a low pressure (LP) and a high-pressure (HP) compressor. The LP flow shown in Table 3-5 enters into the LP compressor. The MP flow enters the LP compressor through a sidestream after the first few stages of compressor. The discharge of the LP compressor is mixed with the HP-1 and HP-2 flows at about 250 PSI and enters into the HP compressor. Since each compressor is a back-to-back design, intercooling is used for each body as well as for the flow exiting the LP compressor. The Dresser-Rand calculations were compared to a thermodynamic analysis of the compression process performed by SwRI, in order to validate the SwRI analysis, using the conventional Dresser-Rand selection technology. The results of the two analyses are shown in Table 3-5.

Table 3-5. SwRI and Dresser-Rand Analysis of Conventional Centrifugal

Comparison of Conventional Approach "Option A" Dresser Rand and SwRI Calculations

\begin{tabular}{|c|c|c|c|c|c|c|}
\hline \begin{tabular}{|r|} 
Compressor \\
Gas Mix \\
\end{tabular} & $\frac{\text { D18R7B }}{\text { LP }}$ & $\frac{\text { D18R7B }}{\text { MP }}$ & $\frac{\text { D16R9B }}{\text { Blend }}$ & $\begin{array}{c}\text { D16R9B } \\
\text { Blend }\end{array}$ & & \\
\hline & & & & & & \\
\hline \multirow{6}{*}{$\begin{array}{l}\text { Inlet Pressure (psia) } \\
\text { Inlet Temperature (degF) } \\
\text { Discharge Pressure (psia) }\end{array}$} & 99.52 & 97.63 & 92.13 & 92.13 & & \\
\hline & 188119 & 260872 & 602750 & 517475 & & \\
\hline & & & & & & \\
\hline & 21.9 & 96.58 & 248 & 1087 & & \\
\hline & 51 & 90.21 & 100 & 100 & & \\
\hline & 106.6 & 258 & 1097 & 2215 & & \\
\hline Dresser Rand Calculations & & & & & D-R Total & \\
\hline Discharge Temperature (degF) & 299.3 & 258.1 & 369.8 & 231.4 & & \\
\hline Polytropic Efficiency & 85.07 & 78.93 & 81.33 & 63.11 & 75.4 & Flow wtd \% eff \\
\hline BHP Required & 3739 & 3711 & 12169 & 5199 & 24818 & Total BHP \\
\hline SwRI Calculations & & & & & SwRI Total & \\
\hline Discharge Temperature (degF) & 300 & 226.3 & 370 & 205 & & \\
\hline Polytropic Efficiency & 84.20 & 74.30 & 79.00 & 64.50 & 75.7 & Flow wtd \% eff \\
\hline BHP Required & 3899 & 3130 & 12745 & 3477 & 23251 & Total BHP \\
\hline
\end{tabular}

The suction pressure, suction temperature, and discharge pressure were selected by SwRI to match the Dresser-Rand inlet pressure for each stage. The difference in polytropic efficiency and resulting horsepower for each stream is due to the gas composition variations in the two analyses. Dresser-Rand used the actual gas composition shown in Table 3-4 for each gas stream, while SwRI used $100 \%$ carbon dioxide for the analysis. For the purposes of comparing to other compression options in a relative sense, using 100\% carbon dioxide simplifies the analysis and assures that the gas mixture properties do not affect the results for the other compression options.

The analysis of the various compression options uses the polytropic efficiency calculation for efficiency comparisons. Since the polytropic efficiency calculation uses an approximation of 
the compressor head, the polytropic head should be multiplied by a correction term to provide an accurate calculation of efficiency more similar to isotropic efficiencies. The correction term is based on the work of J. Schultz [18]. This factor is defined as the Schultz correction factor and is calculated as follows:

$$
f=\frac{h_{2 s}-h_{1}}{\frac{k}{k-1} \cdot\left(\frac{P_{2}}{\rho_{2 s}}-\frac{P_{1}}{\rho_{1}}\right)}
$$

Typically, the factor affects the polytropic efficiency on the order of less than $1.0 \%$. Using the Schultz correction factor, the formulation for the polytropic efficiency is:

$$
\eta_{P}=\frac{\left(\frac{n_{p}}{n_{p}-1}\right) \cdot\left({\frac{P_{2}}{P_{1}}}^{\frac{n_{p}-1}{n_{p}}}-1\right) \cdot \frac{P_{1}}{\rho_{1}} \cdot f}{\left(h_{2}-h_{1}\right)}
$$

As Table 3-5 shows, the Option A conventional compression technology requires a total horsepower of 23,251 BHP (using SwRI calculations, which assume 100\% carbon dioxide). Option A provides a baseline to compare to alternative compression technologies. This conventional approach was compared to alternative methods of compression to evaluate the merits of intercooling between stages, increased pressure ratio, and refrigeration of the $\mathrm{CO}_{2}$ in order to pump it as a liquid stream. The alternative compression technologies are summarized in Table 3-6. The thermodynamic calculations for each compression technology option are provided in Appendices B.1-B.5 to document the horsepower results provided herein. Figure 3-15 provides a summary of the various thermodynamic paths taken by each of the compression technology options. The compression paths are shown on the pressure versus enthalpy diagram for carbon dioxide. As the results show, the amount of horsepower required by each compression option varies significantly according to the thermodynamic path.

\subsubsection{Option B - Conventional Approach with Intercooled Stages}

In Option B, the conventional technology is used to reach the same discharge pressures for each train as in Option A. The difference in the two conventional approaches is that in Option B, the inlet suction temperature for each train is reduced. This technology option assumes that some type of heat exchanger could be used to reduce the inlet gas temperature. The comparison of the two thermodynamic paths taken by Option A and Option B is shown in Figure 3-16.

If an air separation unit in the IGCC plant has available nitrogen gas available at a reduced temperature, the ASU could provide cool gas for the heat exchanger. A typical ASU releases a cold waste nitrogen stream at the rate of 150,000 lbm/hr for a $700 \mathrm{MW}$ IGCC plant. This flow rate was used to calculate the amount of the reduction in inlet $\mathrm{CO}_{2}$ gas temperature between trains. The carbon dioxide is reduced to $60^{\circ} \mathrm{F}$ at 97 PSIA and 258 PSIA prior to entering the next compression stage. At 1,097 PSIA, the suction temperature is reduced slightly from $100^{\circ} \mathrm{F}$ (Option A) to $90^{\circ} \mathrm{F}$ (Option B). It is expected that the cost of using the cooler nitrogen from the ASU will have an associated power cost, but the amount of power has not been determined at this time. 
Table 3-6. Summary of Compression Technology Options - Power and Cooling Requirements Summary of Calculations

\begin{tabular}{|c|c|c|c|c|c|}
\hline Option & Compression Technology & $\begin{array}{c}\text { Power } \\
\text { Requirements } \\
\end{array}$ & $\begin{array}{c}\% \text { Diff from } \\
\text { Option A } \\
\end{array}$ & Cooling Technology & $\begin{array}{c}\text { Cooling } \\
\text { Requirements } \\
\end{array}$ \\
\hline A & $\begin{array}{l}\text { Conventional Dresser-Rand } \\
\text { Centrifugal 10-stage Compression }\end{array}$ & 23,251 BHP & $0.00 \%$ & $\begin{array}{l}\text { Air-cool streams between } \\
\text { separate stages }\end{array}$ & $\begin{array}{l}\text { Air Mass Flow = } \\
2.03 \mathrm{e} 6 \mathrm{lbm} / \mathrm{hr}\end{array}$ \\
\hline B & $\begin{array}{l}\text { Conventional Dresser-Rand } \\
\text { Centrifugal 10-stage Compression } \\
\text { with additional cooling }\end{array}$ & 21,522 BHP & $-7.44 \%$ & $\begin{array}{l}\text { Air-cool streams between } \\
\text { separate stages using ASU } \\
\text { cool N2 stream }\end{array}$ & $\begin{array}{l}\text { Air Mass Flow = } 1.7 \mathrm{e} 6 \\
\mathrm{lbm} / \mathrm{hr}\end{array}$ \\
\hline C.1 & $\begin{array}{l}\text { Isothermal compression at } 70 \text { degF } \\
\text { and } 80 \% \text { efficiency }\end{array}$ & $14,840 \mathrm{BHP}$ & $-36.17 \%$ & $\begin{array}{l}\text { Tc }=70 \text { degF inlet temp } \\
\text { throughout }\end{array}$ & To be determined \\
\hline C.2 & $\begin{array}{l}\text { Isothermal compression at } 100 \mathrm{deg} F \\
\text { and } 80 \% \text { efficiency }\end{array}$ & 18,266 BHP & $-21.44 \%$ & $\begin{array}{l}\text { Tc }=100 \text { degF inlet temp } \\
\text { throughout }\end{array}$ & To be determined \\
\hline C.3 & $\begin{array}{l}\text { Semi-isothermal compression at } 70 \\
\text { degF, Pressure Ratio } ~ 1.3\end{array}$ & $\begin{array}{c}\text { 15,374 BHP } \\
\text { (Required Cooling } \\
\text { Power TBD) }\end{array}$ & $-33.88 \%$ & $\begin{array}{l}\text { Tc }=70 \mathrm{deg} F \text { in between } \\
\text { each stage. }\end{array}$ & To be determined \\
\hline C.4 & $\begin{array}{l}\text { Semi-isothermal compression at } 70 \\
\text { degF, Pressure Ratio 1.55 }\end{array}$ & $\begin{array}{c}17,025 \text { BHP } \\
\text { (Required Cooling } \\
\text { Power TBD) }\end{array}$ & $-26.78 \%$ & $\begin{array}{l}\text { Tc }=70 \text { degF in between } \\
\text { each stage. }\end{array}$ & To be determined \\
\hline C.5 & $\begin{array}{l}\text { Semi-isothermal compression at } 70 \\
\text { degF, Pressure Ratio } ~ 1.9\end{array}$ & $\begin{array}{c}\text { 18,227 BHP } \\
\text { (Required Cooling } \\
\text { Power TBD) } \\
\end{array}$ & $-21.61 \%$ & $\begin{array}{l}\text { Tc }=70 \mathrm{deg} F \text { in between } \\
\text { each stage. }\end{array}$ & To be determined \\
\hline D.1 & $\begin{array}{l}\text { "High Ratio" compression - two } \\
\text { stages, no inter-stage cooling }\end{array}$ & 41,920 BHP & $80.29 \%$ & Air cool at 2215 psia only & $\begin{array}{l}\text { Air Mass Flow = } \\
3.93 \mathrm{e} 6 \mathrm{lbm} / \mathrm{hr}\end{array}$ \\
\hline D.2 & $\begin{array}{l}\text { "High Ratio" compression - two } \\
\text { stages with intercooling between }\end{array}$ & 28,699 BHP & $23.43 \%$ & $\begin{array}{l}\text { Air cool at } 220 \text { and } 2215 \\
\text { psia }\end{array}$ & $\begin{array}{l}\text { Air Mass Flow = } \\
3.18 \mathrm{e} 6 \mathrm{lbm} / \mathrm{hr}\end{array}$ \\
\hline E.1 & $\begin{array}{l}\text { Centrifugal compression to } 250 \text { psia, } \\
\text { Liquid cryo-pump from } 250-2215 \\
\text { psia }\end{array}$ & $\begin{array}{l}\text { 16,198 BHP } \\
\text { (Includes } 7,814 \\
\quad \text { BHP for } \\
\text { Refrigeration) }^{1}\end{array}$ & $-30.33 \%$ & $\begin{array}{l}\text { Air cool up to } 250 \text { psia, } \\
\text { Refrigeration to reduce } \\
\text { CO2 to }-25 \text { degF to liquify }\end{array}$ & $\begin{array}{l}\text { Refrigeration requires } \\
7814 \text { HP for } 3428 \\
\text { tons, Air Mass Flow = } \\
6.3 \mathrm{e} 5 \mathrm{lbm} / \mathrm{hr}\end{array}$ \\
\hline E.2 & $\begin{array}{l}\text { Centrifugal compression to } 250 \text { psia } \\
\text { with semi-isothermal cooling at } 100 \\
\text { degF, Liquid cryo-pump from } 250- \\
2215 \text { psia }\end{array}$ & $\begin{array}{l}15,145 \text { BHP } \\
\text { (Includes } 7,814 \\
\quad \text { BHP for } \\
\text { Refrigeration) }^{1}\end{array}$ & $-34.86 \%$ & $\begin{array}{l}\text { Air cool up to } 250 \text { psia } \\
\text { between centrifugal stages, } \\
\text { Refrigeration to reduce } \\
\text { CO2 to }-25 \text { degF to liquify }\end{array}$ & $\begin{array}{l}\text { Refrigeration requires } \\
7814 \mathrm{HP} \text { for } 3428 \\
\text { tons, Air Mass Flow = } \\
5.1 \mathrm{e} 5 \mathrm{lbm} / \mathrm{hr}\end{array}$ \\
\hline
\end{tabular}

\footnotetext{
${ }^{1}$ Air separation unit is used in options B, D and E. Additional power may be required to extract N2 cooling capability.
}

Without including the cost of using the nitrogen stream from the air separation unit at the IGCC plant, the resulting total horsepower required for Option B is 21,522 BHP. The reduction in horsepower is about $\sim 1,730 \mathrm{HP}$, equivalent to $7.4 \%$. Though Option B does not offer a significant savings in energy, the trend towards reducing horsepower by providing intermediate cooling of the gas stream is notable. 


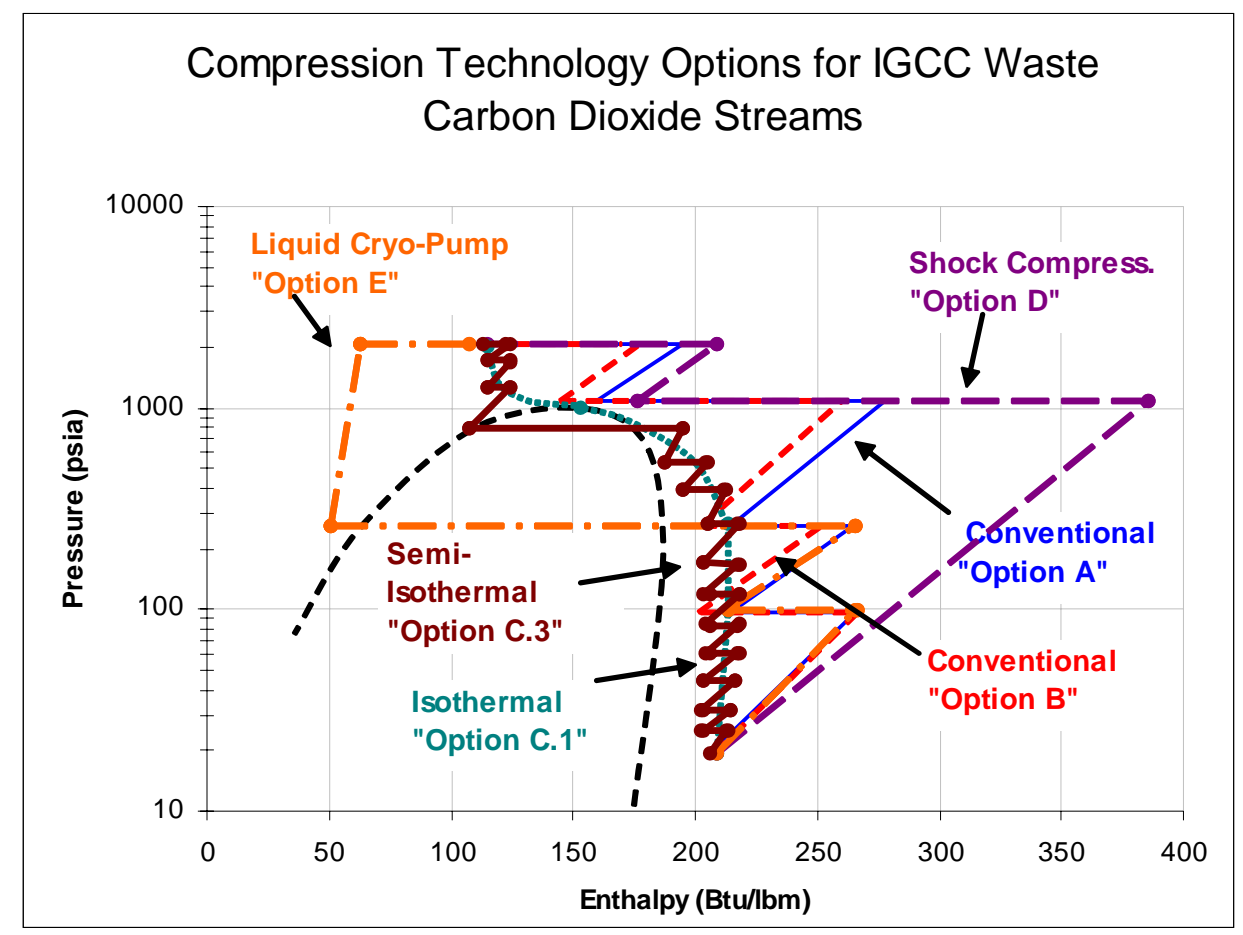

Figure 3-15. Compression Technology Options - on Pressure vs. Enthalpy Diagram for Carbon Dioxide

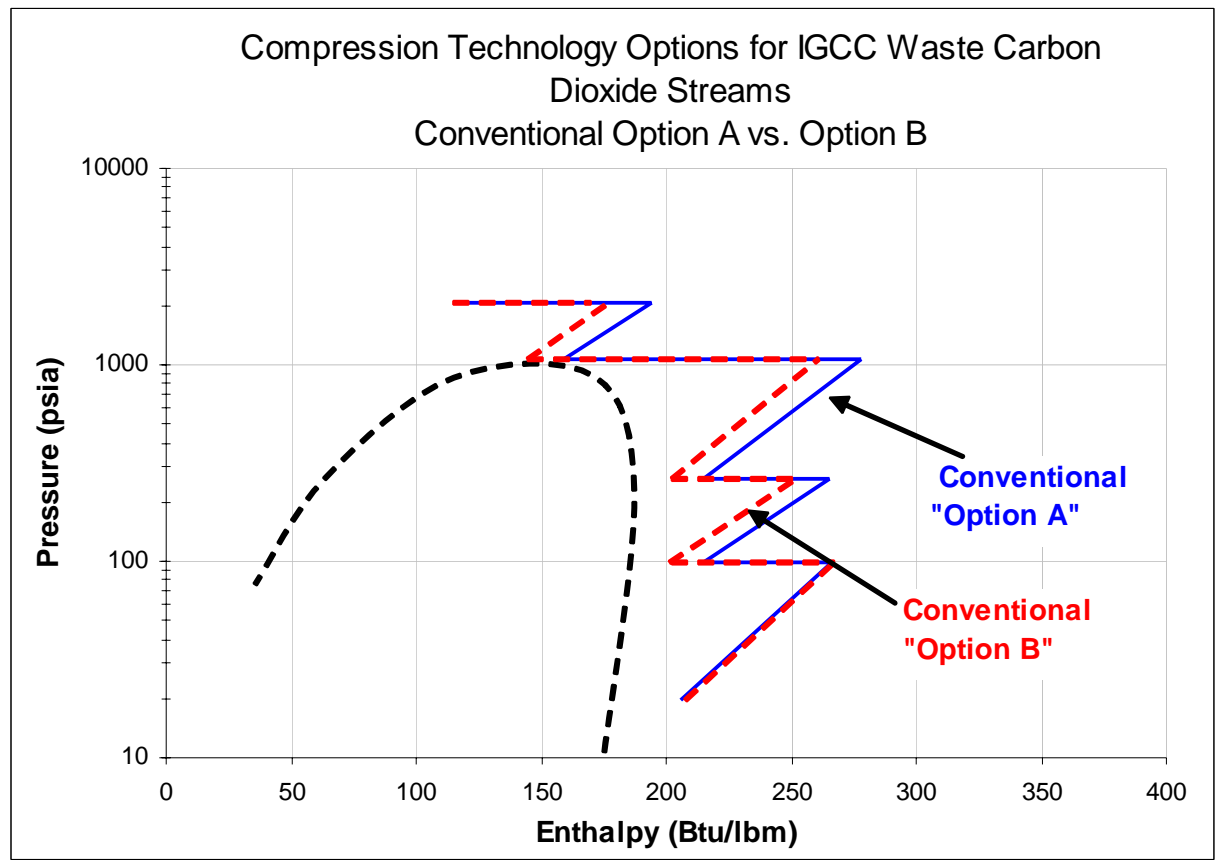

Figure 3-16. Comparison of Thermodynamic Paths for Options A and B 


\subsubsection{Option C - Isothermal and Semi-Isothermal Compression}

In Option C, the inlet-cooling concept is applied to each stage, using the same discharge temperatures and pressures per train as Options A and B. An ideal isothermal compression process was analyzed in Option C. 1 for an isothermal compression temperature of $70^{\circ} \mathrm{F}$. To gauge the effect of the choice of isothermal temperature (and the required cooling power), Option C.2 was analyzed as an isothermal compression with a constant temperature of $100^{\circ} \mathrm{F}$. Assuming an 80\% nominal efficiency for both isothermal processes, Option C.2 requires a total horsepower of 18,266 compared to 14,840 BHP for Option C.1. Thus, using a higher isothermal temperature $\left(100^{\circ} \mathrm{F}\right)$ will require about $15 \%$ more horsepower, but this approach permits aircooling of the gas stream.

In the ideal isothermal compression process, the temperature change (and resulting enthalpy change) is zero. Due to the high pressures involved in the carbon dioxide compression process, the non-ideal gas effects must be accounted for in the isothermal work calculation. An approximation to the isothermal compression power equation using the average compressibility may be used to account for real gas effects in the isothermal compression:

$$
\frac{W}{\dot{m}}(B t u / l b m)=\frac{R}{M W} \cdot Z_{\text {avg }} \cdot T_{o}\left(\ln \frac{P_{2}}{P_{1}}\right)
$$

Equation (3) assumes that an effective number of small steps are used in the isothermal process calculations in order to make the average compressibility $\left(Z_{\text {avg }}\right)$ representative of the compressibility of the gas through each specific isothermal step. For the present calculations, five isothermal steps were used to compress the carbon dioxide from 22 to 2,215 PSIA. Average compressibility was recalculated for each step.

In reality, an isothermal compression process is difficult to achieve. A typical compression process can be implemented using an increasing number of finer compression steps with interstage cooling in between each compression stage to approach the ideal isothermal compression. This actualization of an isothermal process is termed semi-isothermal compression. To analyze the semi-isothermal process, Option C.3 uses many small compression steps with interstage cooling between each stage. An illustration of the thermodynamic path taken by Options C.1 and C.3 is shown in Figure 3-17 to illustrate the semi-isothermal process.

The semi-isothermal calculations were expanded to examine three semi-isothermal processes with an increasing number of inter-cooled stages (8, 11, and 17 compression steps with pressure ratios of $1.9,1.55$ and 1.3 , respectively). For this analysis, the polytropic efficiency was set equal to $80 \%$, and the discharge temperature of each stage was adjusted to maintain the same approximate polytropic efficiency. This modification in the calculation assures that the comparison between Option A and Option C.3-Option C.5 shows the reduction in horsepower achievable through interstage cooling for a compression process at relatively the same polytropic efficiency as the conventional process. For all three semi-isothermal processes, the carbon dioxide was compressed from 22 to 2,215 PSIA, maintaining an interstage cooling temperature of $70^{\circ} \mathrm{F}$.

The resulting horsepower required for these options is shown as Options C.3 through C.5 in Table 3-6. At the highest compression ratio (the least number of intercooling stages/compression steps), the reduction in horsepower is $21 \%$. At the lowest compression ratio 


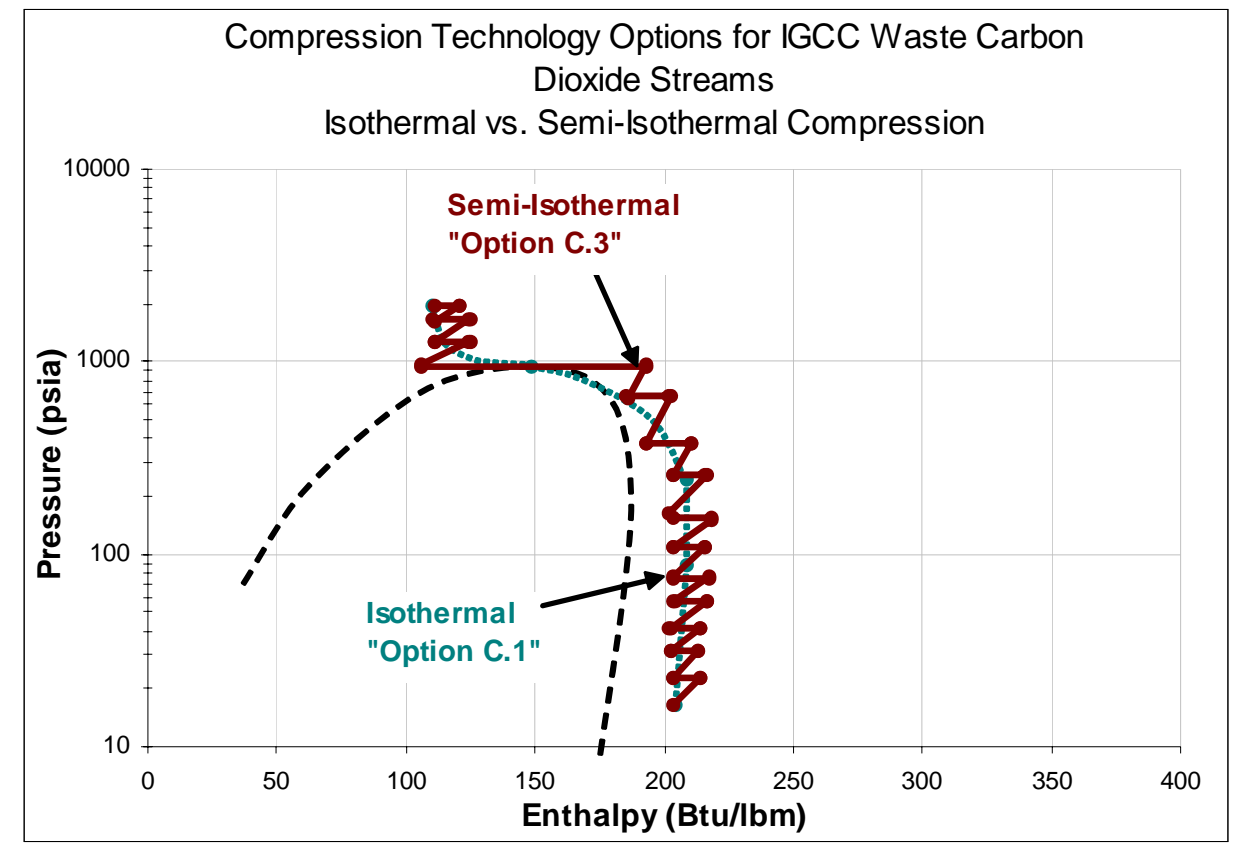

Figure 3-17. Comparison of Isothermal and Semi-Isothermal Compression Paths

(the highest number of intercooled stages), the horsepower reduction approaches that of the isothermal process given in Option C.1. The reduction in horsepower is $33.8 \%$ for the semiisothermal process, Option C.3 with a pressure ratio of approximately 1.3 per stage.

As the number of stages in the semi-isothermal process increases, the total process horsepower begins to asymptotically approach the horsepower required for an isothermal compression process. The results of the semi-isothermal process indicate that as more interstage cooling is applied through a greater number of compression steps, the process results in a lower total horsepower. Experimental testing will determine the practical achievable limit for the amount of cooling (semi-isothermal temperature set point) and the number of compression stages. Figure 3-18 shows the trend towards lower horsepower with the increased number of stages in the semi-isothermal process, compared to the other analyzed processes.

\subsubsection{Option D - High Ratio Compression}

The high ratio compression process calculations were considered in the analysis as Options D.1 and D.2. For the analysis, it was assumed that the carbon dioxide from the low and medium pressure streams would be blended together and compressed from 22 to 220 PSIA. In the second stage, all streams are blended to compress the gas from 220 to 2,215 PSIA. Two designs to a high ratio compression process were considered. The first design (Option D.1) assumed cooling was not possible throughout the entire compression process. Cooling of the gas at the final delivery pressure was accounted for in the analysis of the first option. The second option (Option D.2) utilized ambient air cooling of the gas stream at a pressure of 220 PSIA to reduce the gas stream temperature from $460^{\circ} \mathrm{F}$ to $100^{\circ} \mathrm{F}$, as well as final cooling at the delivery pressure of 2,215 PSIA. 


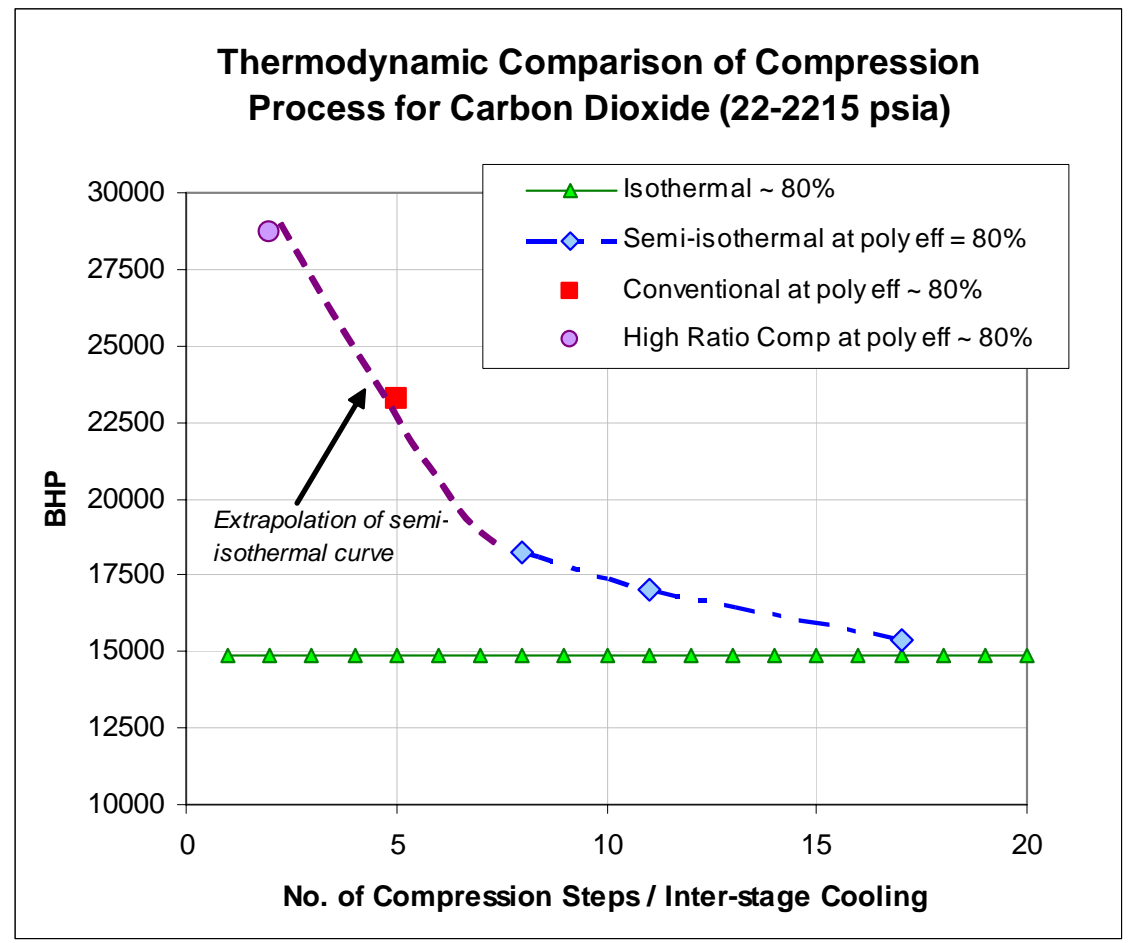

Figure 3-18. Comparison of Isothermal and Semi-Isothermal Total Horsepower vs. Number of Compression Steps

Without the added cooling between the stages of compression, Option D.1 requires significantly more horsepower than Option A. The increase in horsepower for high ratio compression Option D.1 is approximately 80.3\%, assuming an efficiency of approximately 80\%. The total horsepower required is 41,920 BHP. Alternatively, Option D.2 requires less horsepower than the first design option for high ratio compression because of the added cooling. The total horsepower for Option B.2 is 28,699 BHP, which is an increase over the conventional approach of $23.4 \%$.

Figure 3-19 provides a summary of the various thermodynamic paths taken by the two high ratio compression options. This figure illustrates the process differences between high ratio compression and the conventional approach based on the distinctly different compression paths taken by the two processes. Interstage cooling is beneficial to the compression process because of the divergence of the constant entropy lines at higher temperatures, which results in a higher enthalpy difference between the suction and discharge pressure. Losses (or inefficiencies) in the compression process at higher temperatures result in a greater increase in the associated enthalpy change than inefficiencies at lower temperatures. This effect can clearly be seen in a typical carbon dioxide pressure-enthalpy diagram as shown in Figure 3-20 from [17]. 


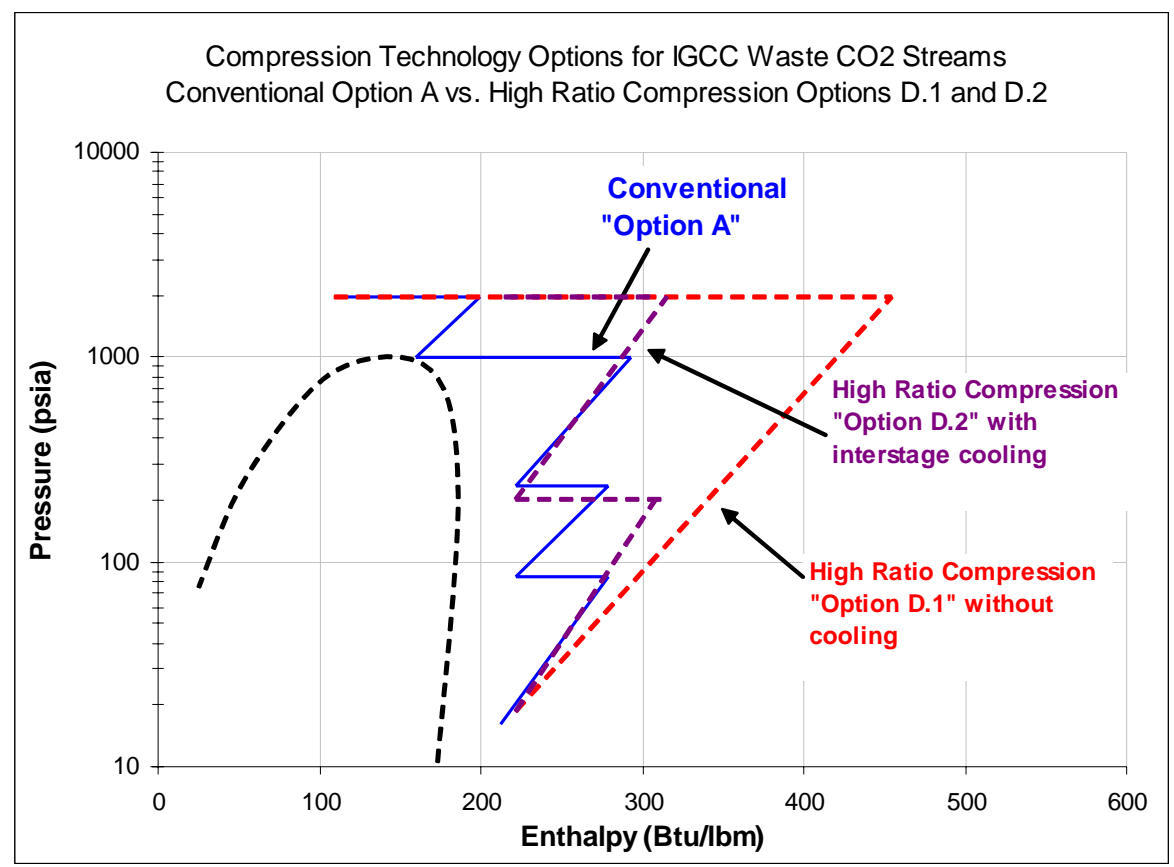

Figure 3-19. Thermodynamic Paths for Option A compared to High Ratio Compression Options

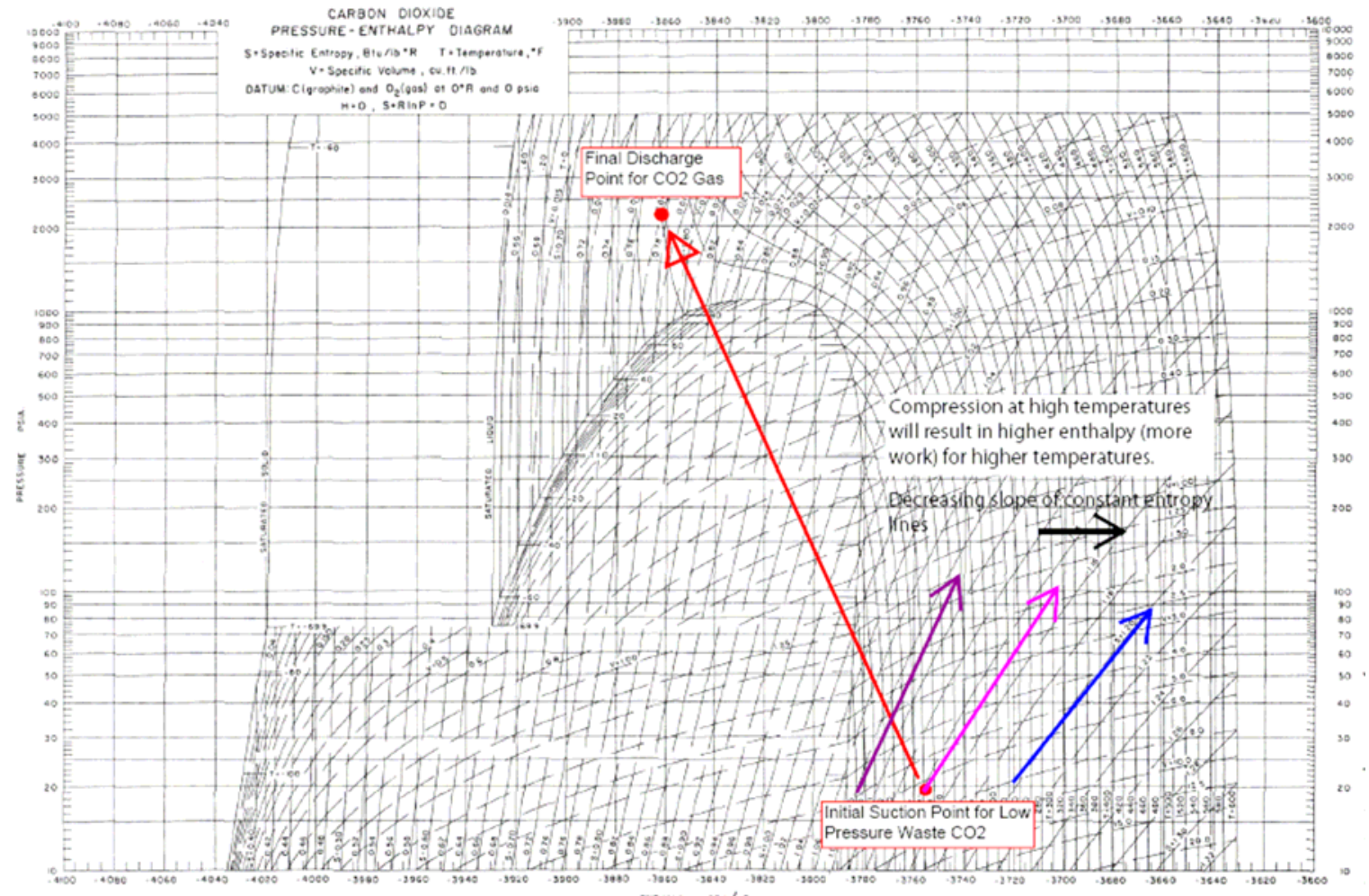

Figure 3-20. Pressure - Enthalpy (P-h) Diagram for Carbon Dioxide [17]

SwRI Project 18.11919; DOE Award No. DE-FC26-05NT42650 


\subsubsection{Option E - Liquefaction and Cryogenic Pump}

The final option (Option E) to consider in compressing the carbon dioxide is to pump the carbon dioxide at cryogenic temperatures to save the horsepower consumed in compressing it as a gas. In order to achieve cryogenic temperatures without forming solid carbon dioxide, it is necessary to compress the low and medium pressure streams to 250 PSIA. The two streams can be joined with the high-pressure stream to undergo a refrigeration process at this pressure. Normal air cooling can be used to reduce the temperature of the carbon dioxide from $255^{\circ} \mathrm{F}$ to $100^{\circ} \mathrm{F}$ or lower. Refrigeration units (typically an ammonia absorption cycle) must be used to reduce the temperature to $-25^{\circ} \mathrm{F}$ because of the significant heat transfer required to overcome the latent heat required for liquefaction. At $-25^{\circ} \mathrm{F}$ and 250 PSIA, the carbon dioxide should be $100 \%$ liquid and can be pumped at a relatively low horsepower cost to 2,215 PSIA. Option E.1 utilizes a cryogenic pump to increase the liquefied $\mathrm{CO}_{2}$ pressure to the final pipeline pressure of 2,215 PSIA. For the Option E calculation, the pump efficiency was assumed to be 80\%. Figure 3-21 illustrates Option E and the reduction in temperature required to clear the gas-liquid dome.

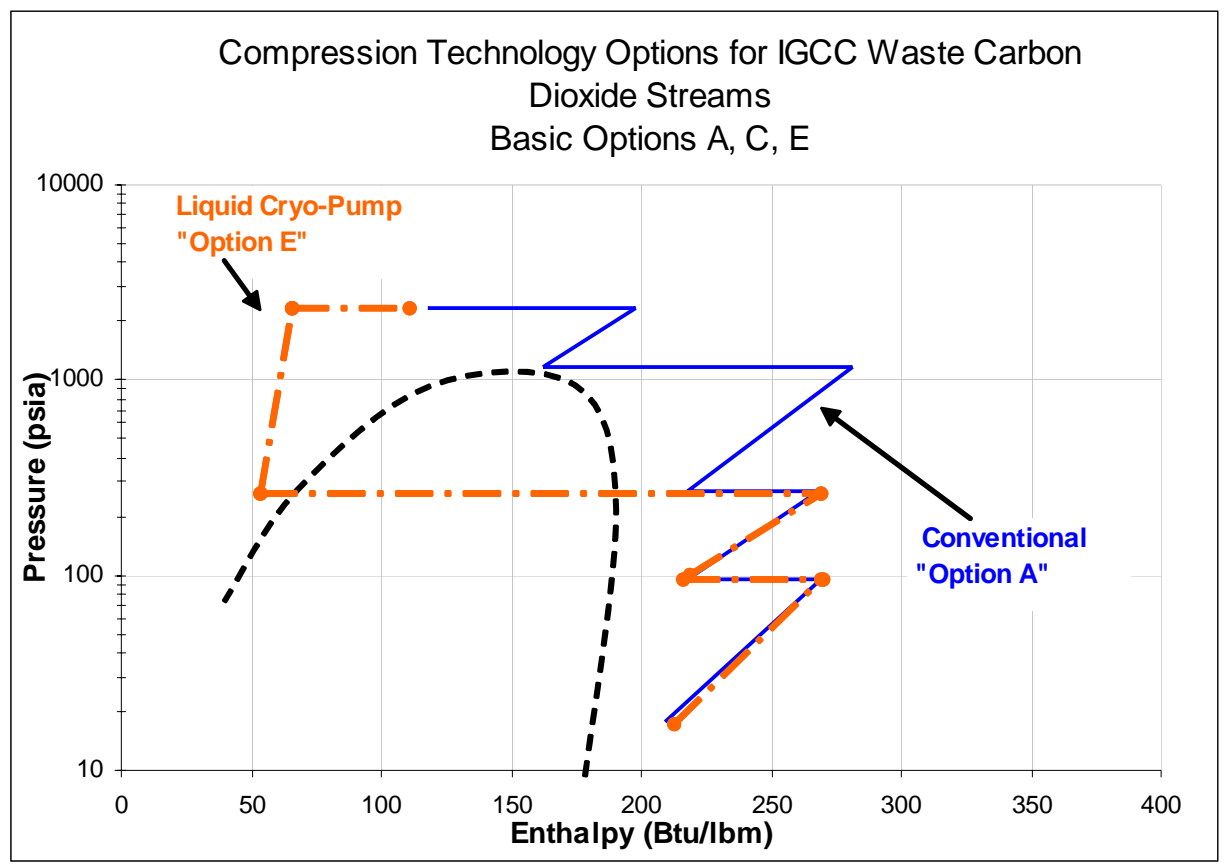

Figure 3-21. Comparison of Option E for Liquid Cryo-Pump to Option A

Option E.1 requires significantly less horsepower at 8,384 BHP compared to 23,251 BHP for Option A. However, the cost of refrigeration must be included. Approximately 3,428 tons of refrigeration would be required to cool the total mass flow of carbon dioxide to $-25^{\circ} \mathrm{F}$. Typically, for cold delivery temperatures $\left(-30^{\circ} \mathrm{F}\right.$ to $\left.0^{\circ} \mathrm{F}\right)$, industrial refrigeration units using ammonia absorption require $1.7 \mathrm{~kW}$ per ton [19]. Based on preliminary calculations, this standard cooling rate equates to 7,814 HP for cooling the carbon dioxide. Combined with the compression power, the total estimated horsepower required for Option E is 16,198 HP. The savings compared to conventional centrifugal compression is approximately $30 \%$. 
Finally, Option E.2 utilizes interstage cooling for the immediate compression stages required to bring the low and medium pressure waste $\mathrm{CO}_{2}$ streams up to the cryo-pump operating pressure of 250 PSIA. The additional cooling in the initial compression stages is beneficial because a significant amount of horsepower is expended on the relatively high flow rate of $\mathrm{CO}_{2}$ in the initial low pressure stream. Four interstage cooling steps are used. The reduction in horsepower adds an additional 4.8\% reduction to the original cryo-pump option (Option E.1). Total horsepower for Option E.2 is estimated at 15,149 HP.

\subsubsection{Summary of Thermodynamic Analysis}

The thermodynamic calculations indicate that internal cooling throughout the compression process (semi-isothermal compression) and cryogenic pumping shows the maximum horsepower reduction. An optimum number of compression stages for the semiisothermal approach were determined in the present analysis. The relationship between the semiisothermal and pure isothermal was established. High ratio compression was considered in two possible approaches, with and without interstage cooling. Both high ratio compression options require significantly more power than baseline conventional case. Based on the thermodynamic models, interstage cooling was further investigated through CFD analysis. This analysis expanded upon the possibility of interstage cooling throughout the compression process by internal cooling of a multistage in-line barrel compressor.

\subsubsection{Task 2.2 - Geometry Generation}

\subsubsection{Description of Centrifugal Compressor Test Rig}

In order to quantify the benefit of interstage cooling, a Computational Fluid Dynamics (CFD) model of a centrifugal compressor was generated. A decision was made to utilize the geometry of the first stage of the test compressor located at SwRI. This compressor has been used for a variety of research tasks and will be utilized in Phase II of this project to test these concepts. Figure 3-22 shows the actual test rig compressor that was used to generate the inlet geometry, gas path and diaphragm dimensions for the CFD modeling.
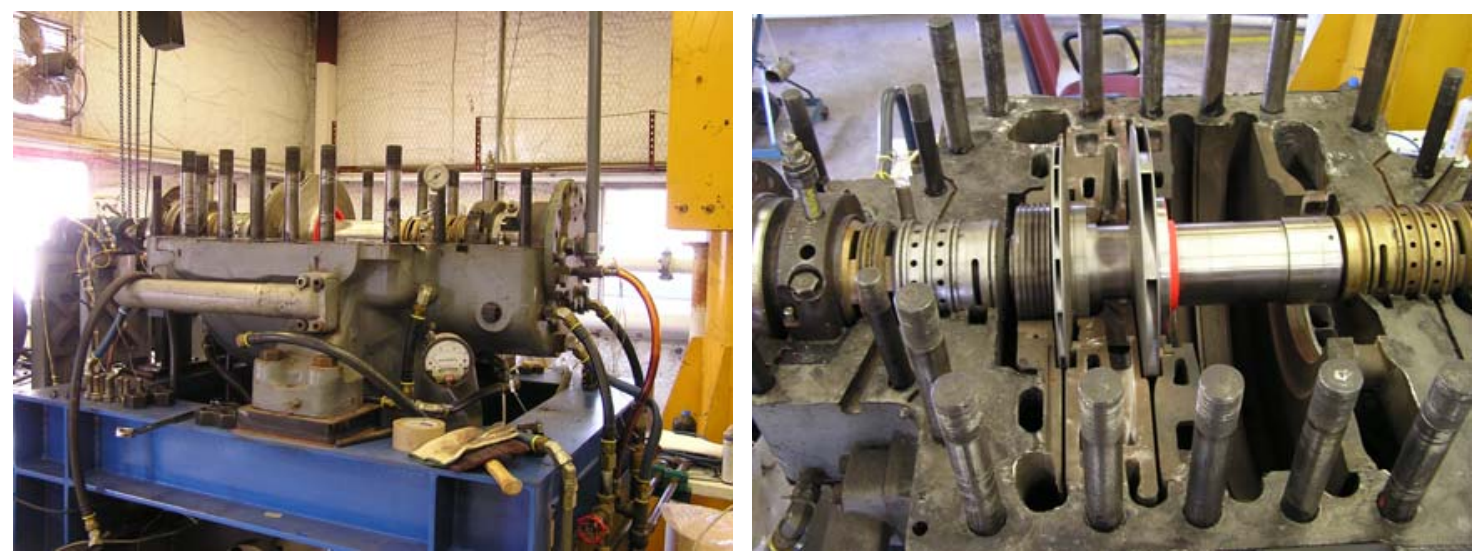

Figure 3-22. Photograph of SwRI Test Rig Compressor Used to Generate CFD Solid Model Dimensions 


\subsubsection{Solid Model Generation of Centrifugal Compressor Test Rig}

Due to the age of the compressor, no manufacturing drawings were available. The flow path, impeller, and diaphragm geometry were reverse-engineered by taking detailed measurements and mold impressions.

Figure 3-23 shows the resulting impeller geometry. Note that the fluid region is treated like a solid and the small gaps are the impeller blades. This impeller design utilizes a parallel disk and cover with large amounts of back-sweep. Figure 3-24 shows a cross-section of the compressor stage assembly including the inlet, bridge-over, impeller, diffuser, and return channel. The compressor flow path is shown in red. The solid regions of the diaphragms are also shown (in gray) along with the cooling passages (shown in blue). Figure 3-25 shows a section of the compressor assembly referred to as a "pie" model. The section follows and is centered about the blade of each section including the bridge-over, impeller, and the return channel. Notice the pie angle is different for each of these sections due to the different number of blades. The pie-slice through the diaphragm is kept constant to facilitate the modeling of both flow path and solid region. The return channel portion consists of two vanes, a long and a short one. Figure 3-26 shows the shape of these return channel vanes.

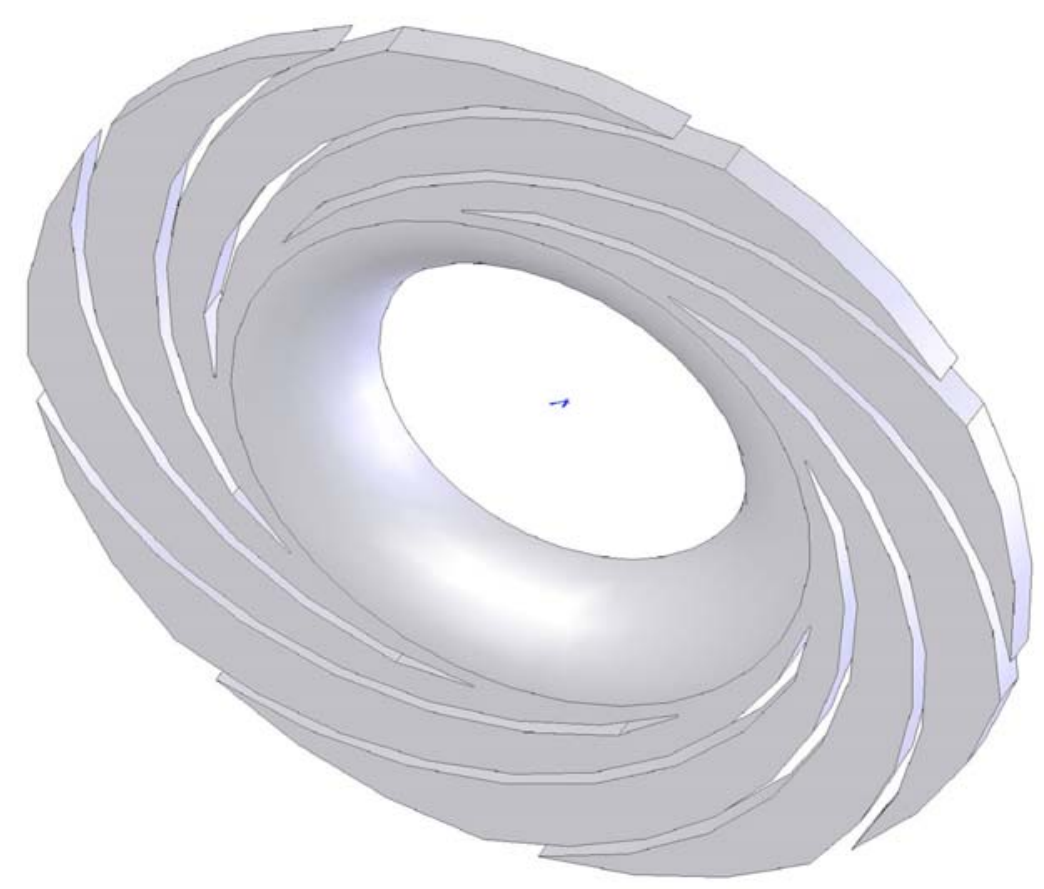

Figure 3-23. Solid Model of Compressor Impeller 


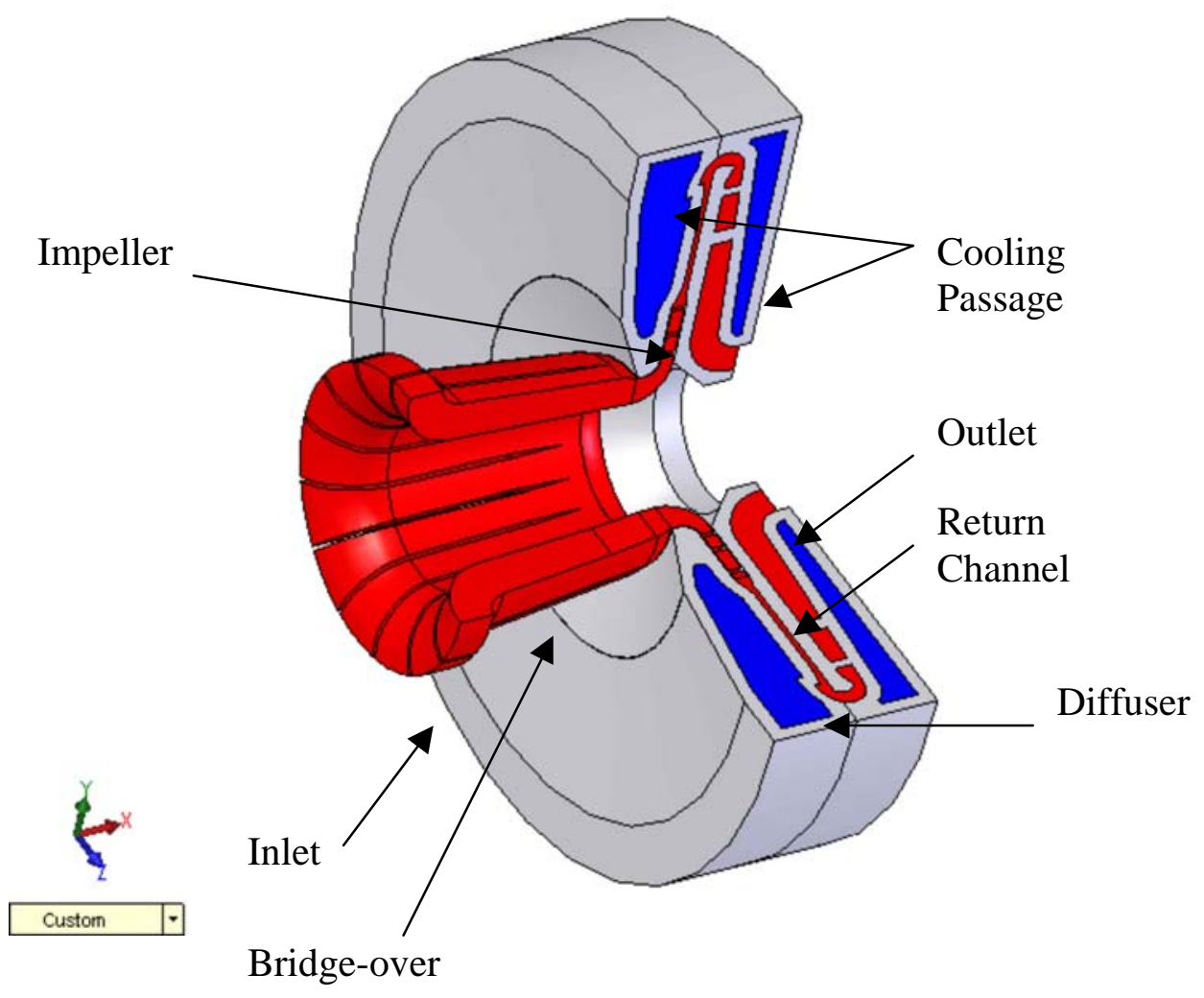

Figure 3-24. Solid Model Assembly of Compressor Stage

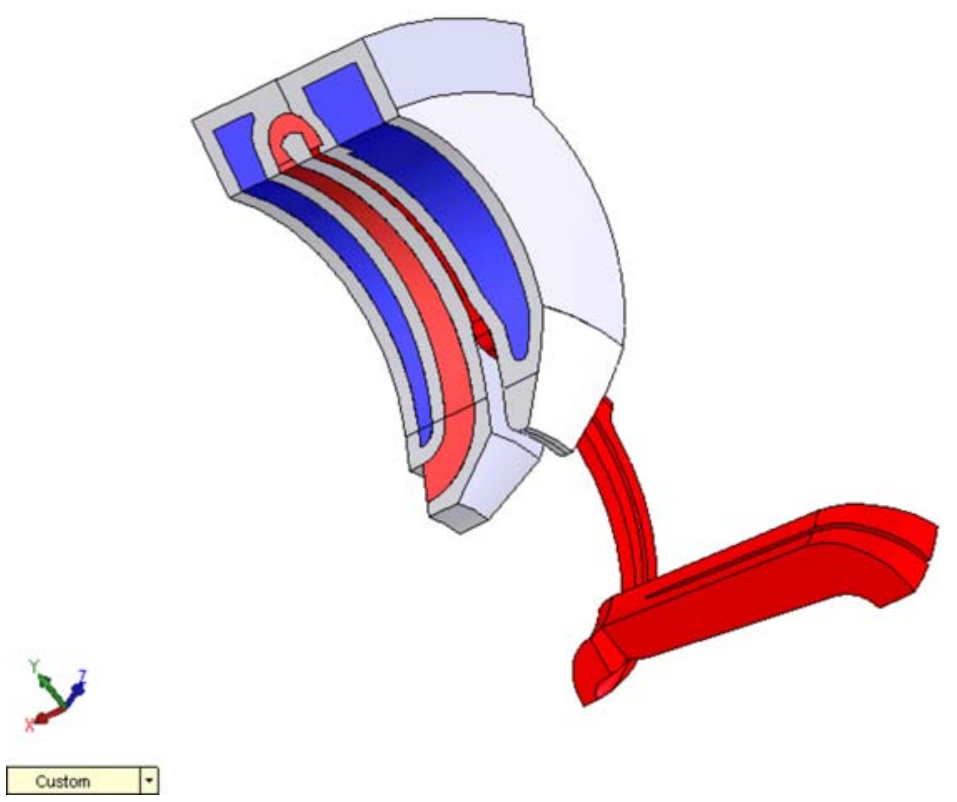

Figure 3-25. "Pie" Model for Use with CFD Analysis 


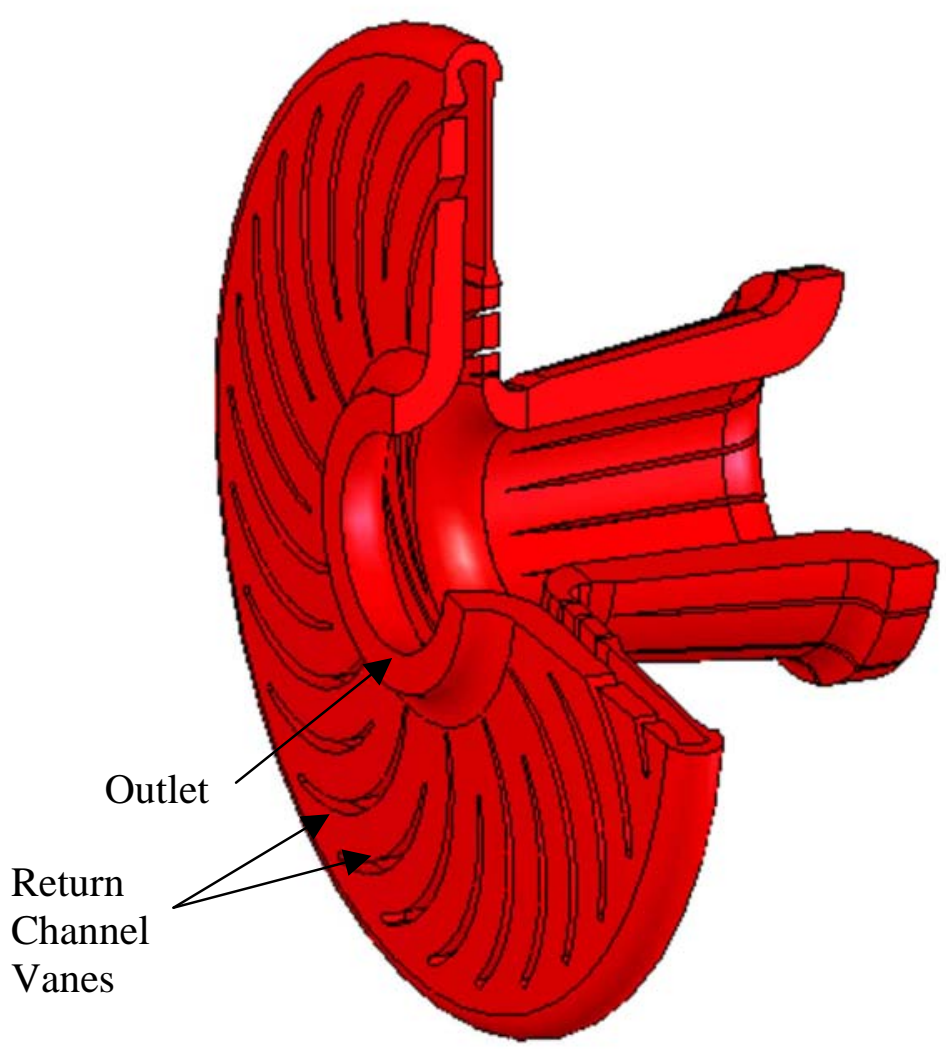

Figure 3-26. Return Channel Vanes for Use with CFD Analysis

\subsubsection{Task 2.3 - 1-D and 3-D CFD Analysis}

\subsubsection{Computational Mesh Generation}

The first step in generating the CFD model is to generate a mesh for the compressor flow path, solid regions, and cooling passages. First, a simplified model of the inlet and compressor impeller is generated as shown in Figure 3-27. The mesh is an unstructured tetrahedral type using a prism layer near the walls to resolve the turbulent boundary layer. In order to keep the model size to a minimum, a so called "pie" model is used, which models a slice of the 3-D model equal to 360 degrees divided by the number of blades or vanes. There are 14 inlet vanes, 9 impeller blades, and 14 return channel vanes. Therefore, the pie angles for these three regions are different as shown. The CFD code can accommodate the different pie angles using a sliding interface, which transforms the flow field from the stationary to the rotating frame of reference near the impeller entrance then back to stationary near the impeller exit. The planes on either side of the "pie" are modeled using periodic boundary conditions, where the flow conditions at one point on a face are to be equivalent to the corresponding point on the other periodic face. 


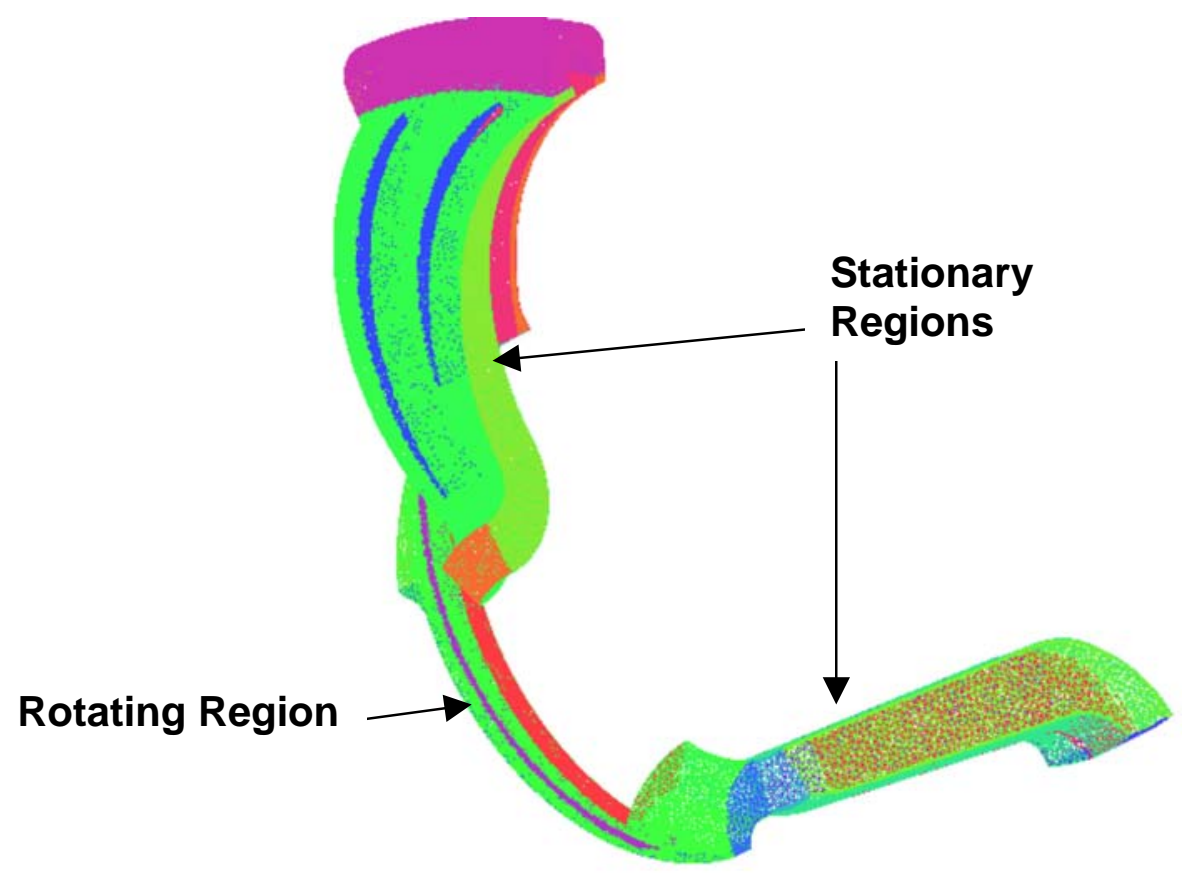

Figure 3-27. CFD Mesh of Adiabatic

Figure 3-28 shows the model used for the conjugate heat transfer calculations that include the internal cooling flow passages. The $\mathrm{CO}_{2}$ fluid passage, as well as the solid in the diffuser stator, is meshed in a combined model. Therefore, at the interface wall, one-to-one connectivity exists. The energy equation in both the gas and solid are solved simultaneously. Therefore, the convection coefficient at this interface is inherently calculated. Within the cooling passage, however, a convection coefficient is used based on fully developed pipe theory for a given cooling flow rate. Therefore, the flow path within the cooling passage is not meshed in the CFD model.

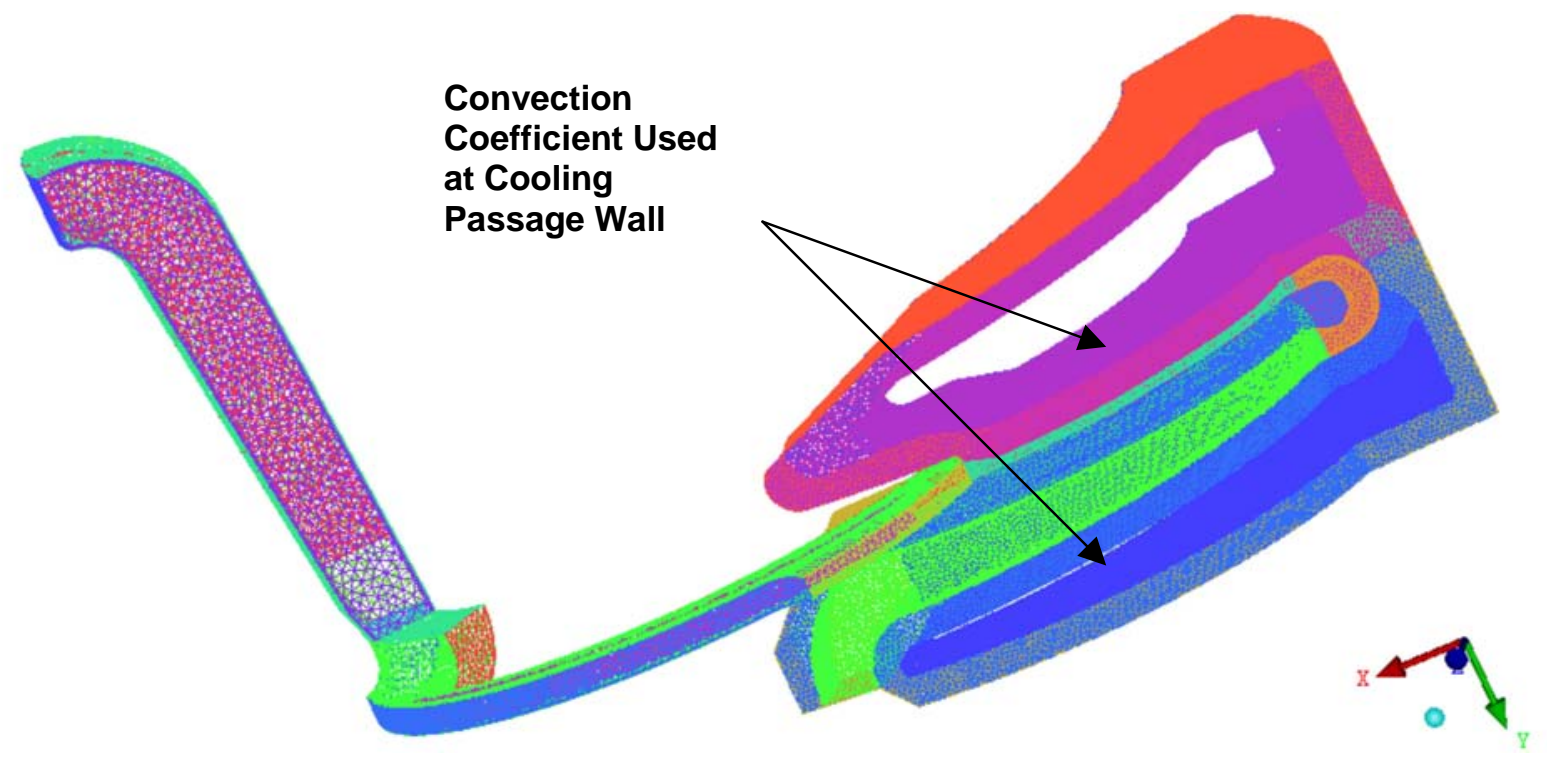

Figure 3-28. CFD Mesh of Model with Heat Transfer 


\subsubsection{CFD Boundary Conditions}

Table 3-7 describes the boundary conditions used in the CFD models. The flow was chosen to allow the compressor impeller to operate near its design flow condition. The cooling water flow is split between the two passages. The convection coefficients were calculated using fully developed pipe flow using a wall roughness (e/D) of 0.005 - resulting in a friction factor of 0.03. Greater heat transfer could be obtained with turbulence generators and cooling fins, but these features are not considered in this preliminary study. The corresponding conduction coefficients for aluminum and steel are used. Aluminum is almost four times better for heat conduction than steel.

Table 3-7. Boundary Conditions Used in CFD Models

\begin{tabular}{|c|c|c|c|c|}
\hline \multicolumn{2}{|c|}{ Variable } & Value & Units & \\
\hline \multicolumn{2}{|c|}{$\mathrm{CO}_{2}$ Inlet Temperature } & 80 & Deg F & \multirow{4}{*}{$\begin{array}{l}\text { Used on all } \\
\text { Models }\end{array}$} \\
\hline \multicolumn{2}{|c|}{$\mathrm{CO}_{2}$ Inlet Pressure } & 30 & PSIA & \\
\hline \multicolumn{2}{|c|}{$\mathrm{CO}_{2}$ Mass Flow } & 1.5204 & $\mathrm{lb} / \mathrm{s}$ & \\
\hline \multicolumn{2}{|c|}{ Cooling Water Flow Rate } & 5 & Gal/min & \\
\hline \multirow{2}{*}{\multicolumn{2}{|c|}{ Cooling Water Temperature }} & 40 & Deg F & \multirow{6}{*}{$\begin{array}{l}\text { Used to } \\
\text { Differentiate } \\
\text { Runs }\end{array}$} \\
\hline & & 70 & $\operatorname{Deg} F$ & \\
\hline \multicolumn{2}{|c|}{ Convection Coefficient @ 40 Deg } & 579.04 & $\mathrm{w} / \mathrm{m}^{2} \star \mathrm{K}$ & \\
\hline \multicolumn{2}{|c|}{ Convection Coefficient @ 70 Deg } & 456.78 & $\mathrm{w} / \mathrm{m}^{2 *} \mathrm{~K}$ & \\
\hline \multirow{2}{*}{$\begin{array}{l}\text { Conduction } \\
\text { Coefficient }\end{array}$} & Steel & 60.5 & $\mathrm{w} / \mathrm{m} \mathrm{K}$ & \\
\hline & Aluminum & 237 & $\mathrm{w} / \mathrm{m} \mathrm{K}$ & \\
\hline
\end{tabular}

\subsubsection{CFD Analysis of Flow Path Only (Adiabatic)}

The first model consists of only the $\mathrm{CO}_{2}$ flow path through the compressor. The walls are treated as adiabatic (no heat transfer). The model establishes the baseline temperature rise across the stage. Flow conditions were chosen for the CFD model using previously obtained test data for the subject compressor using air as the test medium. Non-dimensional flow and head coefficients were used to choose an operating point near the best efficiency point. $\mathrm{CO}_{2}$ was used as the flow medium in the model with an inlet pressure of 30 PSIA, which is a typical inlet test pressure for the SwRI centrifugal compressor used to model the impeller and flow path geometry.

Figure 3-29 shows the predicted streamlines through the stage including the return channel. The flow field is colored by flow velocity. The streamlines show the effectiveness of the return channel blades in straightening out the flow. The single pie slice was repeated to reconstruct the 360-degree impeller for visualization purposes. 


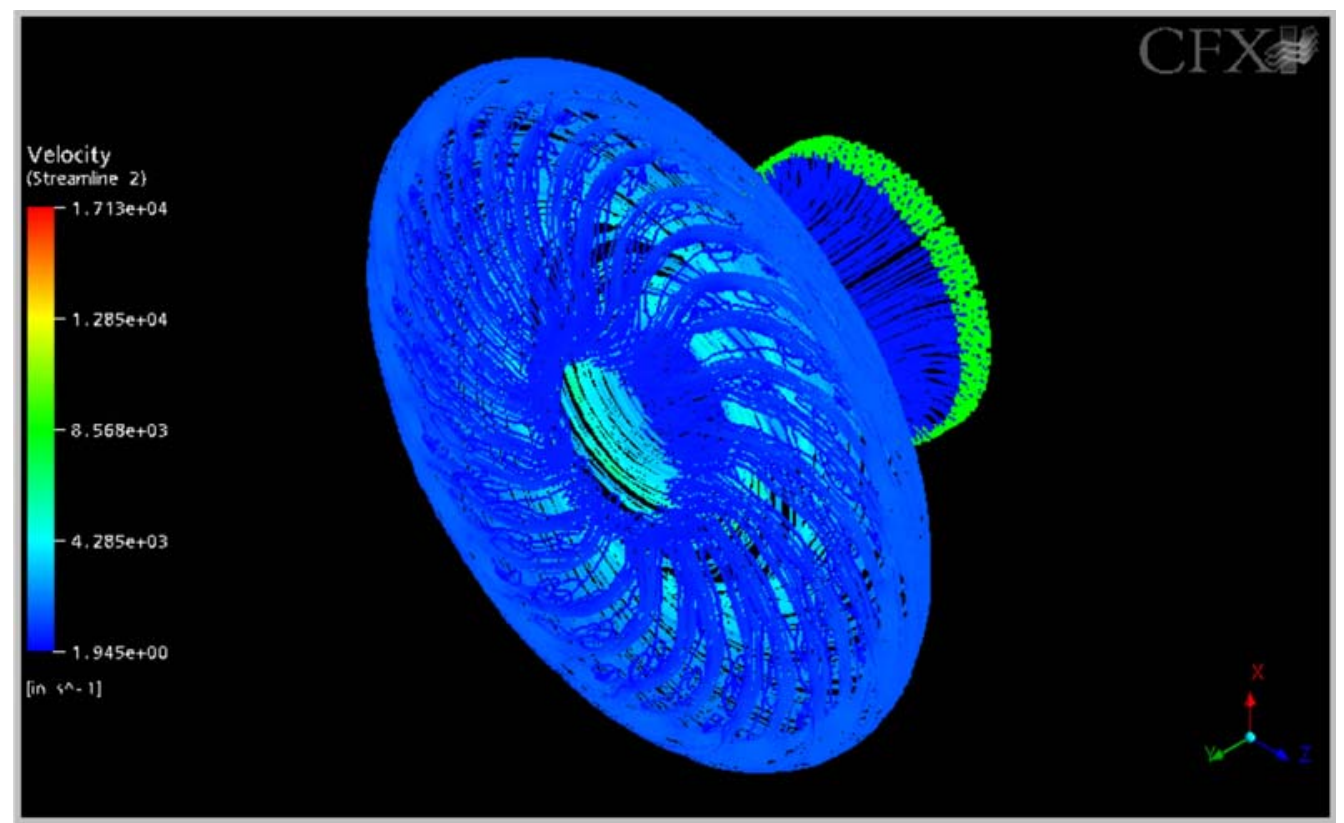

Figure 3-29. Predicted Streamlines in the Entire Stage

Figure 3-30 shows the predicted pressure contours and plots the pressure rise that occurs in the impeller region. The pressure drops locally near the impeller blade leading edge due to the acceleration of the flow.

Figure 3-31 shows the flow velocity represented in Mach number. The velocity is fairly uniform except for an acceleration of the flow near the blade leading edge. This undesirable flow field is typical of parallel disk and cover flow fields using circular arc blades, but it will not have any negative impact on the heat transfer that will ultimately be modeled.

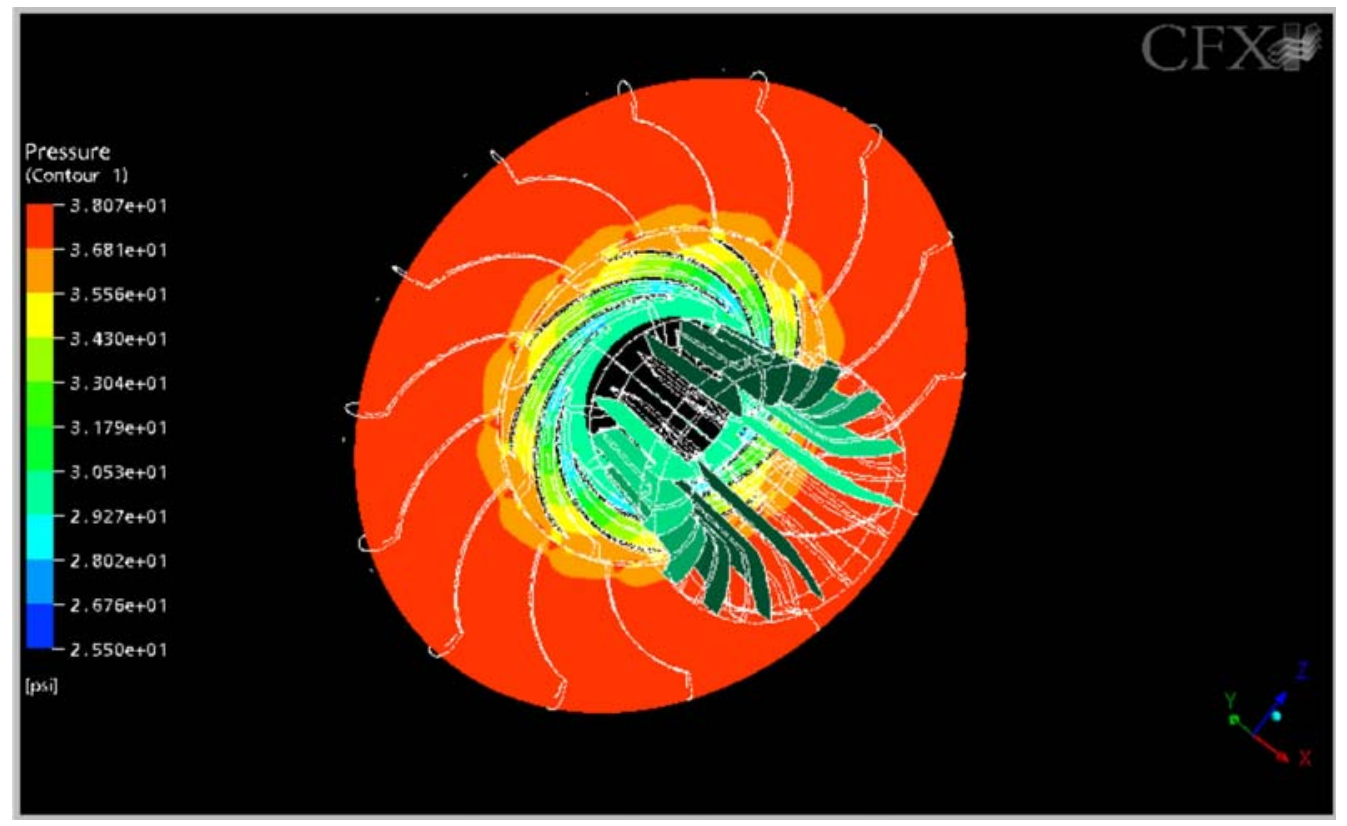

Figure 3-30. Predicted Pressure Contours in Adiabatic Model 


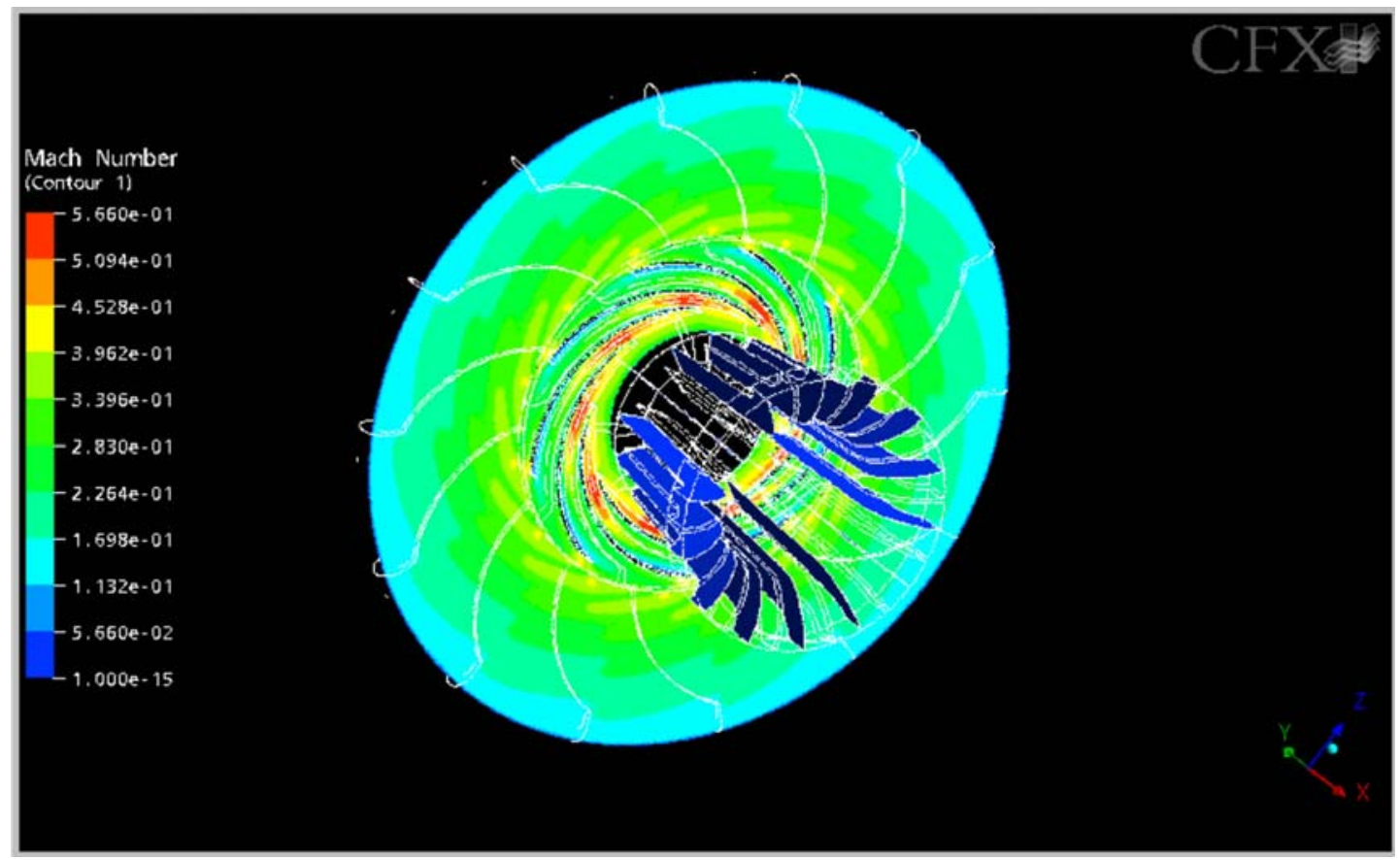

Figure 3-31. Predicted Mach Number Contours in Adiabatic Model

Figure 3-32 gives the static temperature rise through the impeller. This temperature rise is a natural consequence of the compression process. This heat of compression will be removed when the diffuser and cooled diaphragm model is added in the next section.

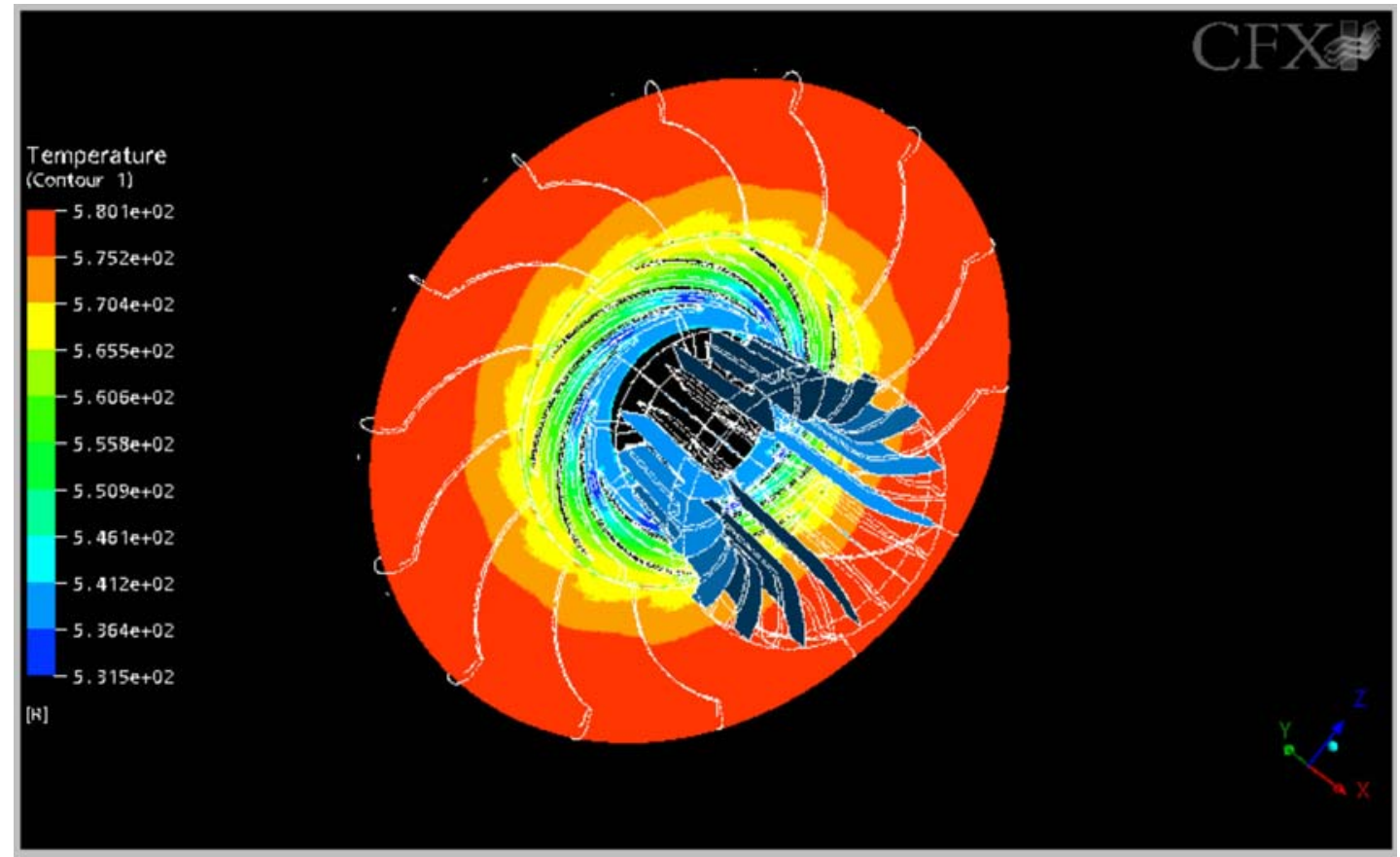

Figure 3-32. Predicted Temperature Contours in Adiabatic Model 


\subsubsection{CFD Analysis with Heat Transfer and Internal Cooling Flow}

The second model considered consists of both the $\mathrm{CO}_{2}$ flow path through the compressor as well as the metallic stator components and the cooling passages. This model predicts the beneficial reduction in temperature rise across the stage due to the internal cooling flow being proposed. A heat transfer coefficient based on fully developed pipe flow was calculated for each cooling passage based on an assumed flow rate for the cooling water. Both steel and aluminum diaphragm (stators) are studied as well as standard $\left(70^{\circ} \mathrm{F}\right)$ and chilled $\left(40^{\circ} \mathrm{F}\right)$ cooling water is considered. Table 3-8 provides a summary of the cases considered.

Table 3-8. Summary of Cases Considered in CFD Analysis

\begin{tabular}{|c|c|c|}
\hline Case & Diaphragm Material & $\begin{array}{c}\text { Cooling Water } \\
\text { Temperature } \\
\left({ }^{(} \mathbf{F}\right)\end{array}$ \\
\hline Baseline (Adiabatic) & - & - \\
\hline w/ Heat Transfer (Coef 1) & Steel & 70 \\
\hline w/ Heat Transfer (Coef 2) & Steel & 40 \\
\hline w/ Heat Transfer (Coef 5) & Aluminum & 70 \\
\hline w/ Heat Transfer (Coef 6) & Aluminum & 40 \\
\hline
\end{tabular}

Figure 3-33 plots the total temperature in the meridian plane showing the inlet, impeller, diffuser, and return channel. As expected, the total temperature rise occurs inside the impeller due to the work of the spinning blades acting on the fluid. The total temperature in the diffuser and return channel reduces due to the heat transfer through the wall.

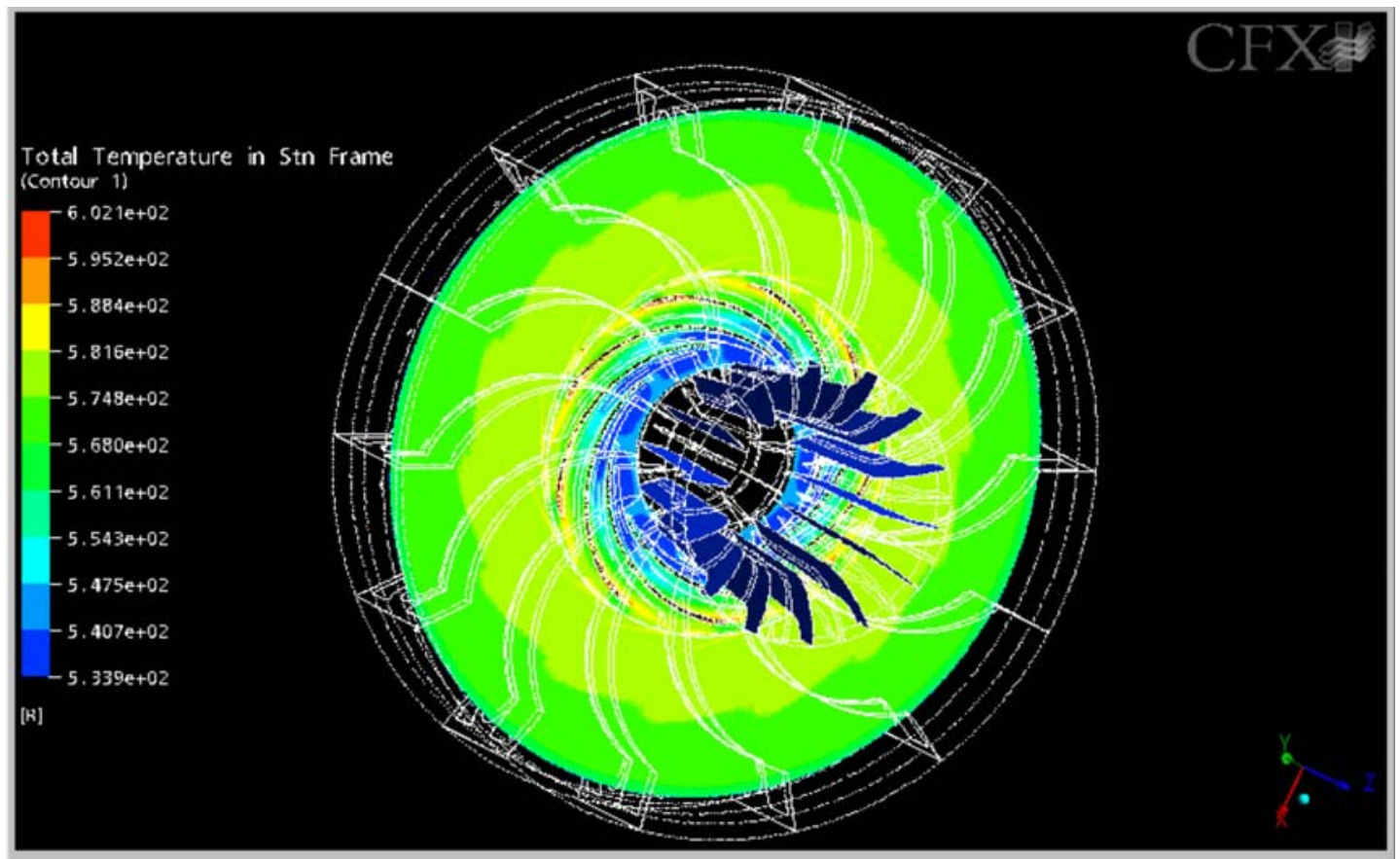

Figure 3-33. Predicted Total Temperature Contours with Heat Transfer in Diffuser 
Figure 3-34 and Figure 3-35 compare the static temperature for both the adiabatic case and the heat transfer case using steel diaphragms and $70^{\circ} \mathrm{F}$ cooling water (Case Coef_1). A similar level of temperature rise occurs across the impeller, since no cooling occurs until the flow exits the impeller and enters the diffuser. The temperature in the diffuser and return channel is essentially constant for the adiabatic case while the temperature continues to reduce with heat transfer. A thermal boundary layer forms on the wall of the diffuser, which begins to reduce the temperature. However, most of the cooling occurs in the return channel due to the reduced velocity and greater surface area on the blades.

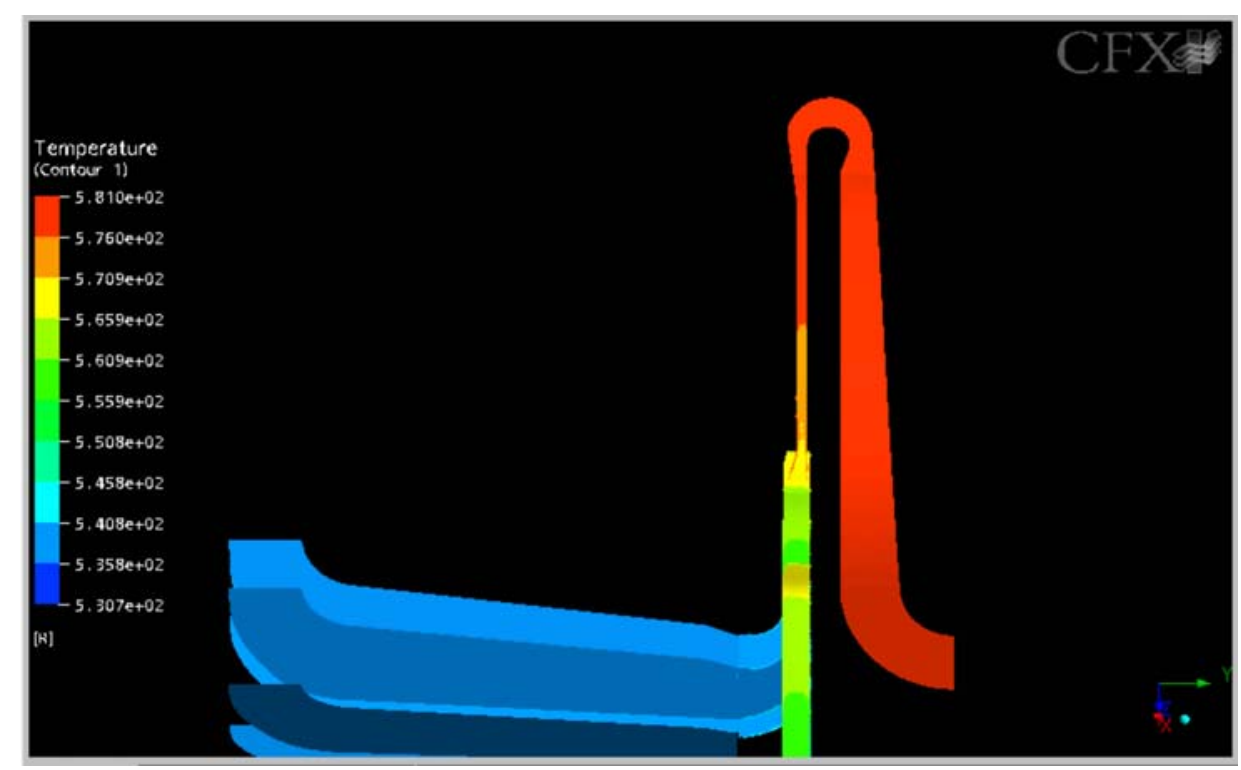

Figure 3-34. Predicted Temperature Contours Adiabatic

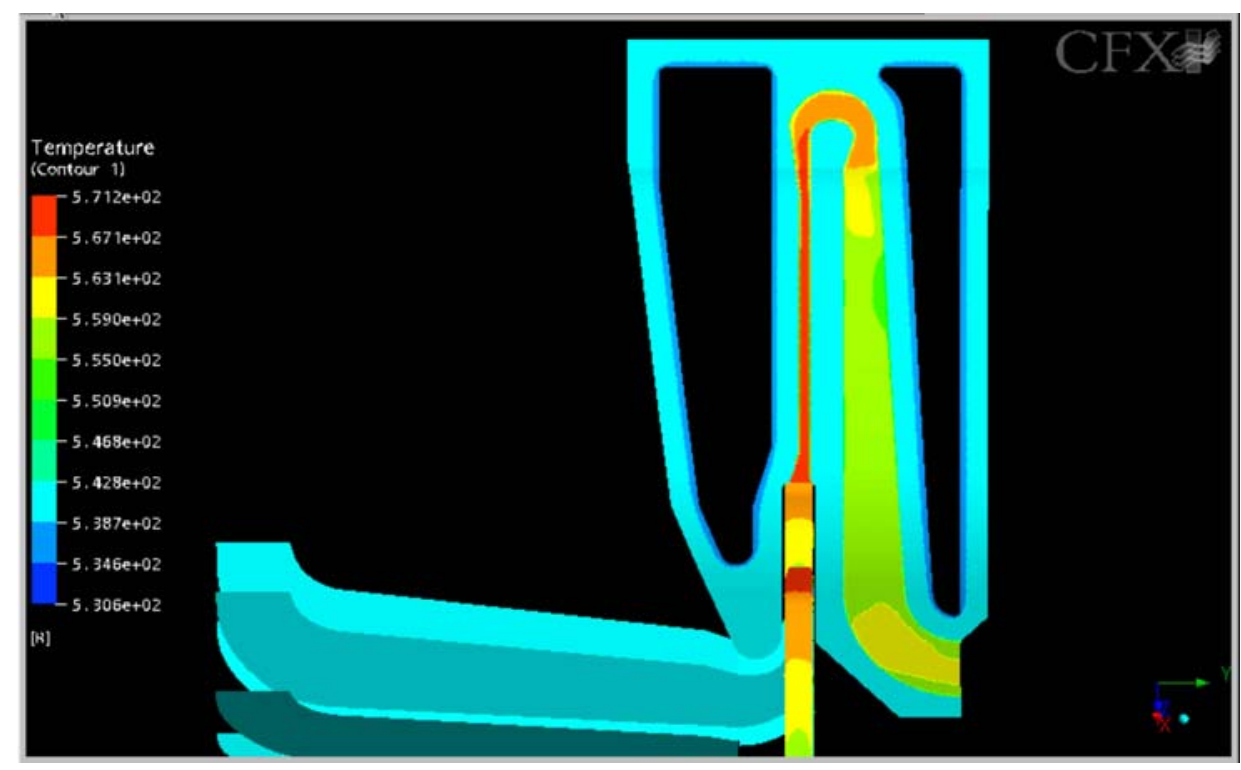

Figure 3-35. Predicted Temperature Contours with Heat Transfer in Diffuser (Aluminum Diaphragm, $70^{\circ} \mathrm{F}$ Cooling Flow) 
Figure 3-36 and Figure 3-37 show total temperature plots for a plane in the return channel for the two cases. The adiabatic case (Figure 3-36) shows essentially constant temperature as expected. Figure 3-37 shows the significant reduction in temperature in the return channel region due to the additional surface area and lower velocity promoting heat transfer.

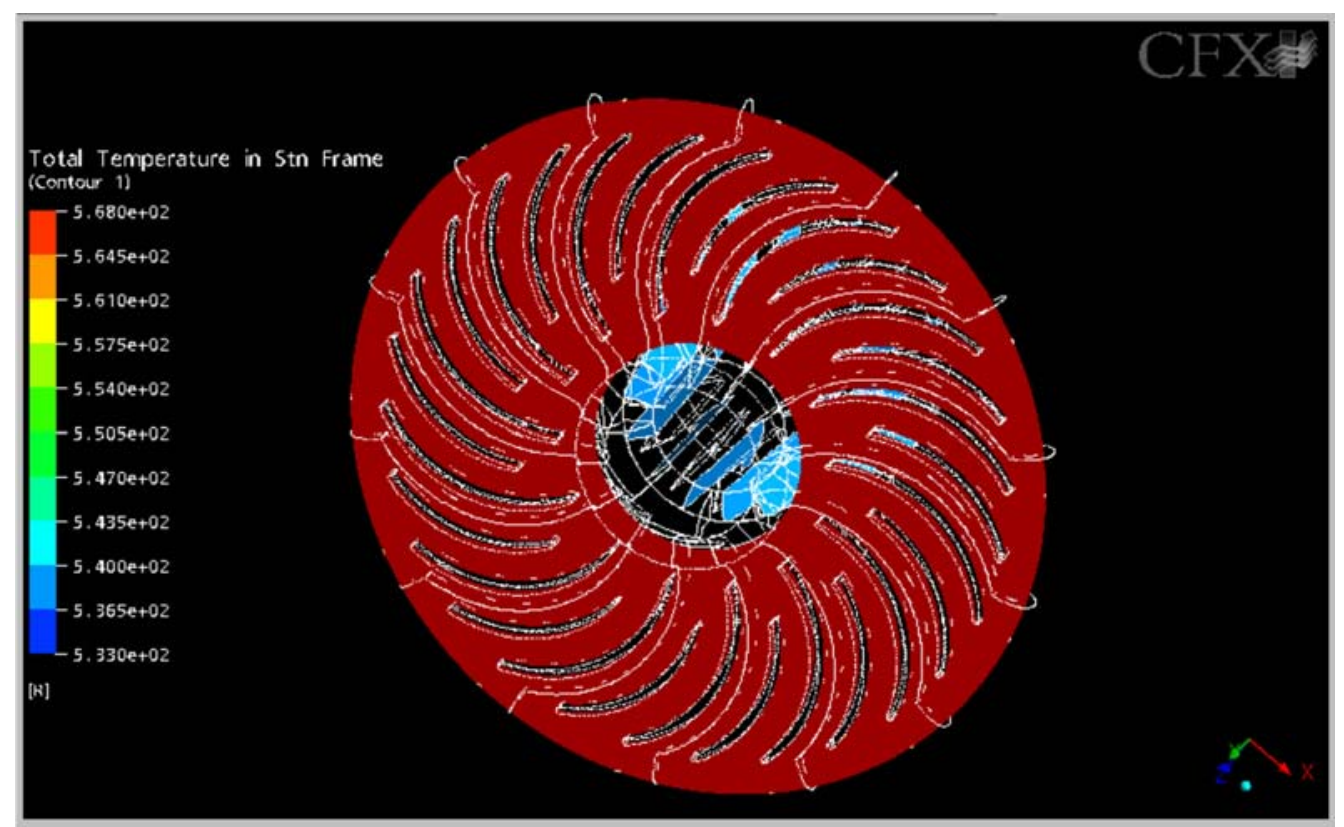

Figure 3-36. Predicted Total Temperature Contours in Return Channel Adiabatic

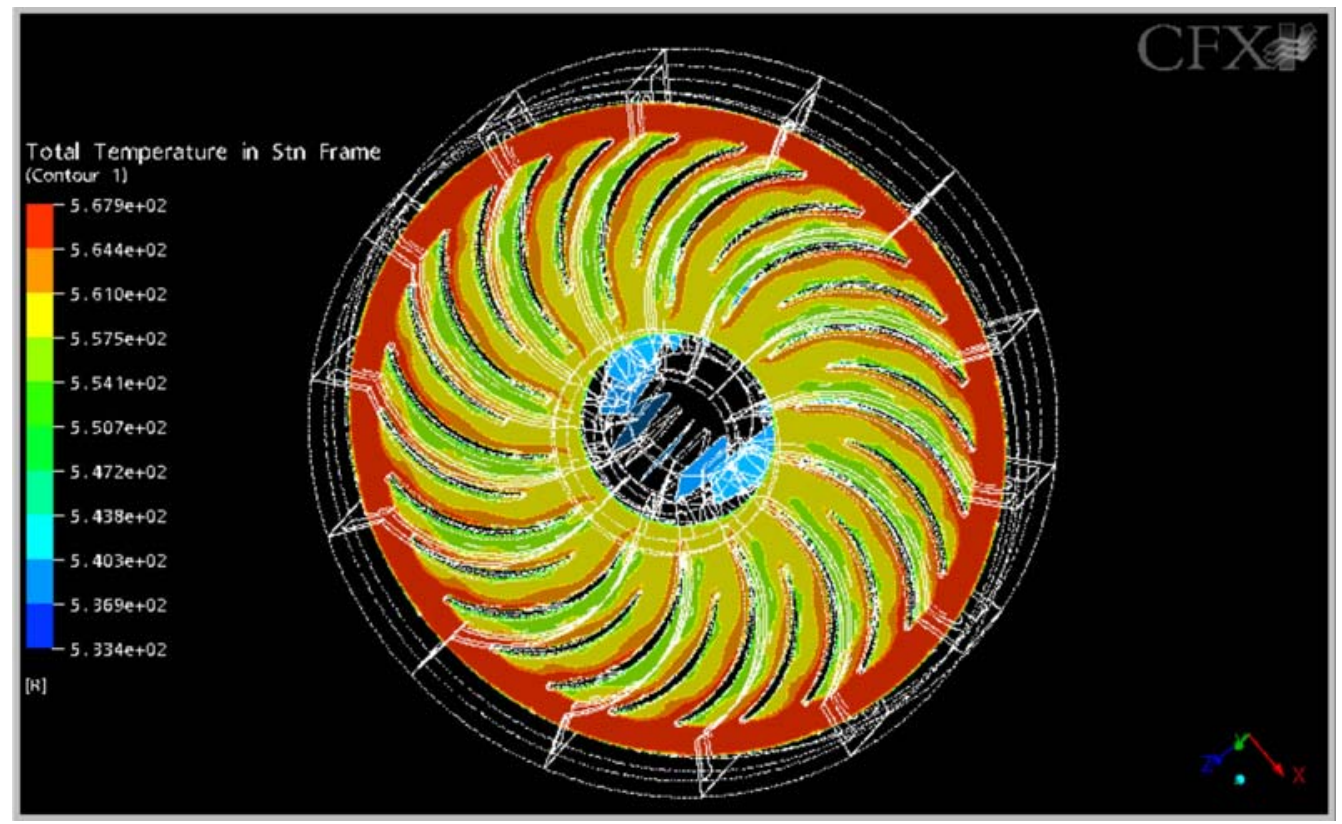

Figure 3-37. Predicted Total Temperature Contours with Heat Transfer in Return Channel (Aluminum Diaphragm, $70^{\circ} \mathrm{F}$ Cooling Flow) 
Figure 3-38 summarizes the temperature rise across the stage for the various cases considered. The baseline (adiabatic) case has a $41^{\circ} \mathrm{F}$ temperature rise using the steel diaphragm. Introducing cooling flow and permitting heat transfer reduces the temperature rise to about $27^{\circ} \mathrm{F}$. Utilizing chilled water further reduces this rise to $20^{\circ} \mathrm{F}$. Using an aluminum diaphragm results in a similar temperature rise even with the $70^{\circ} \mathrm{F}$ water, due to the larger conduction coefficient of aluminum. Surprisingly, using chilled water $\left(40^{\circ} \mathrm{F}\right)$ with the aluminum diaphragms did not result in further reduction. This result impacts the design of the cooling diaphragm and will be discussed further below.

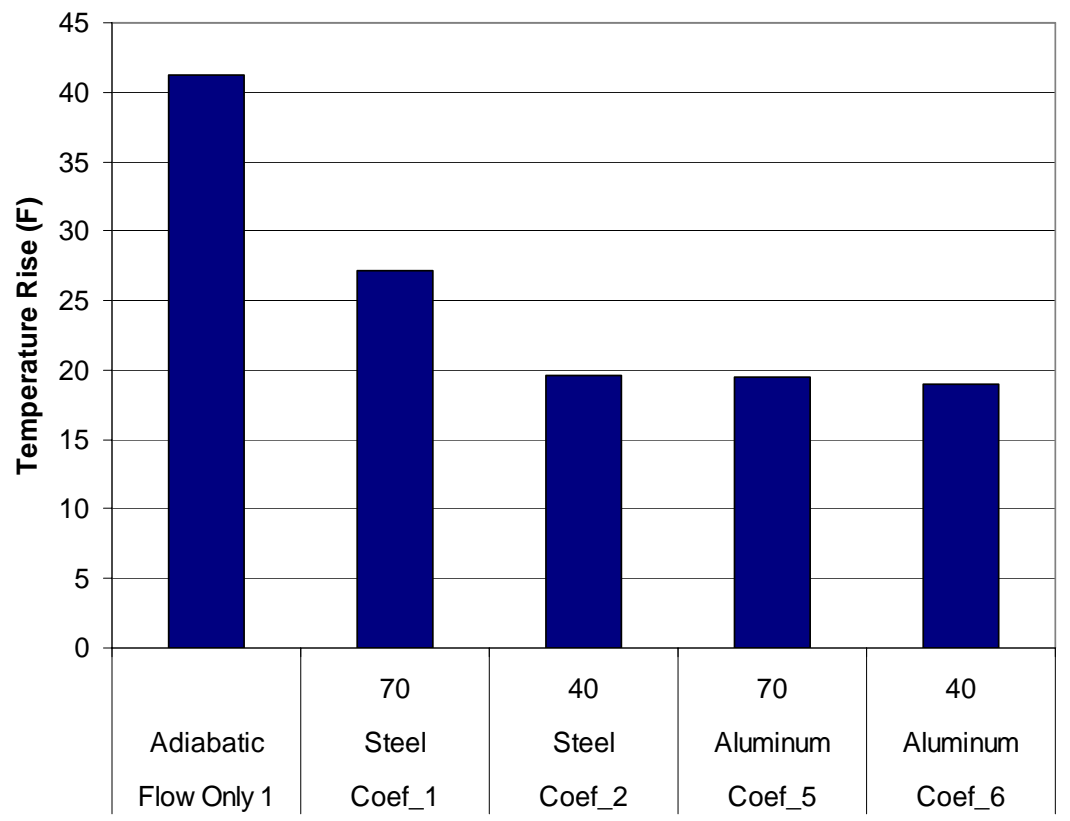

Figure 3-38. Comparison of Static Temperature Rise Across the Stage

To achieve isothermal compression, all of the heat added by the compressor would have to be removed through heat transfer resulting in zero temperature rise. However, even using a standard flow path and introducing a simple cooling jacket removed 55\% of the energy added by the impeller. This can be seen in the reduced temperature rise between the adiabatic model and the aluminum diaphragm case with cooling water at $70^{\circ} \mathrm{F}$.

Additional benefit may be gained in using an aluminum diaphragm with a higher heat transfer coefficient. The heat transfer process between the cooling water and the $\mathrm{CO}_{2}$ gas is governed by the summation of the three thermal resistances (as shown in Figure 3-39). The benefit in using an aluminum diaphragm, however, is somewhat overshadowed by the dominant heat transfer coefficient of the cooling water. Because of the summation of resistance in series, the lower of the three heat transfer coefficients governs the reduction in the overall heat transfer rate, as provided in the thermal circuit equation given in Equation (5).

$$
q=\frac{t_{1}-t_{2}}{\frac{1}{h_{1} A}+\frac{L}{k_{\text {diaph }} A}+\frac{1}{h_{2} A}}
$$


Equation (5) and the thermal circuit diagram shown in Figure 3-39 shows that heat transfer may be maximized for a given temperature difference by maximizing the heat transfer coefficients of the cooling flow and the $\mathrm{CO}_{2}$ flow path, as well as reducing the distance (L) between these flows. Maximizing surface area (A) is also beneficial and explains why a majority of the cooling occurs in the bladed return channel. Figure 3-39 supports the results in the CFD analysis where the reduction in the cooling water temperature to $40^{\circ} \mathrm{F}$ did not offer much improvement. The cooling water coefficient was already considerably lower than the coefficient for the diaphragm materials or the $\mathrm{CO}_{2}$ gas. Therefore, the cooling water interface created the highest resistance to the heat transfer. Future efforts will create designs to improve the heat transfer at this interface.
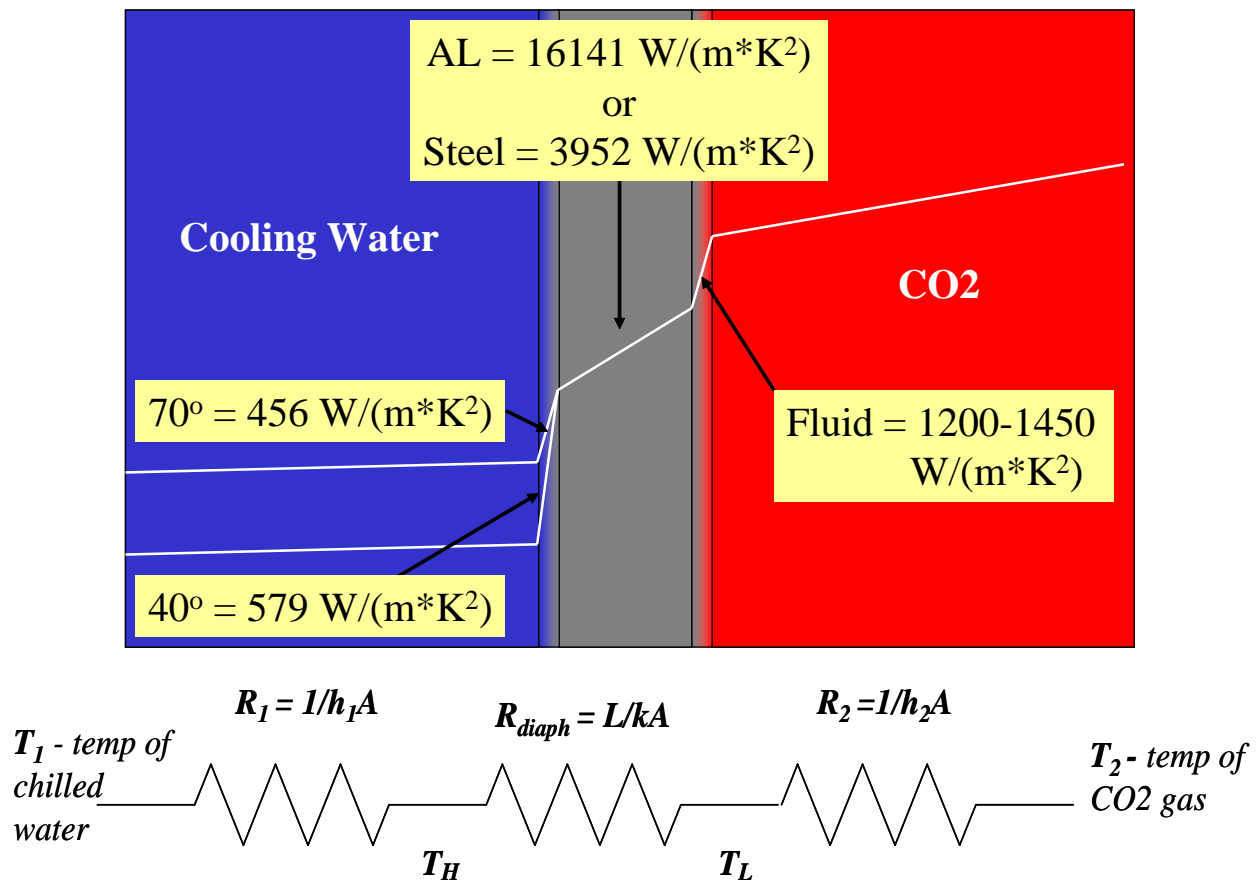

Figure 3-39. Illustration of Heat Transfer Coefficients in Cooling Process for $\mathrm{CO}_{2}$ in Compressor Diaphragm

The reduction in $\mathrm{CO}_{2}$ gas temperature through the heat exchange in the diaphragm would provide significant power savings in a multi-stage compressor. Furthermore, heat transfer enhancing features will be developed in Phase II that will improve the heat transfer and should approach the semi-isothermal compression.

\subsubsection{Task 2.5 - Experimental Measurement of Gas Mixing Streams}

Previous analysis of compression horsepower indicated a significant energy savings associated with reducing the carbon dioxide inlet temperatures at various compression stages. One available cooling source exists in the IGCC plant application through the available nitrogen waste stream exiting the air separation unit. To further evaluate the possible cooling potential of this waste stream, key experimental measurements were performed using nitrogen (as the 
cooling gas) and readily available ambient air (as a substitute for the $\mathrm{CO}_{2}$ gas) in an open loop setup as shown in Figure 3-40. The objective of the experimental measurements was to evaluate the cooling capabilities of liquid nitrogen on a gas stream possessing similar temperatures to $\mathrm{CO}_{2}$ in the IGCC plant application. The mixing process and resulting heat transfer process was evaluated to determine the convective cooling capability of nitrogen gas.

A blower was used to force air into a length of six-inch pipe. The inlet air was maintained at a constant temperature of $80^{\circ} \mathrm{F}$. Liquid nitrogen was injected through a nozzle into the pipe, which forced the hot gas to cool. The liquid nitrogen was injected at an inlet temperature of approximately $-320^{\circ} \mathrm{F}$. The resulting mixture of air and liquid nitrogen reached a steady state temperature of $-200^{\circ} \mathrm{F}$. Figure 3-41 provides the temperature plot over time for the inlet air stream at its resulting final cooled temperature.

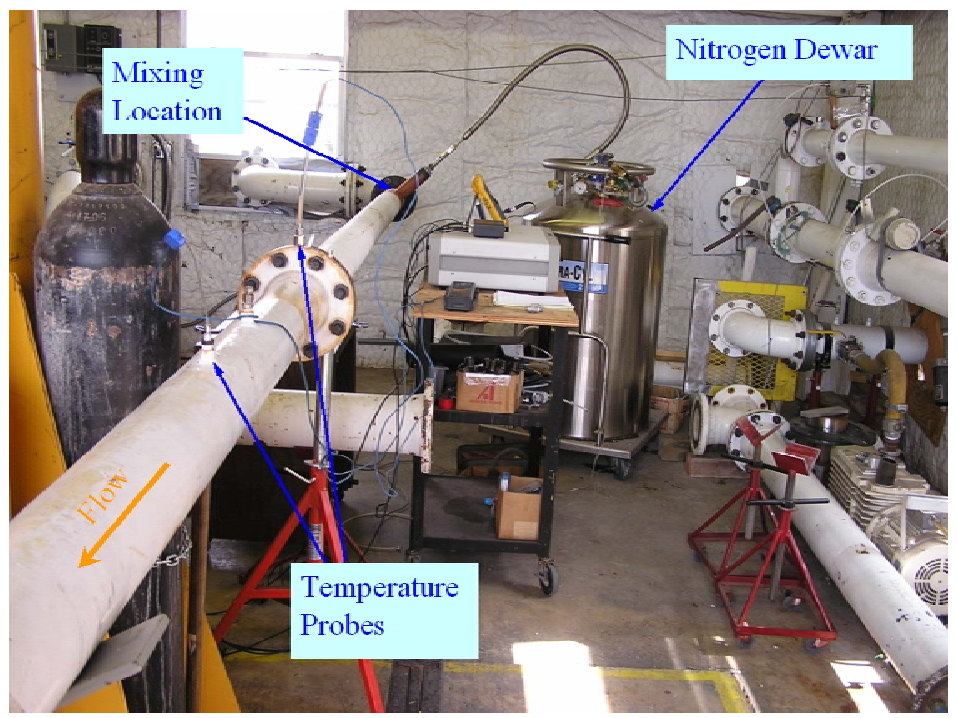

Figure 3-40. Gas Mixing Streams Setup

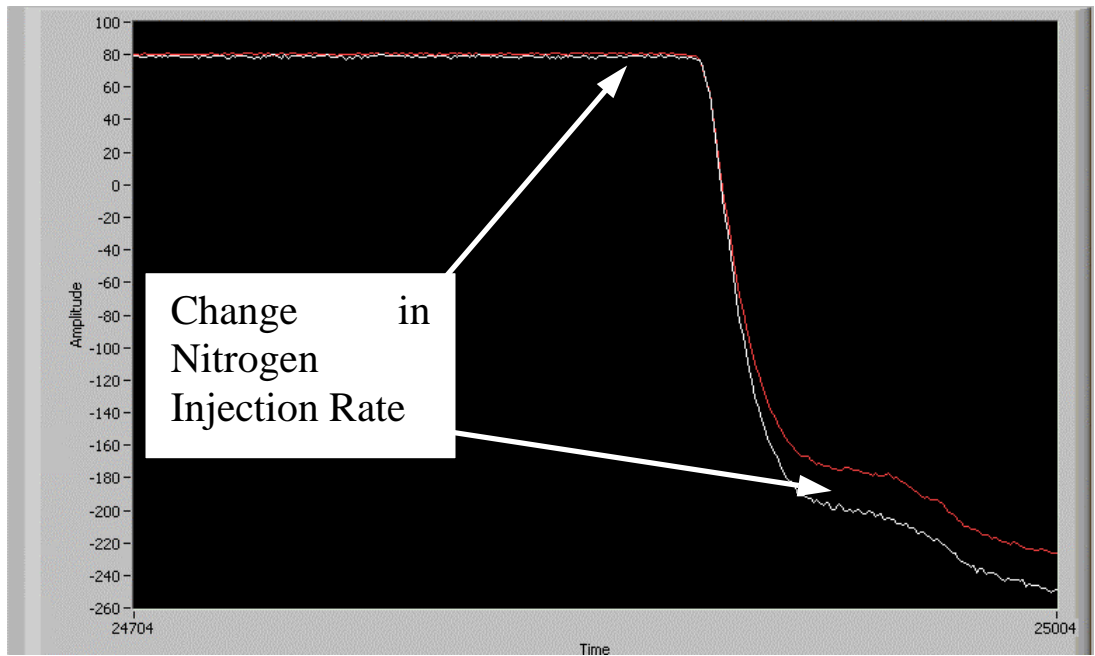

Figure 3-41. Gas Stream Temperature of Mixture 
In the second stage of the experimental measurements, the precipitation of liquid water vapor from air was investigated. Liquid nitrogen was again used as the cooling source of the ambient air. The ambient inlet air stream was highly humid (to allow readily available water vapor to condense out). An aluminum plate was inserted into the flow downstream of the liquid nitrogen injection to evaluate the presence of condensed water vapor. When the liquid nitrogen is introduced, the water vapor in the air stream precipitated out and formed ice crystals as shown in Figure 3-42.

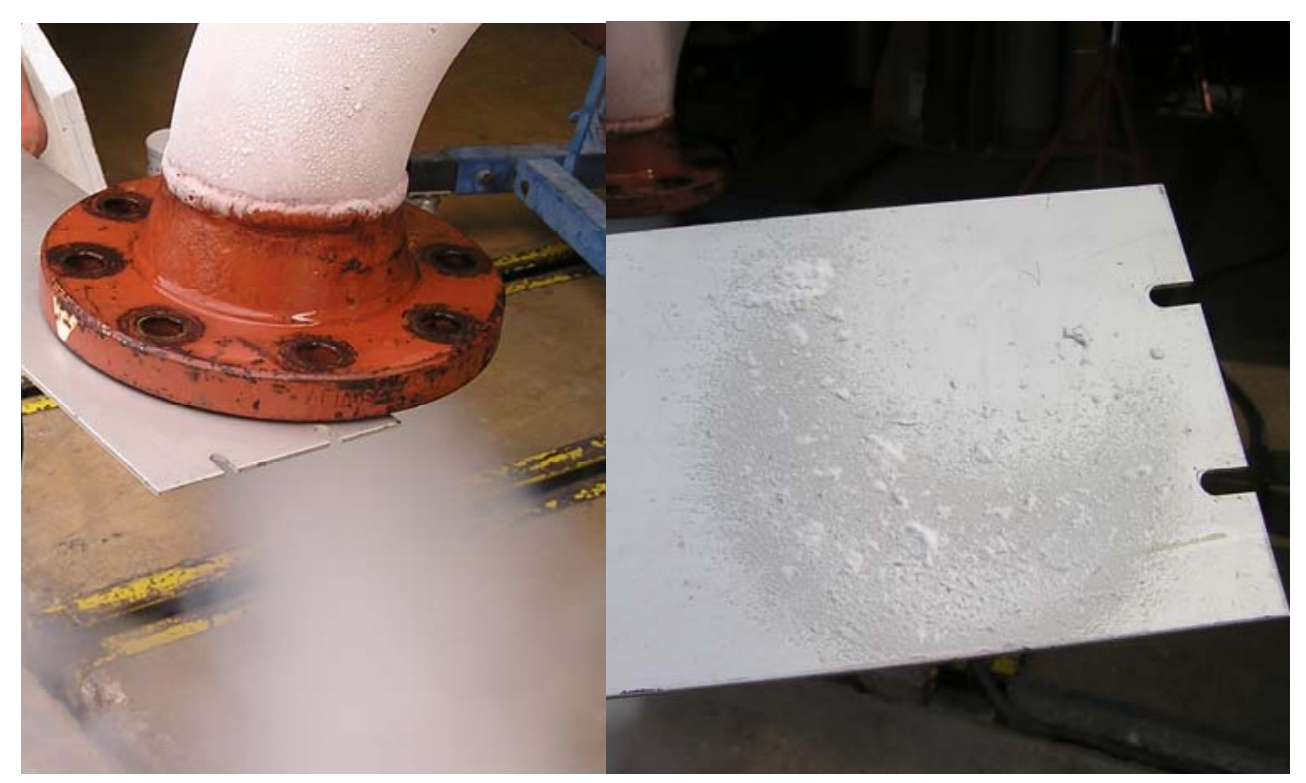

Figure 3-42. Precipitation of $\mathrm{H}_{2} \mathrm{O}$ on Aluminum Plate

The experiments demonstrated the feasibility of mixing two gas streams to reduce the temperature of the final mixture and consequently the temperature of the higher of the two streams inlet gas temperature. However, contaminants (water vapor in this case) can lead to undesirable precipitation, which can cause considerable damage to downstream turbomachinery due to erosion of the material surface due to the solid particles. 


\section{CONCLUSIONS}

Improvements in power generation efficiency reduces the cost of generating electricity, preserves the world's natural resources, and reduces the amount of emissions released to the environment. Through programs like the Department of Energy's Advanced Turbine Systems and other programs, step changes in generating efficiencies have been achieved. However, the penalty for $\mathrm{CO}_{2}$ sequestration, due to compression power requirements, is on the order of $10 \%$ of a power plant's output. This power and cost requirement is significant and is deterring many power producers from implementing $\mathrm{CO}_{2}$ sequestration projects. Reducing this power requirement will improve overall plant efficiencies and encourage sequestration of $\mathrm{CO}_{2}$ on both existing and future power plants.

The first phase of this program has explored many different thermodynamic processes and had identified two optimal $\mathrm{CO}_{2}$ pressure boosting schemes. The first utilizes a semiisothermal compression process but implements the process using an in-line multistage barrel compressor. This approach takes advantage of the high reliability and smaller footprint of the barrel compressor while matching the near isothermal performance of the integrally geared design. The second concept partially compresses the $\mathrm{CO}_{2}$, liquefies it using a refrigeration cycle and pumps the flow to the final discharge pressure. Both of these concepts offer over a $30 \%$ reduction in total required power over the traditional approach. Combining these concepts, where the initial compression of $\mathrm{CO}_{2}$ incorporates intercooled compression will result in an expected net savings of $35 \%$ in compression power.

The next phase (Phase II) will perform prototype testing of both concepts. The deliverables of Phase II include testing of two novel compression technologies that will significantly reduce the compression power required when sequestering $\mathrm{CO}_{2}$. An optimized design for both the interstage cooling concept, as well as the liquid pumping solution, will be generated. The quantitative measurements for the power improvement based on this testing will be provided. The testing will also prove out the design of the liquid $\mathrm{CO}_{2}$ pump. These results will be summarized in a comprehensive report. 


\section{COST AND SCHEDULE STATUS}

The proposed project can be completed within four (4) years from project initiation. The project phases and subtasks are sequential in nature; namely:

YEAR 1 - Phase I: $\mathrm{CO}_{2}$ Compression Conceptual Design (Current Phase)

YEARS 2 and 3 - Phase II: Prototype Design and Testing for Optimum $\mathrm{CO}_{2}$ Compressor Concept

YEAR 4 - Phase III: Commercialization and Field Installation of Full-Scale $\mathrm{CO}_{2}$ Compression Train

In accordance with the project plan shown in Figure 5-1, all tasks have been completed as described above. Table 5-1 compares the planned and actual cost for all activities. The table shows the project is on schedule and slightly under cost.
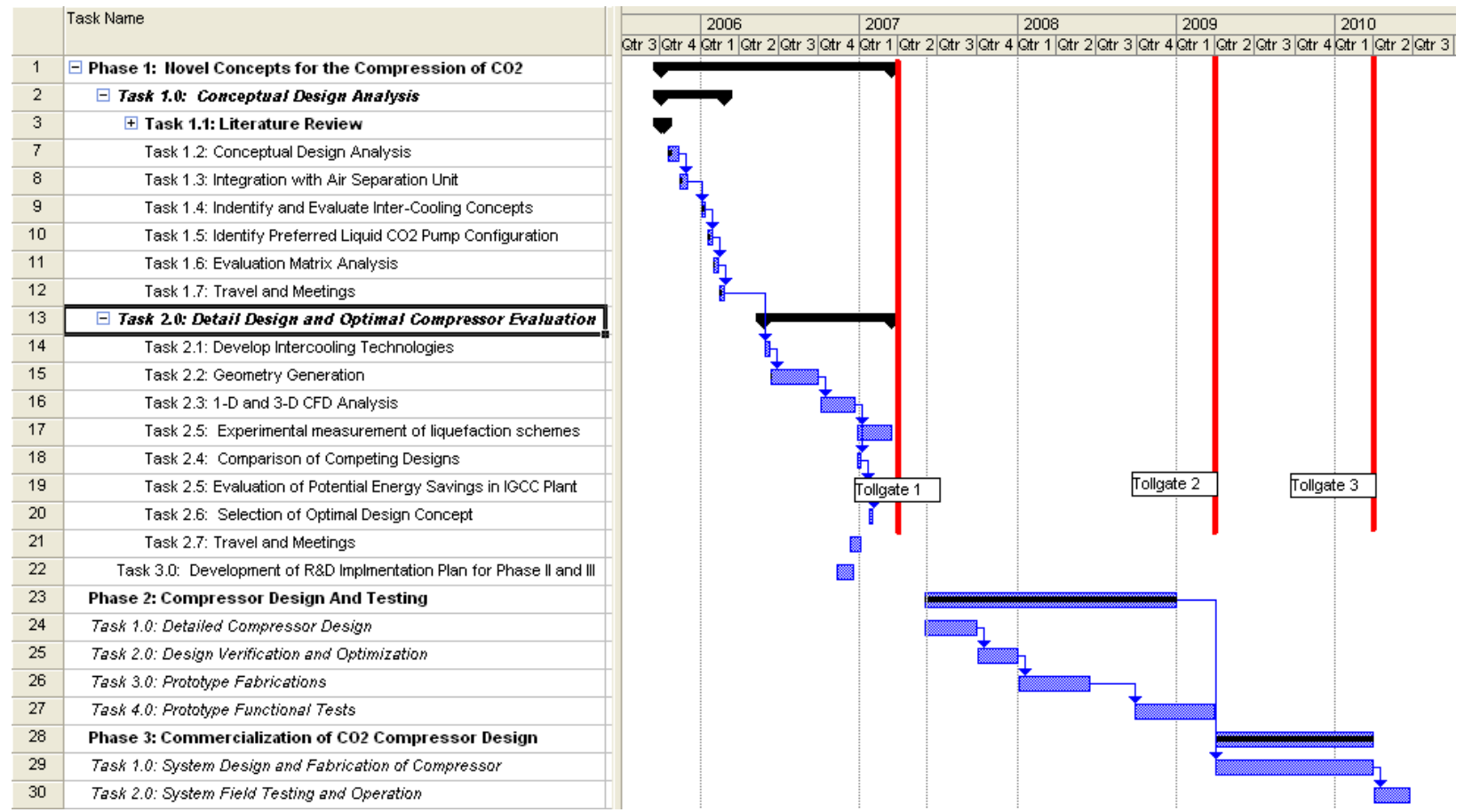

Figure 5-1. Project Schedule 
Table 5-1. Project Cost Status

\begin{tabular}{|c|c|c|c|}
\hline Work Breakdown & $\%$ Complete & $\begin{array}{c}\text { Actual } \\
\text { Cost }\end{array}$ & $\begin{array}{c}\text { Planned } \\
\text { Cost }\end{array}$ \\
\hline \multicolumn{4}{|l|}{ Task 1 - Conceptual Design Analysis } \\
\hline Literature Review & $100 \%$ & & \\
\hline Conceptual Design Analysis & $100 \%$ & & \\
\hline Integration with Air Separation Unit & $100 \%$ & & \\
\hline Identify and Evaluate Inter-Cooling Concepts & $100 \%$ & & \\
\hline Identify Preferred Liquid CO2 Pump Configuration & $100 \%$ & & \\
\hline Evaluation Matrix Analysis & $100 \%$ & & \\
\hline Travel and Meetings & $100 \%$ & & \\
\hline \multicolumn{4}{|c|}{ Task 2 - Detail Design and Evaluation of Optimal Pressure Boosting System } \\
\hline Develop InterCooling Technologies & $100 \%$ & & \\
\hline Geometry generation & $100 \%$ & & \\
\hline 1-D compressor analysis & $100 \%$ & & \\
\hline 3-D CFD Analysis & $100 \%$ & & \\
\hline Experimental measurement of gas mixing streams & $100 \%$ & & \\
\hline Comparison of Competing Designs & $100 \%$ & & \\
\hline Evaluation of Energy Savings in Typical IGCC Plant & $100 \%$ & & \\
\hline Travel and Meetings & $100 \%$ & & \\
\hline Select Optimum Concept & $100 \%$ & & \\
\hline Task 3 - Develop R\&D Implementation Plans for Phase II and III & $100 \%$ & $\$ 218,000$ & $\$ 218,792$ \\
\hline
\end{tabular}




\section{REFERENCES}

[1] Trapp, B., 2004, "Reliable Hydrogen from Coal," 2004 COAL-GEN Conference, July 27-30, 2004.

[2] Brun, K. and Shilling, N., 2001, "Environmental Performance and Viability of Integrated Gasification Combined Cycle," Clean Coal and Power Conference, Washington, DC, November 19-20, 2001.

[3] “Carbon Sequestration Research and Development,” Office of Science, Office of Fossil Energy, U.S. Department of Energy, December 1999.

[4] U.S. Department of Energy website, "Enhanced Oil Recovery/ $\mathrm{CO}_{2}$ Injection," Office of Fossil Energy, August 2, 2004, http://www.fe.doe.gov/programs/oilgas/eor/.

[5] Edmister, W. C. and Lee, B. I. Applied Hydrocarbon Thermodynamics - Volume 1, Second Edition, Gulf Publishing Company, 1984.

[6] IPCC, 2005, "IPCC Special Report on Carbon Dioxide Capture and Storage," Intergovernmental Panel On Climate Change (IPCC).

[7] Wang, B., Jin, H., and Zheng, D., 2004, "Recovery of $\mathrm{CO}_{2}$ with MEA and $\mathrm{K}_{2} \mathrm{CO}_{3}$ Absorption in the IGCC System," International Journal of Energy Research, Vol. 28.

[8] Siriwardane, R., Shen, M., Fisher, E., Poston, J., and Shamsi, A., 2001, “Adsorption and Desorption of $\mathrm{CO}_{2}$ on Solid Sorbents," National Energy Technology Laboratory (NETL) National Conference on Carbon Sequestration, May 2001.

[9] Tam, S. S., Stanton, M. E., Ghose, S., Deppe, G., Spencer, D. F., Currier, R. P., Young, J. S., Anderson, G. K., Le, L. A., and Devlin, D. J., 2001, "A High Pressure Carbon Dioxide Separation Process for IGCC Plants," First National Conference on Carbon Sequestration, National Energy Technology Laboratory (NETL), May 2001.

[10] Spencer, D. F., 2005, "SIMTECHE's Advanced $\mathrm{CO}_{2}$ Capture Process," Carbon Management Workshop, $2005 \mathrm{CO}_{2}$ Conference and EOR Carbon Management Workshop, Midland, Texas, December 2005.

[11] Pashos, K., 2005, "IGCC - An Important Part of our Future Generation Mix,” 2005 Gasification Technologies Conference, October 2005.

[12] Shine, J., 2005, " $\mathrm{CO}_{2}$ Support and Energy Services," Praxair, Carbon Management Workshop, $2005 \mathrm{CO}_{2}$ Conference and EOR Carbon Management Workshop, Midland, Texas, December 2005.

[13] Friedmann, J. S., 2005, “On $\mathrm{CO}_{2}$ EOR and $\mathrm{CO}_{2}$ Storage," Carbon Management Workshop, $2005 \mathrm{CO}_{2}$ Conference and EOR Carbon Management Workshop, Midland, Texas, December 2005.

[14] Kuuskraa, V. A., 2005, "How Large and Real is the Domestic $\mathrm{CO}_{2}$ - EOR Prize?" Carbon Management Workshop, $2005 \mathrm{CO}_{2}$ Conference and EOR Carbon Management Workshop, Midland, Texas, December 2005. 
[15] Steele, R., Kesseli, J., and Baldwin, P., 2005, "Insertion of Shock Wave Compression Technology into Micro Turbines for Increased Efficiency and Reduced Costs,” ASME Turbo Expo 2005, June 2005.

[16] Hansen, T. M.; Smith, I. K.; and Stosic, N., 2004, "Combined Industrial Cooling and Heating with Transcritical $\mathrm{CO}_{2}$ Heat Pumps Utilizing The Work of Expansion," GustavLorentzen Conference on Natural Working Fluids, Glasgow, Scotland.

[17] NASA website, "Fastrac Engine-A Boost for Low-Cost Space Launch," Fact Sheet Number: $\quad$ FS-1999-02-002-MSFC, Release date: 02/99, http://www.nasa.gov/centers/marshall/news/background/facts/fastrac.html.

[18] Schultz, J. "The Polytropic Analysis of Centrifugal Compressors," Journal of Engineering for Power, January 1962.

[19] Guntermann, Alfred E. "Refrigeration System Replacement in a Manufacturing Operation,” ASHRAE Journal, September 1998. 


\section{LIST OF ACRONYMS AND ABBREVIATIONS}

$\begin{array}{ll}\text { ACFM } & \text { Actual Cubic Feet per Minute } \\ \text { ASU } & \text { Air Separation Unit } \\ \text { Atm } & \text { Atmosphere } \\ \text { BHP } & \text { Brake Horsepower } \\ \text { Btu/scf } & \text { British Thermal Unit Per Standard Cubic Feet } \\ \text { CFD } & \text { Computational Fluid Dynamics } \\ \mathrm{CO}_{2} & \text { Carbon Dioxide } \\ \text { EOR } & \text { Enhanced Oil Recovery } \\ \text { HP } & \text { Horsepower } \\ \text { IGCC } & \text { Integrated Gasification Combined Cycle } \\ \text { IPCC } & \text { Intergovernmental Panel on Climate Control } \\ \mathrm{K}_{2} \mathrm{CO} & \text { Potassium Carbonate } \\ \text { lb/hr } & \text { Pound per hour } \\ \text { lbs } & \text { Pounds } \\ \text { lbm/hr } & \text { Pound Mass Per Hour } \\ \text { LNG } & \text { Liquid Natural Gas } \\ \text { MEA } & \text { Monoethanolamine } \\ \text { MMSCFD } & \text { Millions of Standard Cubic Feet Per Day } \\ \text { MPa } & \text { Mega Pascals } \\ \text { MW } & \text { Megawatt } \\ \text { N }_{2} & \text { Nitrogen } \\ \text { NGCC } & \text { Natural Gas Combined Cycle } \\ \text { NPSH } & \text { Net Positive Suction Head } \\ \text { PC } & \text { Pulverized Coal } \\ \text { PPM } & \text { Parts Per Million } \\ \text { PSIA } & \text { Pressure Per Square Inch Absolute } \\ \text { PSIG } & \text { Pounds Per Square Inch Gauge } \\ \text { RPM } & \text { Revolutions Per Minute } \\ & \end{array}$




\section{APPENDIX A}

\section{Dresser-Rand Selection of Conventional Centrifugal Compression Technology}




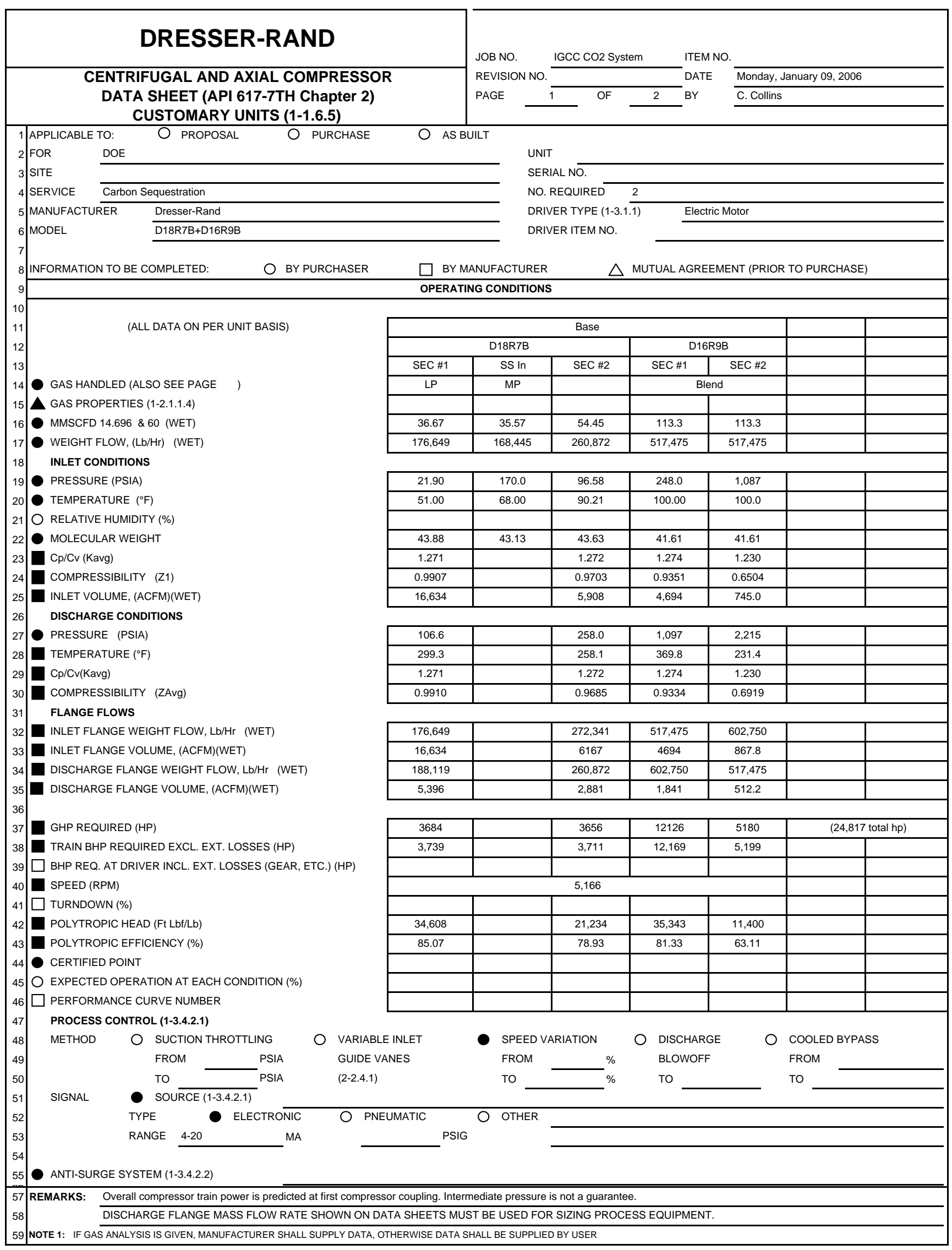




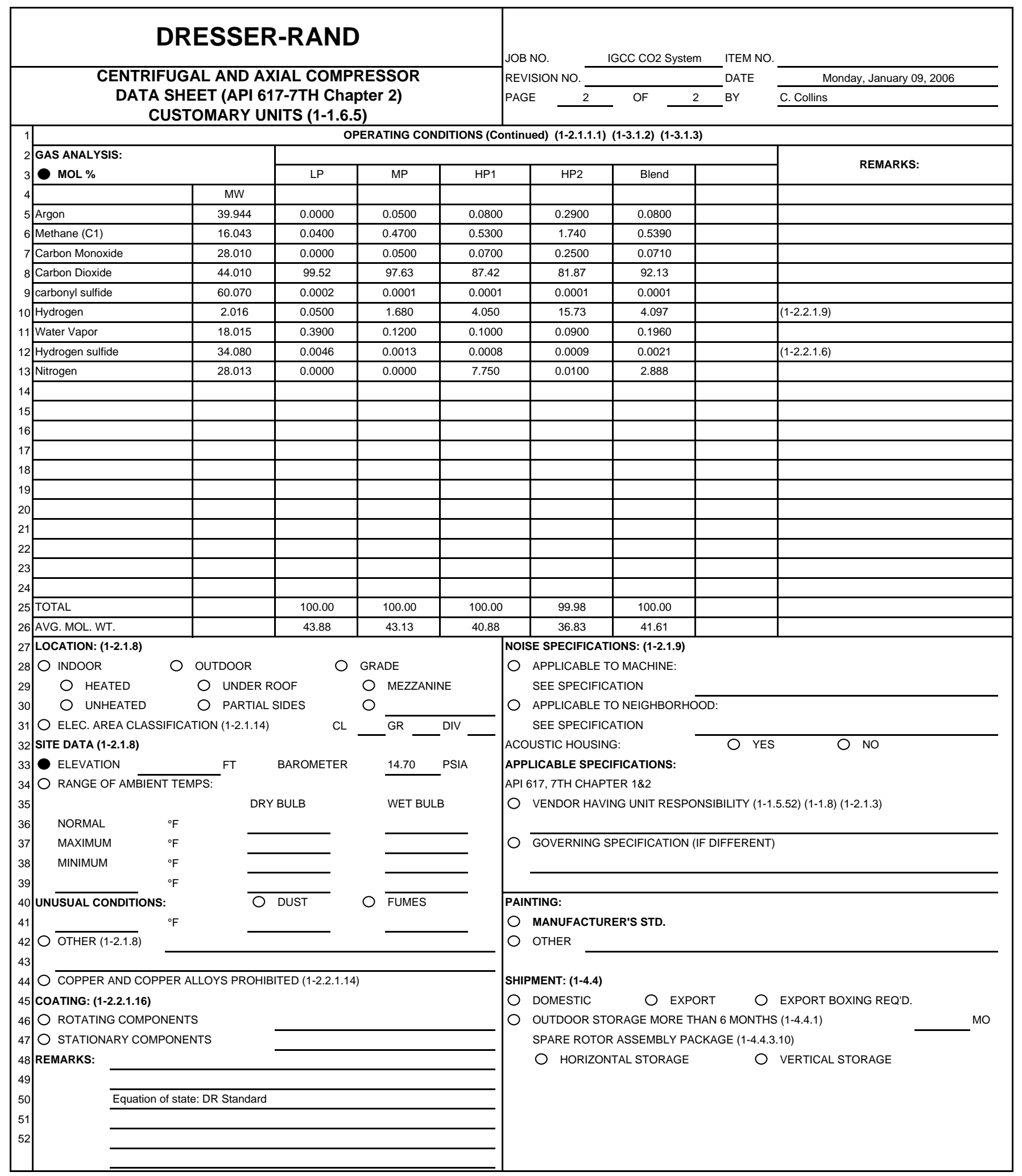




\section{APPENDIX B}

\section{Option A - Conventional Centrifugal Compression}




\begin{tabular}{|c|c|c|c|c|c|c|c|c|c|c|c|}
\hline \multicolumn{10}{|c|}{ Stream 1 - Low Pressure } & \multicolumn{2}{|l|}{ Mdot $(\mathrm{lb} / \mathrm{hr})=$} \\
\hline P1 & P2 & T1 & $\mathrm{T} 2$ & h1 & h2 & $\begin{array}{c}\text { rho1 } \\
(\mathrm{lbm} / \mathrm{ft} 3)\end{array}$ & $\begin{array}{c}\text { rho2 } \\
\text { (lbm/ft3) }\end{array}$ & $\mathrm{np}$ & $\begin{array}{l}\text { Polytropic } \\
\text { Efficiency }\end{array}$ & $\begin{array}{c}\text { W/mdot } \\
\text { (Btu/lbm) }\end{array}$ & BHP \\
\hline 22 & 107 & 50 & 300.00 & 211.95 & 264.73 & 0.17862 & 0.58401 & 1.3352 & 0.842 & 52.780 & 3898.6 \\
\hline \multicolumn{10}{|c|}{ Stream 1+2 - Medium Pressure } & Mdot $(\mathrm{lb} / \mathrm{hr})=$ & 188119 \\
\hline P1 & $\mathrm{P} 2$ & T1 & $\mathrm{T} 2$ & h1 & h2 & $\begin{array}{c}\text { rho1 } \\
\text { (lbm/ft3) }\end{array}$ & $\begin{array}{c}\text { rho2 } \\
\text { (lbm/ft3) }\end{array}$ & $\mathrm{np}$ & $\begin{array}{l}\text { Polytropic } \\
\text { Efficiency }\end{array}$ & $\begin{array}{l}\text { W/mdot } \\
\text { (Btu/lbm) }\end{array}$ & BHP \\
\hline \multirow[t]{2}{*}{97} & 258 & 90 & 265.00 & 218.07 & 254.37 & 0.74708 & 1.5076 & 1.3933 & 0.747 & 36.300 & 2681.3 \\
\hline & & & & & & & & & & Mdot $(\mathrm{lb} / \mathrm{hr})=$ & 84222.5 \\
\hline \multirow{2}{*}{170} & 258 & 70 & 140.00 & 211.55 & 225.14 & 1.4056 & 1.8834 & 1.4256 & 0.732 & 13.590 & 449.4 \\
\hline & & Avg. $=$ & 226.343 & & & & & Avg. = & 0.743 & SubTotal = & 3130.7 \\
\hline \multicolumn{10}{|c|}{ Stream 1+2+3 - High Pressure } & Mdot $(\mathrm{lb} / \mathrm{hr})=$ & 602750 \\
\hline $\mathrm{P} 1$ & $\mathrm{P} 2$ & T1 & T2 & $\mathrm{h} 1$ & $\mathrm{~h} 2$ & $\begin{array}{c}\text { rho1 } \\
\text { (lbm/ft3) }\end{array}$ & $\begin{array}{c}\text { rho2 } \\
(\mathrm{lbm} / \mathrm{ft} 3)\end{array}$ & $\mathrm{np}$ & $\begin{array}{l}\text { Polytropic } \\
\text { Efficiency }\end{array}$ & $\begin{array}{c}\text { W/mdot } \\
\text { (Btu/lbm) }\end{array}$ & BHP \\
\hline \multirow[t]{2}{*}{248} & 1097 & 100 & 370 & 216.08 & 269.93 & 1.9704 & 5.8568 & 1.3649 & 0.790 & 53.850 & 12744.7 \\
\hline & & & & & & & & & & Mdot $(\mathrm{lb} / \mathrm{hr})=$ & 517475 \\
\hline \multirow[t]{2}{*}{1087} & 2215 & 100 & 205 & 177.00 & 194.11 & 15.318 & 22.176 & 1.924 & 0.645 & 17.110 & 3476.5 \\
\hline & & & & & & & & & & Total BHP = & 23250.6 \\
\hline
\end{tabular}

\begin{tabular}{|c|c|c|c|c|c|c|c|c|c|}
\hline \multicolumn{3}{|c|}{ Cooler Calculations } & \multicolumn{4}{|c|}{ Carbon Dioxide (Hot Stream) } & & & \\
\hline \multicolumn{3}{|c|}{ Low Pressure Stream } & & & \multicolumn{2}{|c|}{ S1 mdot (lbm/hr) = } & 188119 & & \\
\hline P1 & T1 & T2 & $\mathrm{h} 1$ & $\mathrm{~h} 2$ & $\begin{array}{c}\text { W/mdot } \\
\text { (Btu/lbm) }\end{array}$ & $\begin{array}{c}\text { Heat } \\
\text { Removal } \\
\text { (Btu/min) }\end{array}$ & Method & & $\begin{array}{c}\text { Cooling } \\
\text { Cost (BHP) }\end{array}$ \\
\hline$\longrightarrow 97$ & 300.00 & 90 & 264.73 & 217.79 & 46.94 & 147172 & AIR COOL & & $\begin{array}{ll}-- \\
\end{array}$ \\
\hline$\longrightarrow 170$ & 70.00 & 90 & 211.55 & 216.02 & -4.47 & -14015 & AIR COOL & & --- \\
\hline \multicolumn{3}{|c|}{ Medium Pressure Stream } & & & \multicolumn{2}{|c|}{ S1 mdot $(\mathrm{lbm} / \mathrm{hr})=$} & 272341 & & \\
\hline P1 & $\mathrm{T} 1$ & T2 & $\mathrm{h} 1$ & $\mathrm{~h} 2$ & $\begin{array}{c}\text { W/mdot } \\
\text { (Btu/lbm) }\end{array}$ & $\begin{array}{c}\text { Heat } \\
\text { Removal } \\
\text { (Btu/min) }\end{array}$ & Method & & $\begin{array}{c}\text { Cooling } \\
\text { Cost (BHP) }\end{array}$ \\
\hline$\rightarrow 258$ & 258 & 100 & 252.72 & 215.79 & 36.93 & 167626 & AIR COOL & & \begin{tabular}{|c|}
--- \\
\end{tabular} \\
\hline \multicolumn{3}{|c|}{ High Pressure Streams } & & & \multicolumn{2}{|c|}{$\mathrm{S} 1 \mathrm{mdot}(\mathrm{Ibm} / \mathrm{hr})=$} & 517475 & & \\
\hline \begin{tabular}{|l}
$\mathrm{P} 1$ \\
\end{tabular} & $\mathrm{~T} 1$ & $\mathrm{~T} 2$ & $\mathrm{~h} 1$ & $\mathrm{~h} 2$ & $\begin{array}{c}\text { W/mdot } \\
\text { (Btu/lbm) }\end{array}$ & $\begin{array}{c}\text { Heat } \\
\text { Removal } \\
\text { (Btu/min) }\end{array}$ & Method & & $\begin{array}{c}\text { Cooling } \\
\text { Cost (BHP) }\end{array}$ \\
\hline$\rightarrow 1097$ & 370 & 100 & 269.93 & 175.96 & 93.97 & 810452 & AIR COOL & & -- \\
\hline$\rightarrow 2215$ & 230 & 100 & 206.41 & 120.04 & 86.37 & 744905 & AIR COOL & & --- \\
\hline & & & & & & & & & \\
\hline & & & & & & & & Total $=$ & 0 \\
\hline
\end{tabular}




\begin{tabular}{|c|c|c|c|c|c|c|c|c|c|c|c|}
\hline \multicolumn{10}{|c|}{ Low Pressure } & \multirow{2}{*}{$\begin{array}{c}\text { Mdot (lb/hr)= } \\
\text { W/mdot } \\
(\text { Btu/lbm) }\end{array}$} & \multirow{2}{*}{$\begin{array}{l}188119 \\
\text { BHP } \\
\end{array}$} \\
\hline P1 & P2 & T1 & T2 & h1 & h2 & $\begin{array}{c}\text { rho1 } \\
\text { (lbm/ft3) }\end{array}$ & $\begin{array}{c}\mathrm{rho} 2 \\
(\mathrm{lbm} / \mathrm{ft} 3)\end{array}$ & $\mathrm{np}$ & $\begin{array}{l}\text { Polytropic } \\
\text { Efficiency }\end{array}$ & & \\
\hline 22 & 107 & 50 & 300.00 & 211.95 & 264.73 & 0.17862 & 0.58401 & 1.3352 & 0.842 & 52.780 & 3898.6 \\
\hline & & & & & & & & & & & \\
\hline \multicolumn{4}{|c|}{ Side Stream + Medium Pressure } & & & & & & & Mdot (lb/hr)= & 188119 \\
\hline P1 & P2 & T1 & T2 & h1 & h2 & $\begin{array}{c}\text { rho1 } \\
\text { (lbm/ft3) }\end{array}$ & $\begin{array}{c}\text { rho2 } \\
\text { (lbm/ft3) }\end{array}$ & $\mathrm{np}$ & $\begin{array}{l}\text { Polytropic } \\
\text { Efficiency }\end{array}$ & $\begin{array}{c}\text { W/mdot } \\
\text { (Btu/lbm) }\end{array}$ & BHP \\
\hline \multirow[t]{2}{*}{97} & 170 & 60 & 150.00 & 211.67 & 229.45 & 0.79566 & 1.1896 & 1.395 & 0.772 & 17.780 & 1313.3 \\
\hline & & & & & & & & & & Mdot (lb/hr)= & 84222.5 \\
\hline \multirow[t]{2}{*}{170} & 258 & 90 & 160.00 & 216.02 & 229.8 & 1.3433 & 1.809 & 1.4015 & 0.754 & 13.780 & 1473.6 \\
\hline & & & & & & & & Avg. = & 0.762 & Total $=$ & 2786.9 \\
\hline \multicolumn{10}{|c|}{ High Pressure } & Mdot (lb/hr)= & 602750 \\
\hline P1 & $\mathrm{P} 2$ & T1 & T2 & h1 & h2 & $\begin{array}{c}\text { rho1 } \\
(\mathrm{lbm} / \mathrm{ft} 3)\end{array}$ & $\begin{array}{c}\mathrm{rho} 2 \\
(\mathrm{lbm} / \mathrm{ft} 3)\end{array}$ & np & $\begin{array}{l}\text { Polytropic } \\
\text { Efficiency }\end{array}$ & $\begin{array}{c}\text { W/mdot } \\
\text { (Btu/lbm) }\end{array}$ & BHP \\
\hline \multirow[t]{2}{*}{248} & 1097 & 60 & 320 & 206.62 & 256.28 & 2.1792 & 6.3959 & 1.381 & 0.780 & 49.660 & 11753.1 \\
\hline & & & & & & & & & & Mdot (lb/hr)= & 517475 \\
\hline 1087 & 2215 & 90 & 170 & 159.05 & 172.08 & 21.424 & 28.874 & 2.3853 & 0.627 & 13.030 & 3083.8 \\
\hline & & & & & & & & & & Total BHP = & 21522.4 \\
\hline
\end{tabular}

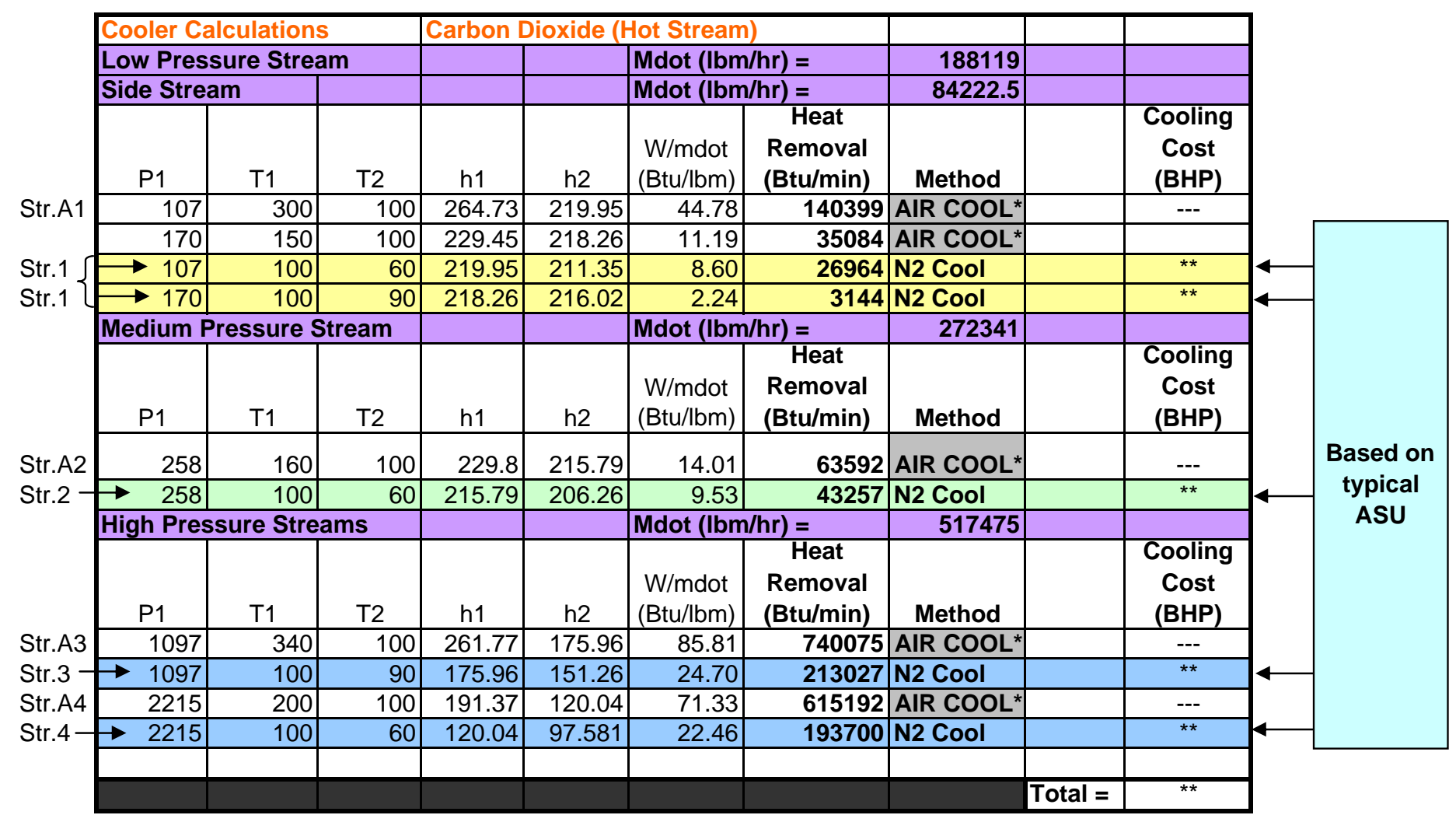

* Assume CO2 may be cooled by ambient cooling down to 100 degF at no horsepower cost.

** Cooling cost for ASU nitrogen stream to be determined. 
Appendix B.3 - Option C.1

Isothermal Compression at $70 \mathrm{deg} F$

\begin{tabular}{|c|c|c|c|c|c|c|c|c|c|c|c|}
\hline \multicolumn{10}{|c|}{ Low Pressure } & \multirow{2}{*}{\begin{tabular}{|c|}
\multicolumn{1}{c}{ Mdot (lb/hr)= } \\
Actual \\
W/mdot \\
(Btu/lbm)
\end{tabular}} & \multirow{2}{*}{$\begin{array}{l}188119 \\
\text { BHP } \\
\end{array}$} \\
\hline P1 & $\mathrm{P} 2$ & To & P2/P1 & $\begin{array}{c}\text { In } \\
(\mathrm{P} 2 / \mathrm{P} 1)\end{array}$ & $\mathrm{Z1}$ & $\mathrm{Z2}$ & Zavg & $\begin{array}{c}\text { Ideal } \\
\text { W/mdot } \\
\text { (Btu/lbm) }\end{array}$ & $\begin{array}{l}\text { Assumed } \\
\text { Efficiency }\end{array}$ & & \\
\hline 22 & 107 & 70 & 4.86 & 1.58 & 0.9924 & 0.9635 & 0.9780 & 36.97 & 0.800 & \begin{tabular}{|l|}
46.218 \\
\end{tabular} & 2731.1 \\
\hline \multicolumn{4}{|c|}{ Side Stream + Medium Pressure } & & & & & & & Mdot $(\mathrm{lb} / \mathrm{hr})=$ & 188119 \\
\hline P1 & $\mathrm{P} 2$ & To & $\mathrm{P} 2 / \mathrm{P} 1$ & $\begin{array}{c}\text { In } \\
(\mathrm{P} 2 / \mathrm{P} 1)\end{array}$ & $\mathrm{Z1}$ & $\mathrm{Z2}$ & Zavg & $\begin{array}{c}\text { Ideal } \\
\text { W/mdot } \\
\text { (Btu/lbm) }\end{array}$ & $\begin{array}{l}\text { Assumed } \\
\text { Efficiency }\end{array}$ & $\begin{array}{c}\text { Actual } \\
\text { W/mdot } \\
\text { (Btu/lbm) }\end{array}$ & BHP \\
\hline \multirow[t]{2}{*}{97} & 258 & 70 & 2.66 & 0.98 & 0.9639 & 0.9010 & 0.9325 & 21.80 & 0.800 & 27.253 & 1610.5 \\
\hline & & & & & & & & & & Mdot $(\mathrm{lb} / \mathrm{hr})=$ & 84222.5 \\
\hline 170 & 258 & 70 & 1.52 & 0.42 & 0.9359 & 0.9010 & 0.9185 & 9.16 & 0.800 & 11.447 & 302.9 \\
\hline \multicolumn{10}{|c|}{ High Pressure } & Mdot (lb/hr)= & 602750 \\
\hline $\mathrm{P} 1$ & $\mathrm{P} 2$ & To & $\mathrm{P} 2 / \mathrm{P} 1$ & $\begin{array}{c}\text { In } \\
(\mathrm{P} 2 / \mathrm{P} 1) \\
\end{array}$ & $\mathrm{Z1}$ & $\mathrm{Z2}$ & Zavg & $\begin{array}{c}\text { Ideal } \\
\text { W/mdot } \\
\text { (Btu/lbm) }\end{array}$ & $\begin{array}{l}\text { Assumed } \\
\text { Efficiency }\end{array}$ & $\begin{array}{c}\text { Actual } \\
\text { W/mdot } \\
\text { (Btu/lbm) }\end{array}$ & BHP \\
\hline \multirow[t]{2}{*}{258} & 1097 & 70 & 4.25 & 1.45 & 0.9010 & 0.5422 & 0.7216 & 24.96 & 0.800 & 31.205 & 7385.2 \\
\hline & & & & & & & & & & Mdot $(\mathrm{lb} / \mathrm{hr})=$ & 602750 \\
\hline \multirow{2}{*}{1087} & 2215 & 70 & 2.04 & 0.71 & 0.5422 & 0.5746 & 0.5584 & 9.50 & 0.800 & 11.876 & 2810.7 \\
\hline & & & & & & & & & & & \\
\hline & & & & & & & & & & Total BHP = & 14840.3 \\
\hline
\end{tabular}


Appendix B.3 - Option C. 2

Isothermal Compression at $100 \mathrm{deg} F$

\begin{tabular}{|c|c|c|c|c|c|c|c|c|c|c|}
\hline \multicolumn{2}{|l|}{ Option C.2 - Isothermal Compressor Calculations at 100 degF } \\
\hline Low Pressure \\
\hline
\end{tabular}




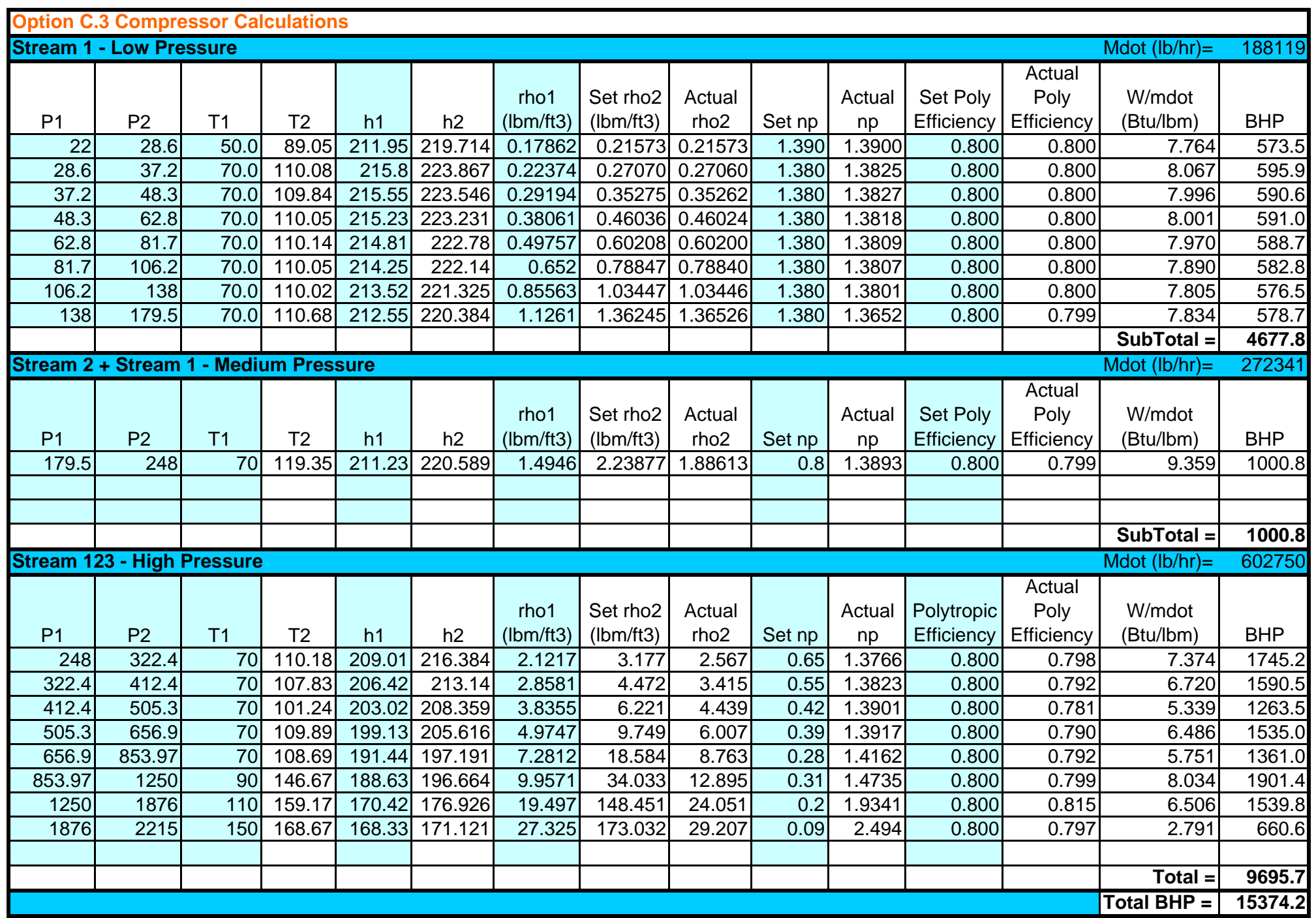


Option C.4 Compressor Calculations

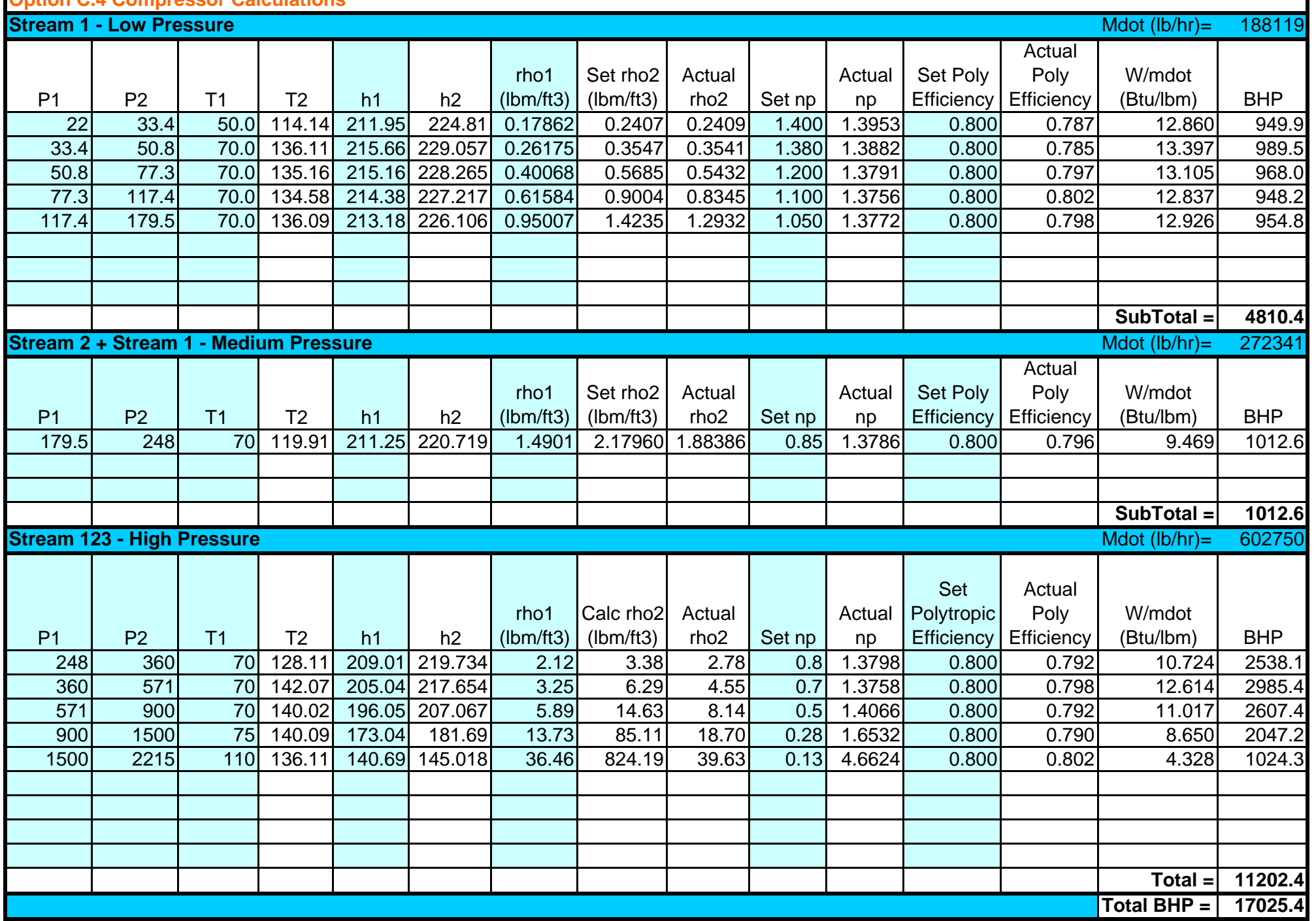




\begin{tabular}{|c|c|c|c|c|c|c|c|c|c|c|c|c|c|c|}
\hline \multicolumn{15}{|c|}{ Option C.5 Compressor Calculations } \\
\hline \multirow[t]{2}{*}{ Stream 1} & \multirow[t]{2}{*}{ Low Pres } & \multirow[t]{2}{*}{ sure } & \multirow[b]{2}{*}{ T2 } & \multirow[b]{2}{*}{ h1 } & \multirow[b]{2}{*}{ h2 } & \multirow[b]{2}{*}{$\begin{array}{c}\text { rho1 } \\
\text { (lbm/ft3) }\end{array}$} & \multirow[b]{2}{*}{$\begin{array}{l}\text { Set rho2 } \\
(\mathrm{lbm} / \mathrm{ft} 3)\end{array}$} & \multirow[b]{2}{*}{$\begin{array}{l}\text { Actual } \\
\text { rho2 }\end{array}$} & \multirow[b]{2}{*}{ Set np } & \multirow[b]{2}{*}{$\begin{array}{c}\text { Actual } \\
\mathrm{np}\end{array}$} & \multirow[b]{2}{*}{$\begin{array}{l}\text { Set Poly } \\
\text { Efficiency }\end{array}$} & \multirow[b]{2}{*}{$\begin{array}{c}\text { Actual } \\
\text { Poly } \\
\text { Efficiency }\end{array}$} & \multirow{2}{*}{$\begin{array}{c}\text { Mdot }(\mathrm{lb} / \mathrm{hr})= \\
\mathrm{W} / \mathrm{mdot} \\
(\mathrm{Btu} / \mathrm{lbm})\end{array}$} & \multirow{2}{*}{$\begin{array}{l}188119 \\
\mathrm{BHP}\end{array}$} \\
\hline & & & & & & & & & & & & & & \\
\hline 22 & 42 & 50.0 & 150.15 & 211.95 & 232.252 & 0.17862 & 0.29153 & 0.28513 & 1.320 & 1.3826 & 0.800 & 0.796 & 20.302 & 1499.6 \\
\hline 42 & 81.7 & 70.0 & 176.15 & 215.42 & 237.095 & 0.33019 & 0.55087 & 0.53550 & 1.300 & 1.3761 & 0.800 & 0.793 & 21.675 & 1601.0 \\
\hline \multirow[t]{2}{*}{81.7} & 180 & 70.0 & 197.69 & \multirow[t]{2}{*}{214.25} & 240.039 & 0.652 & 1.22656 & 1.15938 & 1.250 & \multirow[t]{2}{*}{1.3723} & 0.800 & 0.793 & 25.789 & 1904.9 \\
\hline & & & & & & & & & & & & & & \\
\hline & & & & & & & & & & & & & & \\
\hline & & & & & & & & & & & & & & \\
\hline & & & & & & & & & & & & & & \\
\hline & & & & & & & & & & & & & & \\
\hline & & & & & & & & & & & & & SubTotal = & 5005.5 \\
\hline Stream 2 & Stream & - Medit & m Press & iure & & & & & & & & & Mdot $(\mathrm{lb} / \mathrm{hr})=$ & 272341 \\
\hline P1 & P2 & T1 & T2 & h1 & h2 & $\begin{array}{c}\text { rho1 } \\
\text { (lbm/ft3) }\end{array}$ & $\begin{array}{l}\text { Set rho2 } \\
(\mathrm{lbm} / \mathrm{ft} 3)\end{array}$ & $\begin{array}{l}\text { Actual } \\
\text { rho2 }\end{array}$ & Set $n p$ & $\begin{array}{c}\text { Actual } \\
\mathrm{np}\end{array}$ & $\begin{array}{c}\text { Set Poly } \\
\text { Efficiency }\end{array}$ & $\begin{array}{c}\text { Actual } \\
\text { Poly } \\
\text { Efficiency }\end{array}$ & $\begin{array}{l}\text { W/mdot } \\
\text { (Btu/lbm) }\end{array}$ & BHP \\
\hline 180 & 248 & 70 & 119.48 & 211.23 & 220.62 & 1.4946 & 2.17904 & 1.88559 & 0.85 & 1.3791 & 0.800 & 0.796 & 9.390 & 1004.1 \\
\hline & & & & & & & & & & & & & & \\
\hline & & & & & & & & & & & & & & \\
\hline & & & & & & & & & & & & & SubTotal = & 1004.1 \\
\hline Stream 12 & - High F & essure & & & & & & & & & & & Mdot $(\mathrm{lb} / \mathrm{hr})=$ & 602750 \\
\hline P1 & P2 & $\mathrm{T} 1$ & $\mathrm{~T} 2$ & h1 & h2 & $\begin{array}{c}\text { rho1 } \\
\text { (lbm/ft3) }\end{array}$ & $\begin{array}{l}\text { Set rho2 } \\
(\mathrm{lbm} / \mathrm{ft} 3)\end{array}$ & $\begin{array}{c}\text { Actual } \\
\text { rho2 }\end{array}$ & Set np & $\begin{array}{c}\text { Actual } \\
\mathrm{np}\end{array}$ & $\begin{array}{l}\text { Polytropic } \\
\text { Efficiency }\end{array}$ & $\begin{array}{c}\text { Actual } \\
\text { Poly } \\
\text { Efficiency }\end{array}$ & $\begin{array}{l}\text { W/mdot } \\
\text { (Btu/lbm) }\end{array}$ & BHP \\
\hline 248 & \begin{tabular}{l|l}
471.2 \\
\end{tabular} & 70 & 169.40 & 209.01 & 227.299 & 2.1217 & 4.5147 & 3.407 & 0.85 & 1.2 & 0.800 & 0.802 & 18.289 & 4328.4 \\
\hline \begin{tabular}{l|}
2 \\
471.2
\end{tabular} & 854 & 70 & 164.22 & 200.61 & 216.337 & 4.5384 & 10.7444 & 6.954 & 0.69 & 1.3935 & 0.800 & 0.792 & 15.727 & 3722.1 \\
\hline 854 & 1300 & 90 & 152.58 & 188.63 & 197.615 & 9.9571 & 34.2653 & 13.191 & 0.34 & 1.4941 & 0.800 & 0.795 & 8.985 & 2126.4 \\
\hline 1300 & 2215 & 110 & 156.39 & 163.93 & 172.55 & 22.594 & 190.4209 & 26.393 & 0.25 & 3.4292 & 0.800 & 0.795 & 8.620 & 2040.2 \\
\hline & & & & & & & & & & & & & & \\
\hline & & & & & & & & & & & & & & \\
\hline & & & & & & & & & & & & & & \\
\hline & & & & & & & & & & & & & & \\
\hline & & & & & & & & & & & & & & \\
\hline & & & & & & & & & & & & & Total $=$ & 12217.1 \\
\hline & & & & & & & & & & & & & Total BHP = & 18226.7 \\
\hline
\end{tabular}




\begin{tabular}{|c|c|c|c|c|c|c|c|c|c|c|c|}
\hline \multicolumn{4}{|c|}{ Low + Medium Pressure Stream } & & & & & & & Mdot (lb/hr)= & 272342 \\
\hline P1 & $\mathrm{P} 2$ & T1 & $\mathrm{T} 2$ & h1 & h2 & $\begin{array}{c}\text { rho1 } \\
(\mathrm{lbm} / \mathrm{ft} 3)\end{array}$ & $\begin{array}{c}\text { rho2 } \\
(\mathrm{lbm} / \mathrm{ft} 3)\end{array}$ & $\mathrm{np}$ & $\begin{array}{l}\text { Polytropic } \\
\text { Efficiency }\end{array}$ & $\begin{array}{c}\text { W/mdot } \\
(\mathrm{Btu} / \mathrm{lbm})\end{array}$ & BHP \\
\hline 22 & 220 & 50 & 460 & 211.95 & 302.04 & 0.17862 & 0.99084 & 1.344 & 0.80 & 90.090 & 9633.8 \\
\hline \multicolumn{2}{|c|}{ All Streams } & & & & & & & & & Mdot (lb/hr)= & 517475 \\
\hline 220 & 2215 & 460 & 1070 & 302.04 & 460.94 & 0.99084 & 5.7869 & 1.3086 & 0.79 & 158.900 & 32286.4 \\
\hline & & & & & & & & & & & \\
\hline & & & & & & & & & & Total BHP = & 41920.3 \\
\hline
\end{tabular}

\begin{tabular}{|c|c|c|c|c|c|c|c|c|c|}
\hline \multicolumn{3}{|c|}{ Cooler Calculations } & \multicolumn{4}{|c|}{ Carbon Dioxide (Hot Stream) } & & & \\
\hline & \multirow[b]{2}{*}{$\mathrm{T} 1$} & \multirow[b]{2}{*}{ T2 } & \multirow[b]{2}{*}{ h1 } & \multirow[b]{2}{*}{$\mathrm{h} 2$} & \multicolumn{2}{|c|}{ Mdot (Ibm/hr) = } & 517475 & & \\
\hline P1 & & & & & $\begin{array}{c}\text { W/mdot } \\
\text { (Btu/lbm) }\end{array}$ & $\begin{array}{c}\text { Heat } \\
\text { Removal } \\
\text { (Btu/min) }\end{array}$ & Method & & $\begin{array}{c}\text { Cooling } \\
\text { Cost (BHP) }\end{array}$ \\
\hline 2215 & 1070 & 100 & 460.94 & 120.04 & 340.90 & 2940120 & AIR COOL & & --- \\
\hline & & & & & & & & Total = & 0 \\
\hline
\end{tabular}

* Assume CO2 may be cooled by ambient cooling from 1060 degF to 100 degF at no horsepower cost.

\begin{tabular}{|c|c|c|c|c|c|c|c|}
\hline \multicolumn{8}{|c|}{ Air Tower Cooling Requirements } \\
\hline & & & & & & & \\
\hline P1 & $\mathrm{T} 1$ & T2 & h1 & h2 & $\begin{array}{c}\text { W/mdot } \\
\text { (Btu/lbm) }\end{array}$ & $\begin{array}{c}\text { Required } \\
\text { Heat Added } \\
\text { (Btu/min) }\end{array}$ & $\begin{array}{c}\text { Mass } \\
\text { Flow } \\
\text { Required } \\
\text { (Ibm/hr) }\end{array}$ \\
\hline 15 & 70 & 250 & 131.31 & 176.15 & -44.84 & -2940120 & 3934149 \\
\hline & & & & & & & \\
\hline & & & & & & & \\
\hline
\end{tabular}




\begin{tabular}{|c|c|c|c|c|c|c|c|c|c|c|c|}
\hline \multicolumn{4}{|c|}{ Low + Medium Pressure Stream } & & & & & & & Mdot (lb/hr)= & 272342 \\
\hline P1 & P2 & T1 & T2 & h1 & h2 & $\begin{array}{c}\text { rho1 } \\
\text { (lbm/ft3) }\end{array}$ & $\begin{array}{c}\mathrm{rho} 2 \\
(\mathrm{lbm} / \mathrm{ft} 3)\end{array}$ & $\mathrm{np}$ & $\begin{array}{l}\text { Polytropic } \\
\text { Efficiency }\end{array}$ & $\begin{array}{c}\text { W/mdot } \\
\text { (Btu/lbm) }\end{array}$ & BHP \\
\hline 22 & 220 & 50 & 460 & 211.95 & 302.04 & 0.17862 & 0.99084 & 1.344 & 0.80 & 90.090 & 9633.8 \\
\hline \multicolumn{2}{|c|}{ All Streams } & & & & & & & & & Mdot (lb/hr)= & 517475 \\
\hline 220 & 2215 & 100 & 550 & 216.87 & 310.7 & 1.7307 & 9.3907 & 1.3655 & 0.80 & 93.830 & 19065.1 \\
\hline & & & & & & & & & & & \\
\hline & & & & & & & & & & Total BHP = & 28698.9 \\
\hline
\end{tabular}

\begin{tabular}{|c|c|c|c|c|c|c|c|c|c|}
\hline \multicolumn{3}{|c|}{ Cooler Calculations } & \multicolumn{4}{|c|}{ Carbon Dioxide (Hot Stream) } & & & \\
\hline & & & & & Mdot (Ibm & $\mathrm{hr})=$ & 517475 & & \\
\hline P1 & $\mathrm{T} 1$ & $\mathrm{~T} 2$ & h1 & h2 & $\begin{array}{c}\text { W/mdot } \\
(\mathrm{Btu} / \mathrm{lbm})\end{array}$ & $\begin{array}{c}\text { Heat } \\
\text { Removal } \\
\text { (Btu/min) }\end{array}$ & Method & & $\begin{array}{c}\text { Cooling } \\
\text { Cost (BHP) }\end{array}$ \\
\hline 220 & 460 & 100 & 302.04 & 216.87 & 85.17 & 734556 & AIR COOL & & --- \\
\hline 2215 & 550 & 100 & 310.7 & 120.04 & 190.66 & 1644363 & AIR COOL & & --- \\
\hline & & & & & & & & Total = & 0 \\
\hline
\end{tabular}

* Assume CO2 may be cooled by ambient cooling from 1060 degF to 100 degF at no horsepower cost.

\begin{tabular}{|r|r|r|l|l|l|l|l|}
\hline \multicolumn{2}{|c|}{ Air Tower Cooling Requirements } & & & & \\
\hline & & & & & & & \\
\hline P1 & T1 & T2 & h1 & h2 & $\begin{array}{c}\text { W/mdot } \\
\text { (Btu/lbm) }\end{array}$ & $\begin{array}{c}\text { Mass } \\
\text { Heat Added } \\
\text { (Btu/min) }\end{array}$ & $\begin{array}{c}\text { Flow } \\
\text { Required } \\
\text { (Ibm/hr) }\end{array}$ \\
\hline 15 & 70 & 250 & 131.31 & 176.15 & -44.84 & $\mathbf{- 2 3 7 8 9 1 9}$ & $\mathbf{3 1 8 3 2 1 0}$ \\
\hline & & & & & & & \\
\hline
\end{tabular}




\begin{tabular}{|c|c|c|c|c|c|c|c|c|c|c|c|}
\hline \multicolumn{9}{|c|}{ Stream 1 - Low Pressure } & \multicolumn{2}{|c|}{ S1 mdot $(\mathrm{lbm} / \mathrm{hr})=$} & 188119 \\
\hline P1 & $\mathrm{P} 2$ & $\mathrm{~T} 1$ & $\mathrm{~T} 2$ & h1 & h2 & $\begin{array}{c}\text { rho1 } \\
\text { (lbm/ft3) }\end{array}$ & rho2 (lbm/ft3) & $\mathrm{np}$ & \begin{tabular}{|l|} 
Polytropic \\
Efficiency \\
\end{tabular} & $\begin{array}{c}\text { W/mdot } \\
\text { (Btu/lbm) }\end{array}$ & BHP \\
\hline 22 & 107 & 50 & 300.00 & 211.95 & 264.73 & 0.17862 & 0.58401 & 1.3352 & 0.842 & 52.780 & 3898.6 \\
\hline \multicolumn{9}{|c|}{ Stream 2 + Stream 1 - Medium Pressure } & \multicolumn{2}{|c|}{ S1+S2 mdot (lbm/hr) = } & 188119 \\
\hline P1 & P2 & T1 & T2 & h1 & h2 & $\begin{array}{c}\text { rho1 } \\
(\mathrm{lbm} / \mathrm{ft} 3)\end{array}$ & rho2 (lbm/ft3) & $\mathrm{np}$ & \begin{tabular}{|l|} 
Polytropic \\
Efficiency
\end{tabular} & $\begin{array}{c}\text { W/mdot } \\
\text { (Btu/lbm) }\end{array}$ & BHP \\
\hline \multirow[t]{2}{*}{97} & 258 & 90 & 265.00 & 218.07 & 254.37 & 0.74708 & 1.5076 & 1.3933 & 0.747 & \begin{tabular}{|r|}
36.300 \\
\end{tabular} & 2681.3 \\
\hline & & & & & & & & & & Mdot $(\mathrm{lb} / \mathrm{hr})=$ & 84222.5 \\
\hline \multirow[t]{2}{*}{170} & 258 & 70 & 140.00 & 211.55 & 225.14 & 1.4056 & 1.8834 & 1.4256 & 0.732 & 13.590 & 449.4 \\
\hline & & Avg. $=$ & 226.343 & & & & & Avg. = & 0.743 & SubTotal = & 3130.7 \\
\hline \multicolumn{12}{|c|}{ Cryogenic Pump Calculations } \\
\hline \multicolumn{9}{|c|}{ Stream 123 - High Pressure } & \multicolumn{2}{|c|}{ S1+S2 mdot (lbm/hr) = } & 517475 \\
\hline P1 & $\mathrm{P} 2$ & $\mathrm{~T} 1$ & $\mathrm{~T} 2$ & $\mathrm{~S} 1=\mathrm{S} 2$ & h1 & h2 & h2s & Isent-W & $\begin{array}{c}\text { Pump } \\
\text { Isentropic } \eta\end{array}$ & $\begin{array}{c}\text { Work } \\
\text { (Btu/lbm) }\end{array}$ & BHP \\
\hline 248 & 2215 & -25 & -12.24 & 0.17557 & 55.886 & 62.554 & 61.220 & 5.334 & 0.800 & 6.668 & 1354.8 \\
\hline & & & & & & & & & & Total BHP = & 8384.1 \\
\hline
\end{tabular}

\begin{tabular}{|c|c|c|c|c|c|c|c|c|}
\hline \multirow{2}{*}{\multicolumn{3}{|c|}{$\begin{array}{l}\text { Cooler Calculations } \\
\text { Stream } 1 \text { - Low Pressure }\end{array}$}} & \multicolumn{4}{|c|}{ Carbon Dioxide (Hot Stream) } & & \multirow[b]{3}{*}{$\begin{array}{l}\text { Cooling } \\
\text { Cost (HP) }\end{array}$} \\
\hline & & & & & Mdot (Ibm & $h r)=$ & 176649 & \\
\hline \multirow{2}{*}{$\frac{\mathrm{P} 1}{107}$} & T1 & $\mathrm{T} 2$ & h1 & h2 & $\begin{array}{c}\text { W/mdot } \\
\text { (Btu/lbm) }\end{array}$ & $\begin{array}{c}\text { Heat } \\
\text { Removal } \\
\text { (Btu/min) }\end{array}$ & Method & \\
\hline & 300.00 & 90 & 264.73 & 218.07 & 46.66 & 137374 & AIR COOL & --- \\
\hline \multicolumn{3}{|c|}{ All Streams Combined } & & & \multicolumn{2}{|c|}{ Mdot $(\mathrm{lbm} / \mathrm{hr})=$} & 517475 & \\
\hline P1 & $\mathrm{T} 1$ & $\mathrm{~T} 2$ & h1 & h2 & $\begin{array}{c}\text { W/mdot } \\
\text { (Btu/lbm) }\end{array}$ & $\begin{array}{c}\text { Heat } \\
\text { Removal } \\
\text { (Btu/min) }\end{array}$ & Method & $\begin{array}{l}\text { Cooling } \\
\text { Cost (HP) }\end{array}$ \\
\hline 248 & 265 & 100 & 254.37 & 216.08 & 38.29 & 330235 & AIR COOL & --- \\
\hline 248 & 100 & 10 & 216.08 & 194.13 & 21.95 & 189310 & N2 COOL * & * \\
\hline 248 & 10 & -25 & 194.13 & 55.886 & 138.24 & 1192297 & REFRIG** & 7814 \\
\hline \multicolumn{3}{|c|}{ All Streams Combined } & & & \multicolumn{2}{|c|}{ Mdot $(\mathrm{lbm} / \mathrm{hr})=$} & 517475 & \\
\hline P1 & T1 & $\mathrm{T} 2$ & $\mathrm{~h} 1$ & $\mathrm{~h} 2$ & $\begin{array}{c}\text { W/mdot } \\
(\mathrm{Btu} / \mathrm{lbm})\end{array}$ & $\begin{array}{c}\text { Heat } \\
\text { Removal } \\
\text { (Btu/min) }\end{array}$ & Method & $\begin{array}{c}\text { Cooling } \\
\text { Cost (BHP) }\end{array}$ \\
\hline \multirow[t]{2}{*}{2215} & -15 & 100 & 61.282 & 120.04 & -58.76 & -506763 & OFFSET & \begin{tabular}{|c|}
--- \\
\end{tabular} \\
\hline & & & & \multicolumn{3}{|c|}{ Total Refrig. Cooling (Btu/hr) = } & 41132018 & 3427.7 \\
\hline
\end{tabular}
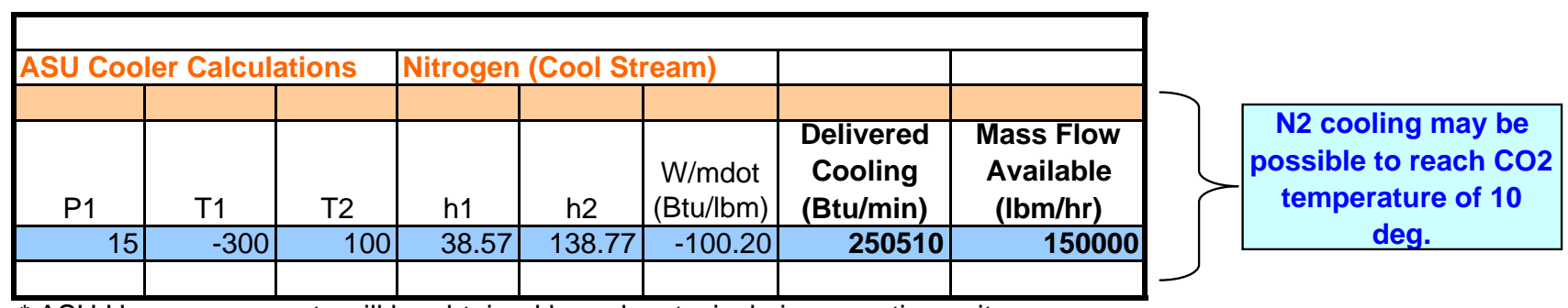

* ASU Horsepower costs will be obtained based on typical air separation unit.

** Assume ammonia refrigeration delivers -25 degF CO2 at efficiency of $1.7 \mathrm{~kW} /$ ton, typical for 120 ton unit at low process delivery temperatures. 


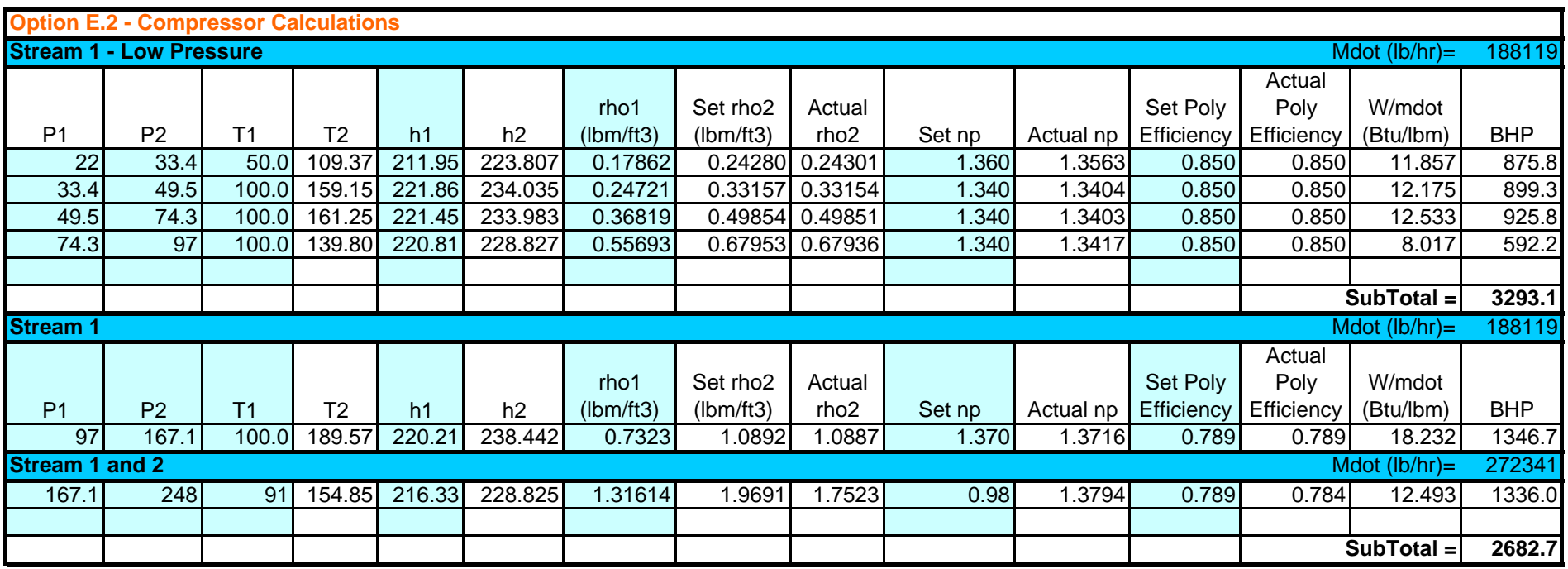

\begin{tabular}{|c|c|c|c|c|c|c|c|c|c|c|c|}
\hline \multicolumn{9}{|c|}{ All Streams } & \multicolumn{2}{|c|}{ S1+S2 mdot (lbm/hr) = } & 517475 \\
\hline P1 & P2 & T1 & T2 & $\mathrm{S} 1=\mathrm{S} 2$ & h1 & h2 & h2s & Isent-W & $\begin{array}{c}\text { Pump } \\
\text { Isentropic } \eta\end{array}$ & $\begin{array}{c}\text { Work } \\
\text { (Btu/lbm) }\end{array}$ & BHP \\
\hline 248 & 2215 & -25 & -12.24 & 0.1756 & 55.886 & 62.554 & 61.220 & 5.334 & 0.800 & 6.668 & 1354.8 \\
\hline & & & & & & & & & & & \\
\hline & & & & & & & & & & Total BHP & $\overline{7330.6}$ \\
\hline
\end{tabular}

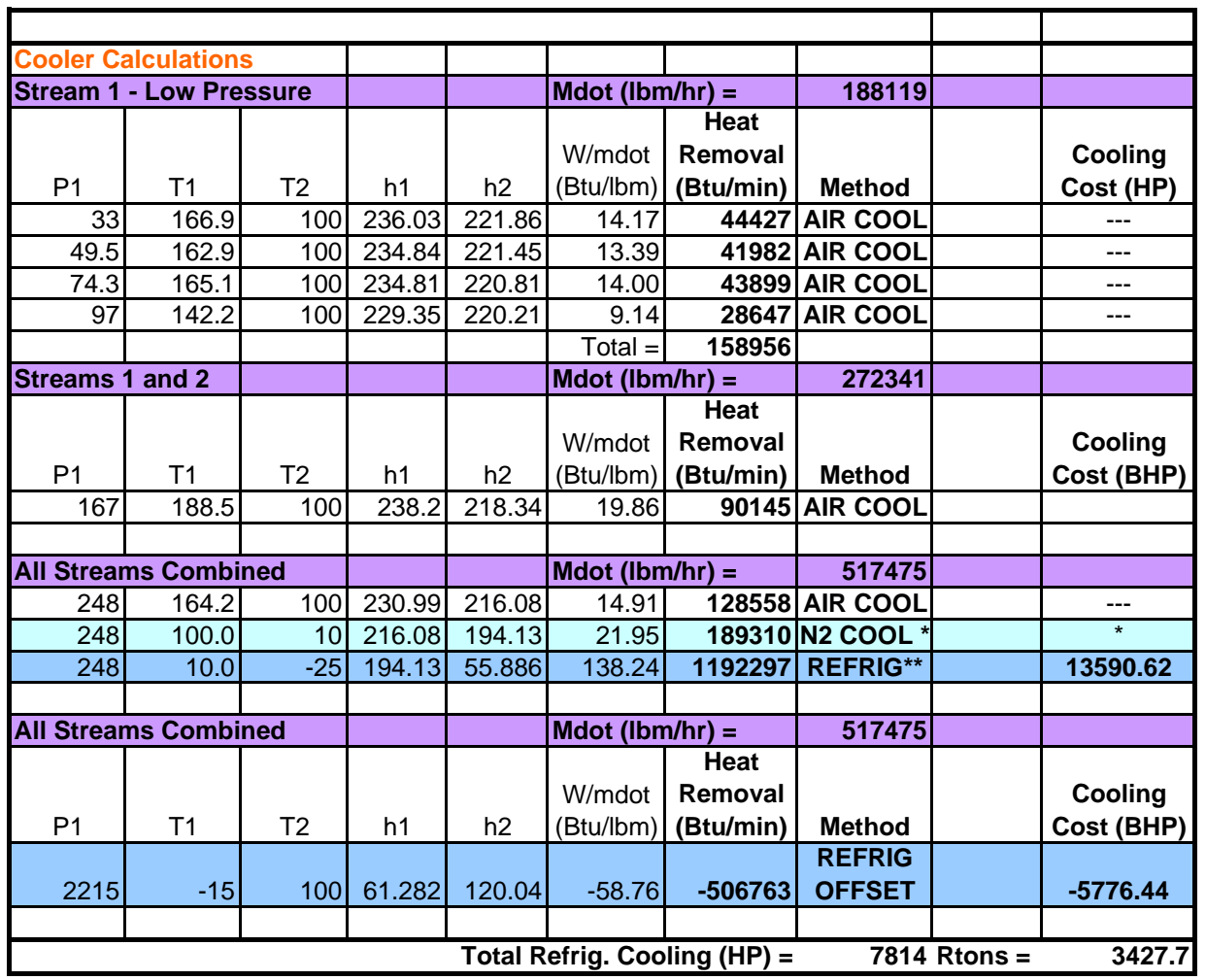

